BENJAMIN M. FRIEDMAN

Harvard University

KENNETH N. KUTTNER

Federal Reserve Bank of Chicago

\title{
Economic Activity and the Short- term Credit Markets: An Analysis of Prices and Quantities
}

The PRotracted WeaKNess of the U.S. economy that began in 1990 (earlier by some measures) has raised once again some long-standing questions about the relationship between economic activity and the short-term credit markets. To what extent did the unavailability of financing from banks and other traditional short-term lenders either help cause the recession or, once it ended, account for the exceptionally anemic recovery? Did the protracted slowdown in all kinds of lending-illustrated in figure 1 by the weakness in lending by banks and other depository intermediaries-merely reflect the absence of loan demand from conventionally creditworthy borrowers, or was it also due in part to some "supply" phenomenon that restricted lenders' ability, or willingness, to advance credit? Among familiar possibilities in this regard, how important was the impairment of banks' capital positions due to real estate losses? Or the apparent toughening of attitudes among bank regula-

We are grateful to Ben Bernanke, Mark Gertler, Robert Gordon, David Romer, and colleagues at Harvard and at the Federal Reserve Bank of Chicago for helpful comments on a previous draft, and to the G.E. Foundation and the Harvard Program for Financial Research for research support. The views expressed in this paper are the authors' own; they do not necessarily reflect the official position of the Federal Reserve system. 
Figure 1. Growth in Credit at Depository Institutions, 1953:1-1993:1 ${ }^{\text {a }}$

Four-quarter percentage change

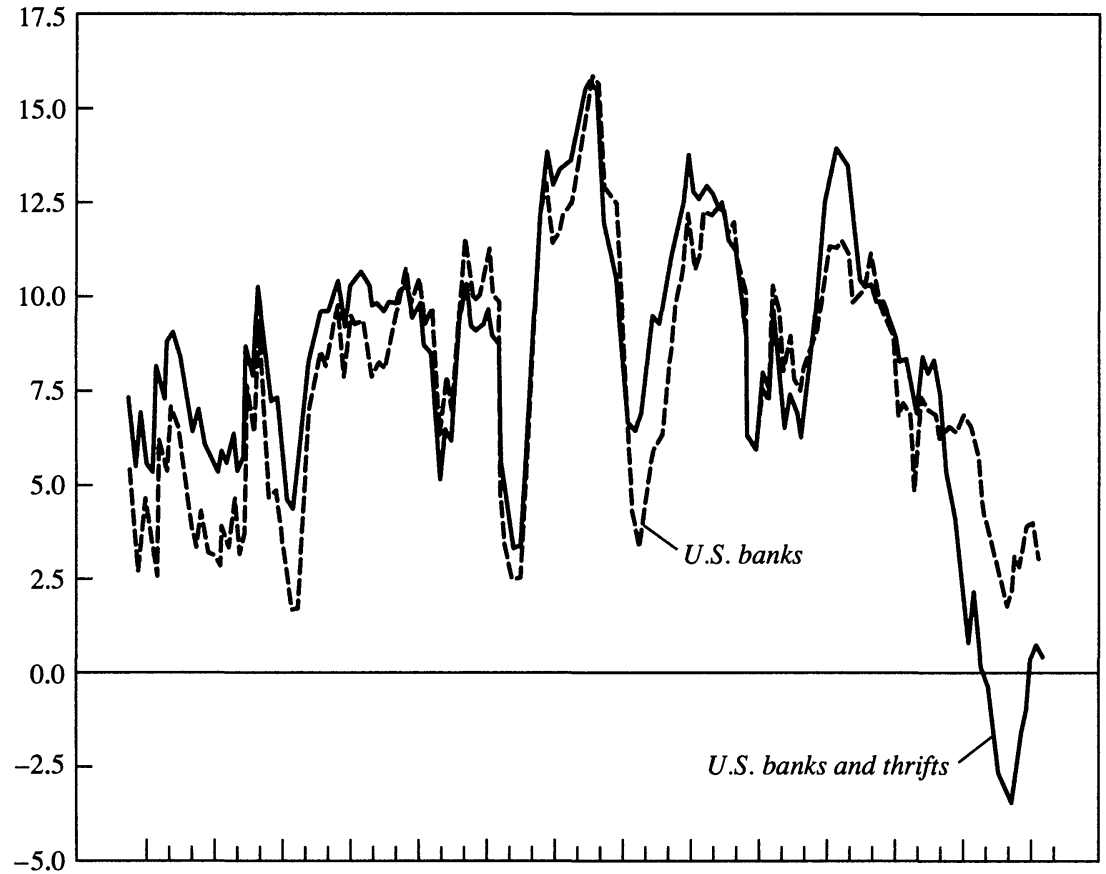

19531956195919621965196819711974197719801983198619891992

Source: Authors' calculations based on Board of Governors of the Federal Reserve System. Flow of Funds Accounts, tables 112 and 117.

a. Data are plotted as a four-quarter moving average.

tors and examiners? Or even something as specific as the Basle agreement mandating an 8 percent capital ratio on a risk-adjusted basis? And if there was no significant new impediment to lenders' willingness to supply credit, what other aspects of financial market behavior accounted for the extraordinary slowdown in lending activity during this period?

Distinguishing demand influences from supply influences is hardly a new problem in economics. Repeated efforts to do so, applied to countless markets, have led to two generally agreed-upon principles. First, one needs to use both price and quantity data. It is difficult, if not impossible, to identify a demand or supply shock by observing only prices or only quantities. Second, identification in this context also requires other 
information, apart from prices and quantities, that can be independently associated with either demand or supply behavior. There is no reason to think these principles are any less relevant to the short-term credit markets than in other standard contexts.

Credit markets do present special problems, however. Most obviously, the observable price of credit-the interest rate on a loan-is typically only one element among many dimensions that together constitute the relevant price as seen by both borrowers and lenders. This problem clearly hinders not only the attempt to distinguish supply and demand influences but a much broader class of efforts to analyze credit market behavior empirically.

From the perspective of trying to unravel the roles of supply and demand, however, a more fundamental problem arises from the possibility that credit market phenomena importantly affect economic activity at the aggregate level. Suppose, for example, that the only shock to the economy is a sharp reduction in lenders' willingness to advance credit, and that this negative shock to credit supply induces a decline in aggregate economic activity. Further suppose that the resulting decline in aggregate activity in turn induces potential borrowers to demand less credit (because credit demand is plausibly conditional not only on price but also on the volume of business to be financed). Then both bankers and economists may accurately report that the weakness of lending volume is largely due to the absence of loan demand, even though in a more fundamental sense the only shock that has disturbed the economy was to loan supply. In the presence of noisy measurements, the econometrician in this case could even find that that part of the weakness in credit volume attributable to supply behavior was not statistically different from zero at standard significance levels, and therefore conclude that weak demand was the only force at work. ${ }^{1}$

Researchers exploring the interrelationships connecting the shortterm credit markets and real economic activity have recently advanced two separate lines of analysis, in both cases motivated by observed empirical regularities. In earlier work, we focused on the predictive content, with respect to real output, of relationships among different shortterm interest rates, in particular, the spread between the commercial paper rate and the Treasury bill rate. ${ }^{2}$ We advanced several different

1. Wojnilower (1992) has made this point, as well.

2. Friedman and Kuttner $(1992,1993)$. 
hypotheses (not mutually exclusive) to explain why movements of this spread might anticipate movements of real output. Anil K. Kashyap, Jeremy C. Stein, and David W. Wilcox have focused on the analogous predictive content of relationships among the quantities of different short-term credit instruments outstanding, in particular, the mix of bank loans and commercial paper. ${ }^{3}$ They developed a model, based on the relative cost of loans versus paper issues, to explain why movements of this mix might anticipate movements of real output.

The motivating hypothesis of this paper is that these two lines of analysis are, respectively, the price and quantity sides of the same underlying set of phenomena-and, further, that for the same reasons that incorporating both prices and quantities in the analysis is essential to successfully distinguishing demand and supply behavior in other market contexts, here too an expanded analysis encompassing both price and quantity aspects is needed to understand how what happens in the shortterm credit markets affects real economic activity and vice versa. In this spirit, the paper's objective is to move beyond the evaluation of the statistical properties of the paper-bill spread, the loan-paper mix, or other similar "indicator" variables, to explore more fundamental questions about the economic and financial behavior underlying their predictive content.

The first section begins by placing these price and quantity investigations, and the substantive hypotheses to which they give rise, in the context of what has increasingly come to be called the "credit view" of linkages between financial and nonfinancial economic activity. Part of our objective here is simply to clarify a discussion that has often been confused by different researchers' meaning different things while using similar (or even identical) terminology. More specifically, this discussion also seeks to distinguish a credit view of how monetary policy affects output from a credit view of financial-nonfinancial linkages more generally.

The second section presents the results of some simple empirical exercises designed not merely to demonstrate the predictive content of the Friedman-Kuttner and Kashyap-Stein-Wilcox variables but to show how their joint interaction is also of interest in this context. An interesting aspect of these results is that, while they do provide support for the

3. Kashyap, Stein, and Wilcox (1993). 
paper-bill spread, they show that the predictive content of the loan-paper mix variable emphasized by Kashyap, Stein, and Wilcox is entirely a reflection of the commercial paper quantity. The volume of loans contains no predictive information with respect to real output, and the loanpaper mix contains none that is not already embodied in the volume of commercial paper. This finding turns out to foreshadow the results of the more detailed analysis presented in the fifth section.

The third section describes a simple model of short-term credit markets that can serve as a vehicle for discussing demand and supply behavior in an analytically distinguishable way. The main actors in this model are businesses, banks, and open-market investors. As in Kashyap, Stein, and Wilcox's model, here all nonfinancial firms are homogeneous. ${ }^{4} \mathrm{~A}$ novel feature of this model is the inclusion of a nonprice element to the cost of borrowing through either loans or commercial paper. Although each of these nonprice costs is in some sense just a reflection of the extent to which reported interest rates fail to measure accurately the true cost of borrowing, the model's nonparallel treatment of how these costs arise in the bank loan and commercial paper markets, respectively, adds to its ability to provide substantive explanations for the predictive content of prices and quantities in these markets.

The fourth section employs this model analytically to examine the consequences of four different kinds of shocks affecting the financial markets, including shocks originating from monetary policy, from changes in banks' capital position or capital requirements, from the risk of business debt default, and from business cash flows. Given the model, each of these different shocks results in a potentially observable set of price and quantity responses in the credit markets. An important distinction, however, is that while monetary policy shocks and bank capital shocks imply that the relationship between these credit market responses and subsequent movements of real economic activity is causal, default risk shocks and business cash flow shocks do not.

The fifth section presents the results of empirical exercises that describe, in a richer way than the simple results shown in the second section, interactions within the credit markets and between the credit markets and nonfinancial economic activity. This descriptive evidence is

4. A companion paper, currently in progress, extends this model to include two separate groups of nonfinancial firms, those that do and those that do not have the ability to borrow in the open market from nonbank lenders. 
mostly consistent with an interpretation of these interactions based on shocks to monetary policy or to corporate cash flows, and, in some respects, also with an interpretation based on shocks to investors' perceptions of default risk. The evidence is inconclusive on the role played by shocks to banks' capital positions (perhaps because of data limitations, discussed below). As the initial results from the second section suggest, however, throughout this analysis there is a contrast between results based on variables drawn from the commercial paper market and results based on variables from the bank loan market. In short, the paper market variables generally do exhibit the predicted behavior while the loan market variables often do not. This finding is ground for caution against basing the substantive interpretation of interactions between the credit markets and real economic activity on any description centered narrowly on substitution between bank loans and commercial paper. It also suggests directions for extending this line of research.

The sixth section presents the results of efforts to estimate empirically some relationships that correspond more directly to the more structural representations of business financing, bank lending, and household investment behavior in the model developed in the third section. Despite the use of instrumental-variable estimation procedures, the resulting estimates do not consistently distinguish supply and demand behavior in such a way as to identify satisfactorily the price (interest rate) effects on these relationships-that is, the relevant slope coefficients. By contrast, these estimates do provide further evidence that shocks to monetary policy, to bank capital positions, to default risk, and to corporate cash flows affect these relationships by shifting them along the lines discussed analytically in the fourth section.

The seventh section focuses more directly on the questions about the most recent few years' experience posed at the outset of this paper. Which (if any) of these four sources of shocks played a major role in accounting for the extraordinarily slow growth of credit during the most recent recession and recovery episode? Here the evidence points to bank capital shocks, default risk shocks, and cash flow shocks-but, interestingly, not monetary policy shocks-as contributing factors underlying the credit slowdown. By contrast, the evidence does point to tight monetary policy, and especially to an increase in the perceived risk of default on business debts, as key factors accounting for the recession itself. This finding is consistent with the concerns raised by numerous 
researchers about the sharp increase in business debt burdens during the mid to late 1980s. The eighth section collects the paper's principal empirical findings.

\section{Credit Markets and Nonfinancial Activity}

Just what is meant by the increasingly widespread notion of a credit view in macroeconomics? Is it a theory in the axiomatic sense, or a set of positive statements about observable behavior that (at least in principle) can be submitted to empirical verification, or both? Are the relevant magnitudes to observe prices or quantities, and if they are quantities, are they stocks or flows? Do the relevant markets clear? To put first things first, what is the credit view a view of?

The central focus of macroeconomics has traditionally been the determination of aggregate nonfinancial economic activity, including its real dimensions like output, employment, income, and spending, as well as the prices (both relative and absolute) placed on those aggregates. A useful way to clarify what the recent proliferation of interest in the credit view is all about is to distinguish the financial content-in the sense of the roles played by whatever financial assets and/or liabilities are present-of five different lines of economic analysis of the determination of real nonfinancial activity. Among these five approaches, the first two do not constitute a credit view but nonetheless help to frame it. (Knowing what something is not often helps in understanding what it is.) The remaining three do constitute a credit view.

\section{Classical Models}

In classical models of the kind associated with Walras, or more recently with Arrow and Debreu, financial markets and what takes place in them have no bearing on the determination of real outcomes. Whether financial markets even exist is irrelevant to real output, labor input, the division of output between consumption and investment, and so on. If the economy has a financial side, the only aspect of it with any relevance to nonfinancial activity is whatever is used as money (in the primary sense of a medium of exchange), the nominal quantity of which determines the absolute price level, but not relative prices, and certainly not any real quantity. 


\section{Neoclassical Models}

In neoclassical models, including Keynesian variants (and those of most self-styled neo-Keynesians and post-Keynesians) as well as monetarist versions, financial phenomena do affect real outcomes. The vehicle that allows them to do so-that is, the impediment to the establishment of whatever outcomes would prevail in a strictly Walrasian model-is typically the rigidity of some absolute price (perhaps all absolute prices) or of the relationship between some two absolute prices. Once absolute prices are imperfectly flexible, variation in the nominal quantity of any asset or liability immediately implies variation in the corresponding real quantity, and in the general equilibrium of all markets, both financial and nonfinancial, other real outcomes may then differ as well. Hence the contrast to classical models. Neoclassical models have often captured familiar intuitions based on empirical relationships. At the theoretical level, the primary challenge confronting such models has been to establish a satisfactory choice-theoretic foundation for the imperfect flexibility that distinguishes them from their classical counterparts. (Alternative approaches to achieving this result include models with "cash in advance" constraints on purchases, or even a role for money in directly affecting consumers' utility.)

What most neoclassical models carry over directly from classicial models, however, is the exclusive focus on money as the only financial quantity to merit attention. The nominal quantity that varies, and that immediately implies a varying real quantity when prices are imperfectly flexible, is money. Some representation of the demand for money (even if only in the solved-out "quantity equation" form) is therefore characteristic of all such models. All other assets are implicitly assumed to be imperfectly substitutable for money but perfectly substitutable for one another, and the demand for them collectively is implicitly modeled by the description of money demand together with whatever determines total wealth holding. As for liabilities, neither households nor firms typically have any in such models. If they do, their liabilities are perfect substitutes for their nonmoney assets and hence are also irrelevant to the determination of real outcomes. In "representative agent" models, there can be no such liabilities even if markets for them exist, since there is no reason for two identical agents to enter into an arrangement whereby one borrows from or lends to the other. 
Models that are neoclassical in this sense can also include a multiplicity of imperfectly substitutable nonmoney assets, although this elaboration is much less typical. For example, in James Tobin's 1961 model and also in his 1969 "Model II," imperfect substitutability between real capital and government-issued bonds is central to the analysis. ${ }^{5}$ Even so, such models do not present a credit view in the sense intended here because they do not include liabilities issued by inside agents like firms or households.

\section{Credit Models: The General Case}

What distinguishes the credit view from conventional neoclassical models is the recognition that households and/or firms do have liabilities, together with the presumption that these liabilities play a role in the determination of nonfinancial economic activity that is at least conceptually on a par with that reserved for money in neoclassical models. For private economic agents' liabilities to matter in this way, it must be true that not all nonmoney assets are perfectly substitutable one for another. Private agents therefore have balance sheets, in the nontrivial sense that there are distinguishable assets and liabilities, and that any agent's liability must be some other agent's asset. ${ }^{6}$ It must also therefore be the case that not all private agents are identical.

The nontrivial existence of balance sheets for households and/or firms introduces two forms of financial variables that can then be posited to play a role in the determination of nonfinancial economic activity: stocks and flows. Different expositions of the credit view have emphasized either or both, and much unnecessary confusion has resulted from the typical failure to recognize that, whatever may appear important empirically, the conceptual basis for a role of one typically implies a role for the other as well. The most immediately transparent credit view models focus on flows, distinguishing the opportunity cost of funds generated internally by firms, or earned by households, from the (presumably greater) explicit cost of external debt financing. ${ }^{7}$ Balance sheet stocks

5. Tobin $(1961,1969)$.

6. Tobin was an early advocate of assigning a central role to inside agents' balance sheets in this context. See, for example, "Model III" in Tobin (1969) and the overview provided there.

7. See Duesenberry (1957) for a statement of early views to this effect. More recent empirical contributions in this vein include Fazzari, Hubbard, and Petersen (1988), Gertler and Gilchrist (1993a), and Oliner and Rudebusch (1993). 
enter the analysis naturally as a straightforward extension of this difference. If the opportunity cost of certain assets held is like that of internally generated funds but less than the cost of external debt financing, real spending or production decisions may depend not only on cash flows, but also on the stock of such assets held ${ }^{8}$ Further, if the marginal cost of debt financing is not fixed but instead depends (presumably positively) on the quantity of debt already owed, relative to the borrower's ability to pay as measured by either income or assets, then stocks of liabilities and perhaps of other assets too can also affect real outcomes.

Like neoclassical models in a different context, models embracing the credit view capture a variety of familiar intuitions based on empirical relationships. Similarly, while neoclassical models face the challenge of establishing satisfactory choice-theoretic foundations for the price rigidities or incomplete markets that imply different real outcomes than the corresponding Walrasian equilibriums, the credit view faces the challenge of establishing such foundations for the differential cost of internal and external funds, or a rising marginal cost of debt finance. At the most fundamental level, such models must account for what makes one nonmoney asset imperfectly substitutable for another and hence makes liabilities not trivially identical to assets. The main lines of analysis introduced to address these questions in recent years have exploited advances in the theory of imperfect information, of relationships between principals and their agents, and of the incentives and constraints embodied in contracts. ${ }^{9}$

\section{Credit Models of Monetary Policy}

In the abstract, the notions that nonmoney assets are not all perfect substitutes, that liabilities exist and are distinct, and that balance sheet stocks and/or flows matter for the determination of nonfinancial economic activity-that is, the central core of the credit view-need imply little or nothing about how monetary policy works. Shocks emanating

8. Anderson (1964) first made this point in the context of firms' holdings of liquid assets. A recent example of a model in which liquid assets held matter for investment decisions is Whited (1991).

9. See, for example, Jensen and Meckling (1976), Stiglitz and Weiss (1981), and Myers and Majluf (1984). Greenwald and Stiglitz (1988) provided a useful summary of many of these lines of research. 
from the central bank's monopoly over the supply of bank reserves presumably represent only one of the many kinds of shocks to which an economy is subject. Even in a model in which other shocks influence nonfinancial activity through a process involving private sector liabilities and balance sheets, as a practical matter monetary policy shocks could still have their effect largely through the equilibration of the demand for and supply of money as spelled out in neoclassical models.

In fact, however, many researchers advancing credit view models have done so as an explicit alternative to the neoclassical account of the monetary policy process. ${ }^{10}$ What immediately makes the credit view at least potentially relevant to monetary policy is that banks (and other depository intermediaries) have balance sheets too. Given the banking system's capital position, or net worth, anything that affects the total amount of bank liabilities correspondingly affects the total amount of bank assets. Monetary policy may therefore affect nonfinancial economic activity by influencing banks' ability to create deposits, or by influencing their ability to extend credit, or in both ways. The force of the deposit mechanism presumably hinges at least in part on whether bank liabilities, seen as assets in households' and firms' portfolios, are substitutable for nonmoney assets. The force of the credit mechanism depends at least in part on whether households and firms see nonbank financing as substitutable for bank loans.

Which of these two accounts of the monetary policy process more nearly corresponds to the prevailing empirical relationships in any given economy at any given time is clearly an important question, with immediate implications for monetary policymaking. (For example, would the central bank do better to target bank liabilities or bank assets? Or would it do even better to use, even if only as an information variable, a broader measure encompassing nonbank liabilities or assets?) But even if the answer is that the deposit process is empirically more important, or perhaps even self-sufficient, in the specific context of how monetary policy works, credit view models in the more general sense described above may still be useful and even important in describing influences on nonfinancial economic activity apart from monetary policy.

10. See, for example, Bernanke and Blinder (1988), Bernanke and Gertler (1989), and Romer and Romer (1990). 


\section{Credit Rationing Models}

The brief sketch of credit view models offered above, be they of the more general kind or specific to monetary policy, says nothing about markets not clearing. By contrast, in some models of how credit market phenomena affect nonfinancial economic activity, the center of attention is precisely on circumstances in which would-be borrowers cannot obtain financing at all, and therefore face what amounts to a quantity constraint on their ability to spend for purposes of consumption, investment, or production. In many such models, the presence and/or intensity of this kind of market failure varies over time, and the motivating argument at an empirical level is that "credit crunches" of limited duration and irregular occurrence account for a significant part of the observed fluctuation of real output and spending. "

Framed in the context of modern theories of imperfect information, principal-agent relationships, and contract theory (which have provided the choice-theoretic foundations for recent credit view models), market failures of the kind emphasized in such credit crunch stories are simply an extension of the same behavioral elements that make nonmoney assets not all perfect substitutes, and private sector liabilities distinct, in the first place. It is now well known that adverse selection, moral hazard, and other phenomena that arise when information is asymmetric and when agents act on behalf of principals can produce market situations in which potential lenders will not finance some would-be borrowers at any interest rate, so that the credit market does not clear even in the strict sense of the term. ${ }^{12}$ It is also straightforward to posit reasons, many of them connected to just the balance sheet stocks and flows that are at center stage in credit view models, why the forces that prevent credit markets from clearing may vary in intensity over time. Hence models of credit rationing, or occasional crunches, are at least as consistent with economic first principles as neoclassical models in which money matters because of price rigidities, and probably more so.

The fact that credit view models can encompass nonclearing markets does not mean that they necessarily do so; on this point too, substantial

11. See, for example, Wojnilower (1980), Eckstein and Sinai (1986), Owens and Schreft (1992), and the earlier references given in those papers.

12. Again, see Stiglitz and Weiss (1981). 
confusion exists. Credit view models may involve ongoing rationing and/or occasional crunches, or they may not. If they do, the credit crunches that occur may or may not be empirically important in explaining fluctuations in real activity. Credit view models in which the markets for all assets and liabilities always clear represent no less an alternative to the money-centered neoclassical model than do models of explicit financial market failure.

\section{What This Paper Is About}

The line of research developed in this paper falls squarely in the third and fourth categories described above. The model presented in the paper's third section incorporates not only nonmoney assets that are imperfect substitutes for one another but also private sector (for simplicity, here only firms') liabilities that are not trivially identical to assets, and in general balance sheet stocks and/or flows affect real spending. The analysis explicitly considers monetary policy shocks, and as it does so, these credit view elements are potentially at work alongside the equilibration of the deposit market taken over from the standard neoclassical model. The analysis considers other shocks too, however: to firms' cash flows, to the perceived riskiness of firms' liabilities, to banks' preferences for loans versus securities on the asset side of their balance sheets, and so on. Hence the model presented below potentially offers a credit view not only of monetary policy as in the third category but more generally, as in the fourth category, as well. By contrast, there is no provision here for markets not to clear. While the spirit motivating this line of research is certainly consistent with the existence and even importance of credit crunches, therefore, such phenomena do not occur in the formal model presented and they play no explicit role in the analysis of this paper.

\section{Some Illustrative Empirical Relationships}

Before embarking on this analysis, is there evidence to suggest that either price or quantity variables that are consistent with a credit view, but that would play no role in the standard money-centered neoclassical 
Table 1. F-Statistics for Alternative Financial Indicators in Real Output Equations ${ }^{\mathrm{a}}$

\begin{tabular}{lccc}
\hline & \multicolumn{3}{c}{ Sample period } \\
\cline { 2 - 4 } Financial variable & $1960: 1-$ & $1960: 1-$ & $1973: 6-$ \\
Monetary base & $1992: 12$ & $1979: 9$ & $1992: 12$ \\
M1 & 1.26 & 0.62 & 1.01 \\
M2 & $1.98^{\mathrm{b}}$ & 1.36 & 1.54 \\
Debt & $3.27^{\mathrm{d}}$ & $3.42^{\mathrm{d}}$ & 1.05 \\
Paper-bill spread & 1.07 & 0.84 & 0.31 \\
Nonfinancial paper & $7.49^{\mathrm{d}}$ & $3.65^{\mathrm{d}}$ & $6.64^{\mathrm{d}}$ \\
Total commercial paper & $3.02^{\mathrm{d}}$ & 1.31 & $6.56^{\mathrm{d}}$ \\
Loans & $3.32^{\mathrm{d}}$ & $3.57^{\mathrm{c}}$ & $2.49^{\mathrm{c}}$ \\
Loan-paper mix & $\ldots$ & $\ldots$ & 0.86 \\
& $\ldots$ & $\ldots$ & $2.13^{\mathrm{b}}$ \\
\hline
\end{tabular}

Source: Authors' calculations based on Board of Governors of the Federal Reserve, Release H.3 and H.6 for monetary base, M1, M2, and debt, all seasonally adjusted; Board of Governors of the Federal Reserve, Release G.13, for prime six-month commercial paper and six-month auction average Treasury Bill rates; Federal Reserve Bank of New York, Market Reports Division, for nonfinancial and total commercial paper; Federal Reserve Bulletin, various issues, table 1.24, for loans (other commercial and industrial loans). The loan-paper mix is outstanding loans divided by the sum of loans and nonfinancial commercial paper.

a. F-statistics for the null hypothesis that the coefficient on the financial (quantity) variable is zero. Regressions are based on equation 1 of the text, where the dependent variable is the change in the log of industrial production. The regressions use monthly data for the sample indicated, and include six lags of each independent variable. Analogous results using twelve lags are similar except for two cases: M2, which is not significant in the full sample, and total paper, which is not significant in the post-1973 sample.

b. Significant at the 10 percent level.

c. Significant at the 5 percent level.

d. Significant at the 1 percent level.

model, are systematically related to real economic activity? Table 1 presents F-statistics for the null hypothesis that all coefficients $\theta_{i}$ are zero in regressions of the form

$$
\begin{aligned}
\Delta X_{t}= & \alpha+\sum_{i=1}^{6} \beta_{i} \Delta X_{t-i}+\sum_{i=1}^{6} \gamma_{i} \Delta P_{t-i} \\
& +\sum_{i=1}^{6} \delta_{i} \Delta r_{P, t-i}+\sum_{i=1}^{6} \theta_{i} \Delta Z_{t-i}+\phi t+u_{t},
\end{aligned}
$$

where $X$ and $P$ are the natural logarithms of industrial production and the producer price index, respectively; $r$ is the interest rate on six-month prime commercial paper; $Z$ is, in turn, each of a series of other financial variables as listed in the table; $u$ is a disturbance term; and $\alpha, \beta_{i}, \gamma_{i}, \delta_{i}$, $\theta_{i}$, and $\phi$ are all coefficients to be estimated. Data are monthly. The table presents results separately for the full 1960:1-1992:12 sample and for two subsamples: 1960:1-1979:9 (that is, up until the Federal Reserve system's adoption of new monetary policy operating procedures in October 1979) and 1973:6-1992:12 (that is, since the availability of monthly 
data on bank loans, a key element in the line of research developed by Kashyap, Stein, and Wilcox). ${ }^{13}$

These results readily show the empirical appeal underlying our own research and, in a less direct way, that of Kashyap, Stein, and Wilcox. ${ }^{14}$ In contrast to the standard money and credit aggregates, the paper-bill spread variable we emphasized exhibits a highly significant relationship to subsequent movements in real economic activity, even in the presence of the interest rate, regardless of which sample period is under study. ${ }^{15}$ So does the quantity of commercial paper, which is a key element in Kashyap, Stein, and Wilcox's analysis. Although the quantity of bank loans is itself not significant over the sample for which monthly data are available for this variable, the loan-paper "mix" ratio emphasized by Kashyap, Stein, and Wilcox is (weakly) so.

Focusing in more detail on just the 1973-92 sample, table 2 extends these results to show the relevance, for the determination of real output, of price-quantity interactions in the short-term credit markets. The table shows F-statistics from regressions that are identical to equation 1 except that they include both the paper-bill spread and, in turn, each of the other financial variables listed in table 1 (along with output, prices, the interest rate, and a linear trend, all as before). The most immediately visible result shown in table 2 is that the predictive content of the paper-bill spread remains highly significant, no matter which of the other variables is included along with it. The volume of commercial paper issued by nonfinancial firms also retains its strong significance in the presence of the spread (although the significance of the loan-paper mix disappears). Especially when the quantity under study is the volume of commercial paper, therefore, these results suggest that the price and quantity dimensions of the short-term credit markets do not just convey identical information in alternative forms. From the perspective of predictive content with respect to real output, looking at credit prices does not make looking at credit quantities irrelevant, nor vice versa.

13. Data for industrial production, the price level, and all money or credit aggregates are seasonally adjusted. Data for interest rates are not.

14. Friedman and Kuttner $(1992,1993)$ and Kashyap, Stein, and Wilcox (1993).

15. Previous research going back to Sims (1980) has emphasized the criterion of significance even in the presence of the interest rate. When a regression like equation 1 does not include an interest rate regressor, other variables may be significant merely because they proxy for the effect of interest rates. 
Table 2. F-Statistics for Quantity Variables in Combination with the Paper-Bill Spread, 1973-92 Subsample ${ }^{\mathrm{a}}$

\begin{tabular}{lcc}
\hline Quantity variable & $\begin{array}{c}\text { Paper- } \\
\text { bill } \\
\text { spread }\end{array}$ & $\begin{array}{c}\text { Quantity } \\
\text { variable }\end{array}$ \\
\hline Monetary base & $6.33^{\mathrm{c}}$ & 0.87 \\
M1 & $5.81^{\mathrm{c}}$ & 0.93 \\
M2 & $6.16^{\mathrm{c}}$ & 0.76 \\
Debt & $6.65^{\mathrm{c}}$ & 0.47 \\
Nonfinancial paper & $5.62^{\mathrm{c}}$ & $5.54^{\mathrm{c}}$ \\
Total commercial paper & $5.82^{\mathrm{c}}$ & $1.85^{\mathrm{b}}$ \\
Loans & $6.58^{\mathrm{c}}$ & 1.02 \\
Loan-paper mix & $5.97^{\mathrm{c}}$ & 1.71 \\
\hline
\end{tabular}

Source: See table 1.

a. F-statistics for the null hypothesis that the coefficient on either the paper-bill spread or quantity variable is zero. Regressions are based on equation 1 of the text, but also include the paper-bill spread as an independent variable, where the dependent variable is the change in the log of industrial production. The regressions use monthly data for the 1973:6-1992:12 sample, and include six lags of each independent variable. Analogous results using twelve lags are similar, except for total commercial paper, which is not significant, and the loan-paper mix, which is significant at the 10 percent level.

b. Significant at the 10 percent level.

c. Significant at the 1 percent level.

The finding in tables 1 and 2 of greater predictive power in the volume of commercial paper issuance than in the loan-paper mix ratio, and of none at all in the volume of bank loans, warrants some further preliminary analysis to learn just what aspects of short-term credit quantities are most relevant to the determination of real output. Given Kashyap, Stein, and Wilcox's definition of the loan-paper mix as $m \equiv L /(P+L)$, where $L$ and $P$ are the outstanding volumes of bank loans and commercial paper, respectively, it is straightforward to decompose the change in the mix (the form that, because of considerations of stationarity, appears in the regressions reviewed above) as

$$
\text { (2) } \Delta m_{t} \approx m_{t-1}\left(1-m_{t-1}\right) \Delta L_{t} / L_{t-1}-m_{t-1}\left(1-m_{t-1}\right) \Delta P_{t} / P_{t-1} \text {, }
$$

where the discrete-time approximation approaches exactness in continuous time. If the mix is the appropriate measure of short-term credit quantities to use for purposes of information about subsequent output fluctuations, then the appropriately weighted $\Delta L / L$ and $\Delta P / P$ terms in equation 2 , entered in place of $\Delta m$ in regressions for real output, will appear with coefficients (approximately) equal in magnitude but opposite in sign. 
Table 3. Performance of Loan-Paper Mix and Paper-Bill Spread ${ }^{a}$

\begin{tabular}{llcc}
\hline $\begin{array}{c}\text { Regression } \\
\text { specification }\end{array}$ & Independent variable specification & $\begin{array}{c}\text { Sum of } \\
\text { coefficients }\end{array}$ & $\begin{array}{c}F- \\
\text { statistic }\end{array}$ \\
\hline Includes financial \\
flows & $\begin{array}{l}\text { Separate paper and lending terms } \\
\text { Weighted change in commercial paper }\end{array}$ & $-0.82^{\mathrm{c}}$ & $2.49^{\mathrm{c}}$ \\
& Weighted change in bank lending & -0.38 & 1.24 \\
& Loan-paper mix and paper terms & & \\
& Change in loan-paper mix & -0.38 & 1.48 \\
Includes interest & Weighted change in commercial paper & -1.21 & $1.86^{\mathrm{b}}$ \\
rates & Separate paper and bill rate terms & & \\
& Change in paper rate & $-1.23^{\mathrm{b}}$ & $2.99^{\mathrm{d}}$ \\
& Change in bill rate & 1.01 & $2.98^{\mathrm{d}}$ \\
& Paper-bill spread and paper rate terms & & \\
& Paper-bill spread & $-0.85^{\mathrm{d}}$ & $6.03^{\mathrm{d}}$ \\
& Change in paper rate & -0.08 & $3.10^{\mathrm{c}}$ \\
& Bill rate constraint & $\ldots .05^{\mathrm{d}}$ \\
\hline
\end{tabular}

Source: See table 1 .

a. The dependent variable is real output. The regressions are based on monthly data for 1973:6-1992:12, and include six lags of each independent variable. The regressions are specified according to the first two columns and as described in the text.

b. Significant at the 10 percent level.

c. Significant at the 5 percent level.

d. Significant at the I percent level.

e. Constraint that the coefficients on the spread and the paper rate are such that only the differenced bill rate appears in the regression.

The upper panel of table 3 shows that this is not the case empirically. In a regression of real output on separate distributed lags of both commercial paper and bank loans (along with output itself and the price index) for the same 1973-92 sample used above, the summed coefficients on the commercial paper terms are negative as predicted, but so are those on the lending terms-although, as is to be anticipated from tables 1 and 2, neither the $t$-statistic for the sum nor the F-statistic for all the coefficients together is statistically significant in the case of bank loans. By contrast, a simple reparameterization of this same regression, reported immediately below in the same panel of the table, shows that when the loan quantity is omitted and the mix variable is entered in its place, neither it nor the paper quantity is significant. In other words, the mix variable and the paper quantity contain the same predictive information about subsequent fluctuations of real output. ${ }^{16}$ Once again, the coefficients on the commercial paper quantity are negative.

16. Kuttner (1992) reported similar results for analogous tests based on quarterly data. 
Since the regressions underlying tables 1 and 2 already include both the paper-bill spread and the commercial paper rate, and the spread does exhibit highly significant predictive context with respect to output in the presence of the paper rate, a similar analysis focused on the spread variable should clearly bear different implications. As the lower panel of table 3 shows, the paper rate and the bill rate are each individually significant at the 0.01 level when the two are entered together in a regression for real output. Reparameterizing this same regression to include the paper-bill spread in place of the bill rate makes the contrast to the corresponding result with the mix and the commercial paper quantity all the more apparent. The spread is significant at the 0.01 level in the presence of the paper rate, and vice versa at the 0.05 level. Moreover, in a separate regression the data also reject at the 0.01 level the further restriction that the coefficients on the spread just cancel the corresponding coefficients on the paper rate so that the relevant predictive content is actually contained in the bill rate alone. ${ }^{17}$

In sum, the U.S. empirical evidence exhibits four main features that together suggest useful avenues for research on the relationship between real output and short-term credit markets. First, both prices and quantities in the short-term credit markets contain statistically significant information about subsequent fluctuations in real output. Second, the information about real output contained in these respective price and quantity variables is not identical. Third, much of the relevant information from price variables in this context is contained in relative prices, like the spread between the commercial paper rate and the Treasury bill rate. Fourth, the relevant information from short-term credit market quantities is contained mostly in the volume of commercial paper issuance; specifically, neither the volume of bank loans nor the relationship

17. Because considerations of stationarity dictate entering either the paper rate or the bill rate separately in differences, but the spread in levels, the form of the constraint here is

$$
\begin{aligned}
\theta_{1}+\phi_{1} & =0 \\
\theta_{2}+\phi_{2}-\phi_{1} & =0 \\
\vdots & \\
\theta_{6}+\phi_{6}-\phi_{5} & =0 \\
\theta_{7}-\phi_{6} & =0
\end{aligned}
$$

where the $\theta_{i}$ and $\phi_{i}$ are the distributed lag coefficients on the spread and on the bill rate, respectively. We reported a similar result in earlier work (Friedman and Kuttner, 1993). 
between loan volume and paper volume (except in so far as it merely reflects paper volume alone) appears to matter much for the determination of real output.

\section{A Model of Credit Markets and Their Interaction with Real Output}

What set of circumstances describing the short-term credit markets might systematically give rise to interactions with real output of this form? A minimal description of the credit markets for this purpose must bring together the behavior of three distinct kinds of private-sector agents (banks, open-market investors, and homogeneous nonfinancial firms) interacting in three different markets (those for Treasury bills, bank loans, and commercial paper). In addition, as in neoclassical models, the analysis must include a market for whatever constitutes money. This section sketches the outlines of such a model. ${ }^{18}$

\section{Nonfinancial Firms}

The place to begin is with the behavior of nonfinancial firms, here taken to be homogeneous, and to be denoted in the aggregate with a superscript $F$. The $i$-th firm's balance sheet constraint, implicitly defining its stockholders' equity as the difference between its assets and its liabilities, is

$$
P E^{i}+B^{i}=L^{i}+P^{i}+E^{i},
$$

where $P E$ represents the firm's stock of physical capital, $B$ its holdings of Treasury bills, $L$ its debt owed to banks, $P$ its commercial paper out-

18. Even with these markets and three kinds of private sector agents, however, this model can account for the observed interactions in only limited ways. For example, because there is no market for long-term assets or liabilities, the entire term structure dimension of portfolio choice is omitted. There is also no role here for international aspects of even the short-term markets. A companion paper, currently in progress, expands the model by further distinguishing between nonfinancial firms that can borrow in the open market and those that cannot, and introducing credit advances between them (trade credit). 
standing, and $E$ its net worth. ${ }^{19}$ The corresponding financing constraint, equating total uses of funds for investment with total sources of funds, is

$$
I^{i}+\Delta B^{i}=N R^{i}+\Delta L^{i}+\Delta P^{i}
$$

where $I$ represents investment outlays and $N R$ stands for net revenues from operations not paid out in interest or dividends. ${ }^{20}$ Under standard conditions admitting aggregation, ${ }^{21}$ the financing constraint for all firms together is

$$
I+\Delta B^{F}=N R+\Delta L^{F}+\Delta P^{F}
$$

A central assumption of the credit view is that conditions in the financial markets play a causal role in determining firms' nonfinancial investment and net revenues. But regardless of whether that is so or those aspects of firms' nonfinancial behavior are predetermined with respect to their financial choices, equation 5 shows that the gap between $I$ and $N R$ must be financed by some combination of loans, paper issuance, and sales of bills previously held. Over a time horizon such that firms' nonfinancial investment and net revenues are predetermined with respect to contemporaneous conditions in the financial markets, their financing choice for a given financing gap $I-N R$ reflects standard principles of risk-averse portfolio selection, supplemented here by the nonprice (that

19. A more realistic model would reflect the fact that nonfinancial firms also typically hold deposits and sometimes issue long-term debt, and that some firms' equity value reflects goodwill as an asset. Adding deposits to the left-hand side of equation 3 and expanding equation 6 to include an additional portfolio equation would make the model more complex but does not seem to provide any further analytical insights. Doing the same for long-term debt on the right-hand side of equation 3 would introduce a variety of potentially interesting substantive issues, but for the most part they lie well beyond the scope of this paper. Assets like goodwill are also beyond the scope of this paper.

20. In principle, issuance of equity securities is another potential source of funds for nonfinancial firms. In practice, most U.S. firms are more likely to retire equity securities than to issue more, and aggregate net issuance of equity by nonfinancial business corporations has been negative in most years since World War II. Expanding the model to include a market for corporate equities (as either a source or a use of funds) would raise many questions that lie beyond the scope of this paper.

21. See Theil (1971, chaper 11) for a discussion of aggregation and the familiar representative agent model. Here as elsewhere, a genuinely plausible description of the relevant behavior is unlikely to satisfy the standard conditions for exact aggregation. 
is, other than the observed interest rate) costs of obtaining external funds,

$$
\begin{array}{r}
\Delta L^{F}=f_{1}\left(I-N R, r_{L}, \theta_{L}, r_{P}, \theta_{P}, r_{B}\right) \\
+\quad-++++ \\
\Delta P^{F}=f_{2}\left(I-N R, r_{L}, \theta_{L}, r_{P}, \theta_{P}, r_{B}\right) \\
+\quad+++-+ \\
\Delta B^{F}=f_{3}\left(I-N R, r_{L}, \theta_{L}, r_{P}, \theta_{P}, r_{B}\right),
\end{array}
$$

where the $r_{i}$ are the interest rates in the three short-term markets, the $\theta_{i}$ are the corresponding nonprice cost elements (assumed to be zero in the bill market), and expected signs are shown below the corresponding variables. Given equation 5, the usual cross-equation restrictions apply, so that the system in equation 6 contains only two independent relationships.

Nothing in equation 6 as written reflects either a greater cost of external financing compared to internal funds or the possibility of a rising marginal cost of external financing as firms have more debt outstanding-two standard features of credit view models as indicated in the first section. Differential costs of internal and external funds are largely a matter of whether the flow of net revenues from operations, $N R$, enters the investment function (as it does below). If the cost of debt is rising at the margin, however, then both the investment function and equation 6 may also include the outstanding stocks of loans and paper, and the stock of nonfinancial capital from the balance sheet. ${ }^{22}$ In addition, since no firm's holdings of Treasury bills can be negative, in general the stock of bills will also enter these expressions even though the return to bills (as seen by any firm) is of course fixed no matter how many bills are held. ${ }^{23}$ As is well known, once either the investment function or the

22. More specifically, these balance sheet stocks will enter the equations describing firms' behavior if the firm itself is responsive to such considerations as the risk of bankruptcy or the volatility of its net revenues. By contrast, if the banks and other investors who hold the firms' securities are sensitive to these matters but the firms themselves are simply present value-maximizers, then firms' balance sheet stocks will affect their behavior indirectly through the market-determined rates of return on their obligations, but balance sheet stocks would not appear directly as arguments of the equations describing the firms' behavior.

23. The argument here is analogous to that made explicitly, just below, about the role of capital in influencing banks' behavior. 
equations describing firms' financial decisions do include balance sheet stocks of either assets or liabilities, the resulting model then provides a vehicle for describing stock-flow dynamics as is familiar in a variety of theoretical and empirical contexts.

\section{Banks}

The firms that behave in this manner interact with two separate classes of lenders. Banks, to be denoted in the aggregate with a superscript $B$, issue deposits, including ordinary transactions accounts as well as deposit certificates (which are negotiable but uninsured), and against these deposits they hold Treasury bills and commercial loans. In addition, by law, each bank must meet two constraints. First, part of its assets, equal to or greater than some stated fraction of its outstanding deposits, must consist of zero-interest reserves held at the central bank. Second, the bank must support a part of its assets, equal to or greater than a (different) stated fraction, with capital rather than deposit liabilities. Because these two restrictions are inequalities, they are not necessarily binding at the margin.

The $i$-th bank's balance sheet constraint is

$$
B^{i}+L^{i}+R^{i}=D^{i}+C D^{i}+K^{i},
$$

where $R$ represents reserves, $D$ transactions deposits, $C D$ certificates of deposit, and $K$ the bank's capital position. The bank's reserve and capital requirements are, respectively,

$$
R^{i} \geq D^{i} k_{1}+C D^{i} k_{2}
$$

$$
K^{i} \geq L^{i} k_{3}+B^{i} k_{4},
$$

where the $k_{j}, 0 \leq k_{j}<1$, are fractions set by the relevant regulatory authorities. A key feature of these requirements as they currently apply in the United States is that $k_{2}=k_{4}=0$. That is, transactions deposits are reservable but certificates are not, and under the Basle agreement (although not for the "tier one leverage ratio") banks must hold capital against their loans but not their securities.

If the model is taken literally as a simple one-period model, with $R$ and $K$ fixed for the period, the inequalities in equation 8 are straightforward constraints binding banks' choices of assets $B$ and $L$ and liabili- 
ties $D$ and $C D .{ }^{24}$ Because banks can readily exchange reserves among one another (in effect, most bank transactions are settled by transferring reserves), what is given is not each bank's individual $R^{i}$ but the aggregate $R$ supplied by the central bank. By contrast, for purposes of the capital requirement, each bank's individual $K^{i}$ is what matters, so the distribution of $K^{i}$ among individual banks within the aggregate $K$ is relevant as well. ${ }^{25}$

In any more dynamic model, however, there is always the possibility that a bank that does not now face a binding reserves or capital constraint may do so later. Expanded loan opportunities may arise, or the bank may experience large deposit outflows (which cause its $R^{i}$ to decline), or it may experience defaults on its existing loans (which cause its $K^{i}$ to decline), or the regulators may even raise the relevant $k_{i}$. For a given distribution describing the probability of any or all of these kinds of shocks, the probability that the bank's reserves or capital contraint will become binding later depends negatively on the amount by which $R^{i}$ or $K^{i}$ exceeds the requirement now. Hence there are implicit nonzero shadow prices on reserves and capital, even for banks for which the respective constraints are not binding. It is plausible to think of both $R$ and $K$ as arguments of the equations describing the banks' choice of $B, L$, $D$, and $C D$, along with the standard portfolio theoretic arguments, here including the noninterest return to bank loans, $\theta_{L} \cdot{ }^{26}$ The resulting representation is

$$
\begin{gathered}
B^{B}=b_{1}\left(r_{B}, r_{L}, \sigma^{2}, \theta_{L}, r_{D}, r_{P}, R, K\right) \\
+-++-++ \\
L^{B}=b_{2}\left(r_{B}, r_{L}, \sigma^{2}, \theta_{L}, r_{D}, r_{P}, R, K\right) \\
-+-+-+++ \\
D^{B}=b_{3}\left(r_{B}, r_{L}, \sigma^{2}, \theta_{L}, r_{D}, r_{P}, R, K\right) \\
++-+-++ \\
+D^{B}=b_{4}\left(r_{B}, r_{L}, \sigma^{2}, \theta_{L}, r_{D}, r_{P}, R, K\right), \\
++-+++-?+
\end{gathered}
$$

24. The resulting solution would be of the Kuhn-Tucker form.

25. In parallel to the treatment of nonfinancial firms above, the model developed here assumes that banks cannot raise capital by issuing new equity within the period; see again footnote 20 .

26. The practice of treating the quantity of reserves as a direct argument of the deposit supply function, on the ground that banks have a target level of free reserves for given 
where $\sigma^{2}$ is the risk of default on loans (Treasury bills are default-free), $r_{D}$ is the rate paid on transactions deposits, and expected signs are again shown below the variables. Here $r_{P}$, the interest rate on commercial paper, represents the interest rate on certificates of deposit because openmarket investors (modeled below) are assumed to treat banks' certificates and firms' paper as perfect substitutes, and therefore to arbitrage the two assets' returns into equality. ${ }^{27}$ Given banks' role as takers of transactions deposits, the most plausible interpretation of the equation for $D^{B}$ is in governing banks' choice of $r_{D}$. The risk of default $\sigma^{2}$, which reflects not only the risk associated with firms' returns on nonfinancial investment but also the relationship among their respective stocks of assets and liabilities as described above, affects banks' willingness to lend negatively, and hence their demand for Treasury bills positively and their supply of deposits negatively.

The system shown in equation 9 determines the composition of the banking system's balance sheet but says nothing explicitly about its scale. Given the reserve and capital requirements, however, the scale of the banking system at any specific time is determined by the amount of reserves supplied by the central bank and the amount of capital that banks have accumulated from past earnings (or equity issues). Given that certificates of deposit are not reservable and Treasury bills carry no capital requirements, it might seem that the banking system would expand indefinitely if $r_{B}>r_{P}$, but in fact $r_{P}>r_{B}$ and so the preferences with respect to balance sheet composition reflected in equation 9 also determine banks' scale once $R$ and $K$ are given. While $R$ and $K$ are both strictly positive influences on the banking system's scale, therefore, the structure of equation 8 still renders their effects on banks' portfolio composition asymmetric. Specifically, as the undetermined derivatives in equation 9 indicate, changes in $R$ have differential effects on banks' choice of liabilities, while changes in $K$ have differential effects on banks' asset choices.

levels of interest rates, is standard in the literature of money supply; see, for example, Meigs (1962) and Modigliani, Rasche, and Cooper (1970). The parallel treatment here of bank capital follows the reasoning set forth by Brainard (1964).

27. Representing certificates of deposit as a distinct asset in investors' portfolios would again make the model more complex without adding insight that is directly relevant here. 


\section{Households}

Finally, open-market investors-what most models identify as households, although that designation misses the essence of this analysis-choose among transactions deposits, Treasury bills, commercial paper, and certificates of deposit, all in a manner constrained by their accumulated net saving. Here open-market investors in the aggregate are denoted by a superscript $H$. In the absence of household borrowing opportunities,,$^{28}$ the $i$-th investor's balance sheet constraint is just

$$
N A^{i}+D^{i}+B^{i}+P^{i}+C D^{i}=N W^{i},
$$

where $N A$ represents nonfinancial assets and $N W$ stands for net worth (in this case identical to total assets). The corresponding constraint equating total uses of funds with total sources is

$$
\Delta D^{i}+\Delta B^{i}+\Delta P^{i}+\Delta C D^{i}=N S,
$$

where $N S$ represents saving net of accumulation of nonfinancial assets. If equation 11 admits aggregation, ${ }^{29}$ standard principles of portfolio selection under conditions of risk then result in

$$
\begin{array}{r}
\Delta D^{H}=h_{1}\left(N S, r_{D}, r_{B}, r_{P}, \sigma^{2}, \theta_{P}, Y\right) \\
++-++++ \\
\Delta B^{H}=h_{2}\left(N S, r_{D}, r_{B}, r_{P}, \sigma^{2}, \theta_{P}, Y\right) \\
+---++- \\
\Delta P^{H}+\Delta C D^{H}=h_{3}\left(N S, r_{D}, r_{B}, r_{P}, \sigma^{2}, \theta_{P}, Y\right) . \\
+--++--
\end{array}
$$

The demand for money for purposes of executing transactions is presumably the origin of the distinct demands (and in general, therefore, different interest rates) for transactions deposits and Treasury bills, despite the absence of risk on either asset. This demand mandates the presence of income $Y$ in the deposit demand equation (and in general, therefore, in each of the other two asset demands). As before, the applicable

28. Modeling not only firms' borrowing and capital spending but households' borrowing and accumulation of nonfinancial assets too would add little in the context of this model. Open-market investors like pension funds and insurance companies do little freestanding borrowing, and their holdings of nonfinancial assets are also limited.

29. Again, see footnote 21 . 
restrictions mean that the system in equation 12 contains only two independent equations.

\section{Nonprice Costs of Borrowing}

While it is widely known that reported interest rates often do not measure accurately the true cost of borrowing, few models include any concrete attempt to allow for the effects of whatever other costs account for this discrepancy. The inclusion here of $\theta_{L}$ and $\theta_{P}$-and, in particular, the nonparallel treatment of these two nonprice cost elements from the perspective of lenders-strengthens this model's ability to explain observed relationships between price-quantity interactions in the credit markets and real economic activity of the kind documented in the second section. From the perspective of nonfinancial firms, the two nonprice costs of borrowing are parallel. Greater $\theta_{L}$ depresses $\Delta L^{F}$ just as would higher $r_{L}$, while greater $\theta_{P}$ depresses $\Delta P^{F}$ just as would higher $r_{P}$ (and, just below, either greater $\theta_{L}$ or greater $\theta_{p}$ depresses firms' nonfinancial investment). The nonparallel treatment lies in the effect of these nonprice costs on lenders.

As many researchers have emphasized, banks typically have ongoing relationships with their borrowers. ${ }^{30}$ In the case of loans, therefore, $\theta_{L}$ represents charges-either explicit (like origination and servicing fees) or implicit (like compensating balances, or the requirement to purchase unrelated services like underwriting or trust operations)-earned by banks as lenders. Interpreted to be net of any additional direct expenses of originating and servicing a particular loan, the elements of $\theta_{L}$ are just additional ways (beyond interest payments) for the bank to earn a profit from the transaction. Hence greater $\theta_{L}$ increases banks' willingness to lend, just as does higher $r_{L}$.

Observers of bank lending relationships typically report that over time these noninterest charges tend to increase or decrease as loan interest rates rise or fall, so that it is reasonable to treat $\theta_{L}$ in part as a positive function of $r_{L}$. To the extent that banks move $r_{L}$ only sluggishly in response to changes in supply-demand conditions in the loan market, how-

30. See again, for example, Bernanke (1983), Bernanke and Gertler (1986), and Gertler and Gilchrist (1993a). For a summary of the earlier literature treating bank customer relationships, see Hodgman (1961). 
ever, even this partial covariation is presumably highly imperfect. Moreover, $\theta_{L}$ plausibly varies both with the volume of loans outstanding and with the change in loans outstanding, since some kinds of noninterest charges (for example, compensating balances) are logically related to the ongoing level of financing while others (for example, origination fees) pertain to new financings only: ${ }^{31}$

$$
\begin{gathered}
\theta_{L}=\theta_{L}\left(r_{L}, L, \Delta L\right) . \\
+++
\end{gathered}
$$

In contrast to banks, open-market investors by definition have no ongoing relationship with the borrowers to whom they lend, and hence cannot capture all, or in some cases any, of the charges $\theta_{P}$ that represent noninterest costs to borrowers. Open-market investors must at least partly share these costs, which then accrue as profit to dealers, advertisers, rating agencies, and the like. ${ }^{32}$ Hence greater $\theta_{P}$ depresses not only $\Delta P^{F}$, as is the case for bank loans, but $\Delta P^{H}$ also. Since the costs that borrowers must incur for such purposes as establishing dealer relationships or obtaining agency ratings do not accrue to lenders, there is no reason for $\theta_{P}$ to covary with $r_{P}$. By contrast, these costs (and the profits made from them) do depend on the volume of business done in the commercial paper market, as the discussion below elaborates, and here too what matters is presumably both the volume of paper outstanding (and being continually refinanced, since commercial paper is a short-term liability) and the change in that volume: ${ }^{33}$

$$
\begin{gathered}
\theta_{P}=\theta_{P}(P, \Delta P) . \\
++
\end{gathered}
$$

31. Since $\theta_{L}$ represents a marginal cost of borrowing, for $\theta_{L}$ to increase with $L$ and $\Delta L$ requires that fees and other charges rise more than in proportion to the volume of lending.

32. To the extent that part of the charges making up either $\theta_{L}$ or $\theta_{P}$ merely serve to cover some entity's direct expenses associated with a specific transaction, it presumably does not matter whether that expense is incurred by and reimbursed to a bank or, for example, a rating agency or a securities dealer. For purposes here, however, both $\theta_{L}$ or $\theta_{P}$ are to be interpreted as net of such direct expenses, and hence as profit to some entity involved in the transaction.

33. Some of the noninterest costs of issuing commercial paper, like the cost of establishing a dealer relationship, are mostly one-time costs. More paper being issued by the same firms that have always issued paper therefore has a different implication than does more paper being issued because there are new issuers. An aggregate relationship like equation 14 necessarily blurs this distinction. 
Table 4. Financial Assets and Liabilities, by Holder and Obligor

\begin{tabular}{llllllll}
\hline & \multicolumn{7}{c}{ Asset/liability } \\
\cline { 2 - 7 } Holderlobligor & Bills & Loans & Paper & Deposits & CDs & Reserves & $\begin{array}{c}\text { Flow } \\
\text { constraint }\end{array}$ \\
\hline Nonfinancial & & & & & & & $=N R-I$ \\
$\quad$ firms & $+\Delta B^{F}$ & $-\Delta L^{F}$ & $-\Delta P^{F}$ & & & & \\
Banks & $+\Delta B^{B}$ & $+\Delta L^{B}$ & & $-\Delta D^{B}$ & $-\Delta C D^{B}$ & $+\Delta R^{B}$ & $=0$ \\
Households & $+\Delta B^{H}$ & & $+\Delta P^{H}$ & $+\Delta D^{H}+\Delta C D^{H}$ & & $=N S$ \\
Government & $-\Delta B^{G}$ & & & & & $-\Delta R^{G}$ & $=-D E F^{\mathrm{a}}$ \\
Market-clearing & & & & & & \\
$\quad$ condition & $=0$ & $=0$ & $=0$ & $=0$ & $=0$ & $=0$ & \\
\hline
\end{tabular}

Source: Based on the equations and conditions as described in the text.

a. DEF is the consolidated federal government budget deficit.

\section{Market Clearing}

Given participation in the short-term credit markets by nonfinancial firms, banks and open-market investors as described in equations 3-14, market clearing requires

$$
\begin{aligned}
\Delta B^{F}+\Delta B^{B} & +\Delta B^{H}=\Delta B^{G} \\
\Delta L^{B} & =\Delta L^{F} \\
\Delta P^{H} & =\Delta P^{F} \\
\Delta D^{H} & =\Delta D^{B} \\
\Delta C D^{H} & =\Delta C D^{B} \\
\Delta R^{B} & =\Delta R^{G},
\end{aligned}
$$

where $B^{G}$ is the outstanding volume of Treasury bills (net of ownership by the central bank and by foreign investors) and $R^{G}$ is the outstanding volume of reserves created by the central bank. (The superscript $G$ denotes the government sector.) Table 4 provides the standard tableau summarizing this set of market-clearing conditions together with the balance sheet restrictions embedded in equations 6,9 , and 12 .

\section{Links to Nonfinancial Activity}

The representation of the behavior of firms, banks, and open-market investors in equations 3-15 describes these agents' financial behavior 
only. Relevant aspects of firms' and households' nonfinancial activityfirms' investment and revenues, households' saving and accumulation of nonfinancial assets-enter this description but are not determined there. What is missing is the connection between the financial prices and quantities determined in equations 3-15 and nonfinancial outcomes. In most simplified models, of either the neoclassical or the credit variety, the main link between the financial markets and real economic activity is firms' investment behavior.

If the model is not to dictate before the fact any conclusion about whether the empirical connection between short-term credit markets and real activity is causal, the representation of investment behavior must include the makings of financial influences on investment as well as independent influences determining investment that, in turn, needs to be financed. Given the spirit of the description of financial behavior in equations 3-15, the most natural starting place for such a representation focuses on matters of risk and return. In addition, however, a principal object of the model developed here is to admit a potential role for balance sheet stocks and flows, as well as to expand the treatment of the risk and return variables to allow for nonprice elements of borrowers' cost of financing.

A skeletal representation of firms' investment that excludes any balance sheet stock variables is

$$
I=I\left(N R, r_{l}-\bar{r}, \bar{\theta}, \sigma^{2}\right),
$$

where, apart from purely stochastic fluctuations (due to unintended inventory accumulation, for example) investment responds positively to net revenues from operations, positively to the excess of the expected rate of return on investment $r_{I}$ over firms' composite interest cost of additional funds $\bar{r}$, negatively to the corresponding composite of nonprice elements of firms' cost of external funds $\bar{\theta}$, and negatively to the risk $\sigma^{2}$ associated with firms' return on investment. The composite interest cost $\bar{r}$ depends on $r_{L}, r_{P}$, and $r_{B}$ with weights that reflect the respective importance of $\Delta L, \Delta P$, and $\Delta B$ that firms choose in their financing of investment at the margin. The composite noninterest cost $\bar{\theta}$ depends in an analogous way on $\theta_{L}$ and $\theta_{P}$. The presence of $N R$ in equation 16 reflects the standard credit view assumption that internal funds are less costly than external financing (again, for reasons of asymmetric information, princi- 
pal-agent interactions, and contracts). ${ }^{34}$ Finally, in addition to these arguments of equation 16, a rising cost of debt at the margin, as discussed above in connection with firms' financing choice in equation 6 , would also imply a role for balance sheet stocks $L^{F}$ and $P^{F}$, and the nonnegativity constraint on firms' holdings of bills would likewise imply a role for $B^{F}$.

At a formal level, closing the model then simply requires making explicit the standard dependence of aggregate spending (income) on investment, of firms' revenues on spending, and of saving on income (and perhaps on interest rates). Given the two government variables $R^{G}$ and $B^{G}$, banks' capital position $K$, and all existing balance sheet stocks, the resulting model is then sufficient to determine the market-clearing values of all of the financial quantities, interest rates, and nonprice financing costs in equations $3-15$, as well as nonfinancial investment in equation 16. What remains undetermined, of course, is the prospective return $r_{I}$ and risk $\sigma^{2}$ associated with firms' nonfinancial investment. But that is a matter for a different paper.

\section{Hypotheses about the Credit Markets and Real Economic Activity}

How then can the model sketched immediately above account for the observed relationships between the short-term credit markets and real economic activity? And does whatever interaction is involved imply that the predictive content of credit market variables with respect to real activity is causal?

\section{A Causal Hypothesis: Monetary Policy Shocks}

One such mechanism, suggested by Kashyap, Stein, and Wilcox, as well as by our own work, centers on monetary policy and does make the observed relationships causal. ${ }^{35}$ Given equation 9 , a tightening of monetary policy in the form of a negative shock to $R^{G}$ restricts banks' willingness to make loans, so that the loan interest rate increases and the vol-

34. Whether investment is codetermined with net revenues, so that the financing gap $I-N R$ is a jointly determined variable in equation 6 , is a matter of time lags.

35. Bernanke (1990) also argued along these lines. 
ume of loans decreases. As firms that do not receive bank loans seek credit elsewhere, specifically in the commercial paper market, both the quantity of paper issued and the associated interest rate increase. With higher interest rates on financing, firms' investment declines. As is familiar, such a negative monetary policy shock also raises interest rates more broadly. Banks may seek to shrink their balance sheets not only by cutting back on loans but also by selling bills, and firms also sell bills from their portfolios (or accumulate less) as a way of obtaining additional investable funds. In the meantime, the supply of bills to be held by all private investors together is greater, because the central bank's means of reducing the quantity of reserves is to sell bills to the market. Hence interest rates rise not only in the loan and paper markets but in the bill market, too.

With plausible lags in the investment function, this story clearly can account for the empirical regularity emphasized by Kashyap, Stein, and Wilcox, that firms' mix between loan and paper financing tends to shift toward paper in advance of a decline in real output. (Recall, however, a caveat flagged in the second section, that the predictive content with respect to real output is contained entirely in the volume of paper issuance, with essentially none in the behavior of bank loans; more on this below.) By contrast, it is not obvious that anything in this process will cause the paper-bill spread to widen in advance of a decline in real output. The general equilibrium of the credit markets described above implies that a negative shock to $R^{G}$ will produce an increase in the bill rate along with the rates on loans and paper, and there is no reason why the paper rate increase should systematically exceed the bill rate increase as tends to occur empirically. ${ }^{36}$

One way of accounting for this phenomenon would be to appeal to the heterogeneity of firms. If the obligations of borrowers that shift from the bank loan market to the commercial paper market when monetary policy tightens are systematically less attractive to open-market investors than the obligations of borrowers whose paper is already outstandingeither because these new borrowers are less creditworthy, or because

36. As we explained in an earlier work (Friedman and Kuttner, 1993), the differential tax treatment of Treasury bills and commercial paper can account for some widening of the paper-bill spread as interest rates in general rise, but we also showed that the part of the variation of the spread not accounted for in this way also has predictive content with respect to real output. 
they deal in smaller volume so that their paper is less liquid-then the resulting rise in risk or loss of liquidity for the representative issuer's paper will lead the market-average commercial paper rate to rise relative to the rate on Treasury bills (or any other instrument for which risk and liquidity remain unchanged). This is essentially the story told verbally by Kashyap, Stein, and Wilcox, although it stands outside the model they present, which assumes homogeneous borrowers. Making such a story explicit would require a model with at least two classes of firms. ${ }^{37}$

A way of accounting for the widening of the paper-bill spread in these circumstances, even when all borrowing firms are homogeneous, is to exploit the fact that investors recognize the differing tax, risk, and liquidity features of commercial paper and Treasury bills, and hence treat these instruments as imperfect substitutes in their portfolios. When assets are imperfectly substitutable, changes in their relative supplies in general affect their relative market-clearing expected returns. In earlier work, we showed that the relative supplies of commercial paper and Treasury bills do have statistically significant effects, in the direction predicted by standard portfolio analysis, on the paper-bill spread ${ }^{38}$ As long as the increase in the quantity of paper that open-market investors have to hold when monetary policy tightens is relatively greater than the corresponding increase in the quantity of bills to be held, a direct consequence of that tightening is a widening of the paper-bill spread.

Finally, the model of the short-term credit markets developed in the third section of this paper can also account for an increase in the paperbill spread when monetary policy tightens because of the role played by the nonprice cost of commercial paper issuance, $\theta_{P}$, and in particular the asymmetry between $\theta_{P}$ and the nonprice cost of bank loans, $\theta_{L}$. Figure 2 illustrates the basic interaction at work by plotting borrowers' and lenders' behavior in the respective markets for bank loans, commercial paper, and Treasury bills. The negative shock to $R^{G}$ shifts the $\Delta L^{B}$ curve inward $\Delta L$ falls and banks raise the measured price of loans $r_{L}$, and probably the nonobserved price element $\theta_{L}$, as well. (Because the equations

37. Moreover, the paper-bill spread systematically widens in these circumstances even when, as in the results presented in the first section and in Friedman and Kuttner $(1992,1993)$, the paper rate is calculated only from issues rated P1 (the highest rating) by Moody's Investors Service. Hence the heterogeneity at work would have to be within the P1-rated subset of firms.

38. Friedman and Kuttner (1993). 
Figure 2. Effects of a Contractionary Monetary Policy Shock Loan market

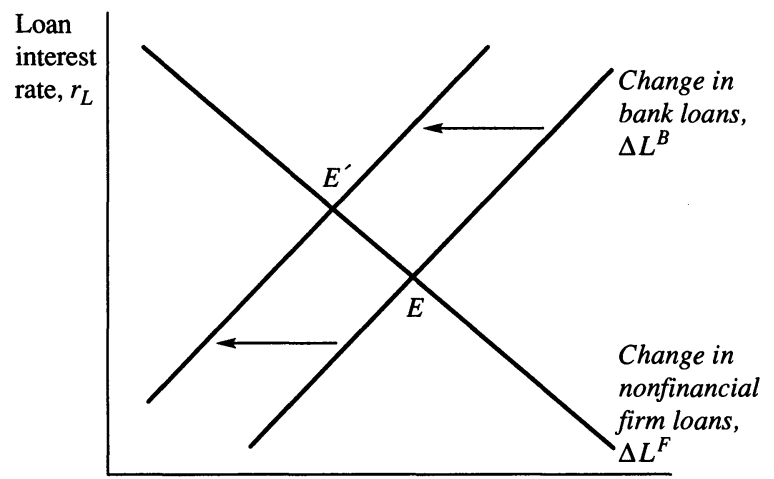

Change in loans, $\Delta_{L}$

Paper market

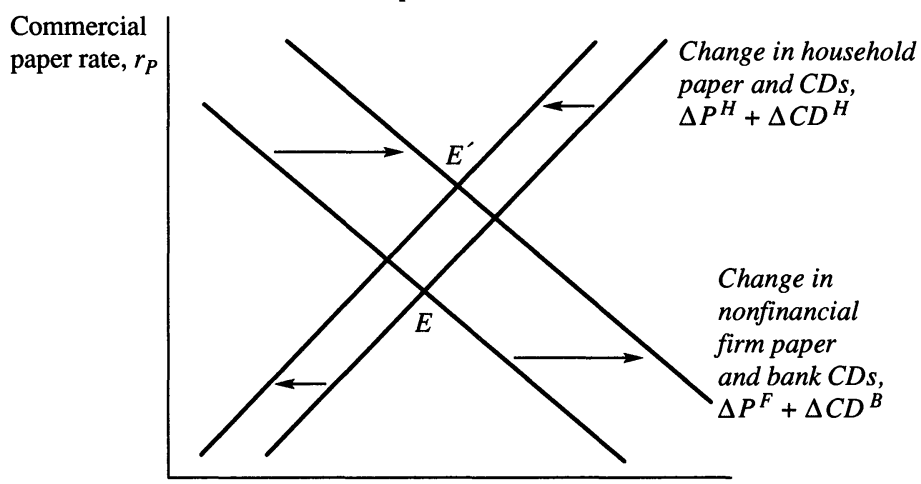

Change in paper and $\mathrm{CDs}, \Delta P+\Delta C D$

Treasury bill market

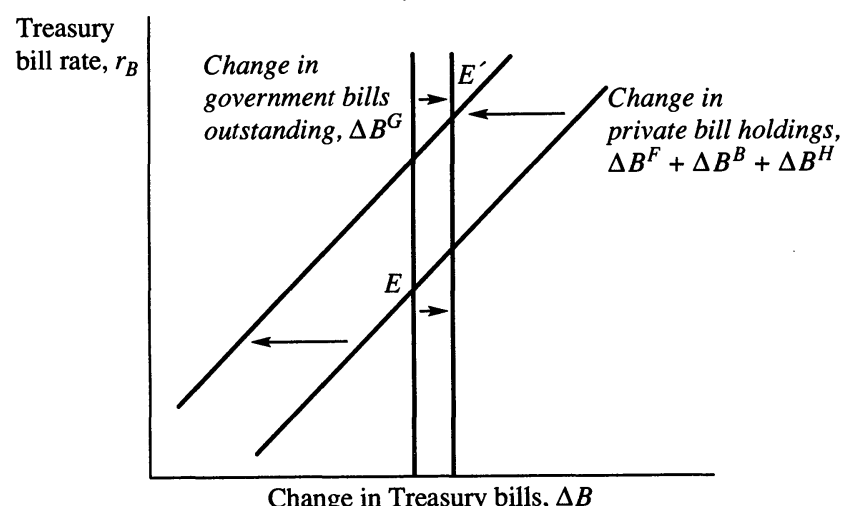

Change in Treasury bills, $\Delta B$ 
in the model are simultaneous-that is, curves plotted in figure 2 to represent borrowers' and lenders' behavior in each market are conditional on outcomes in the other markets-any attempt to describe the effects of a specific shock verbally is necessarily imprecise because it is only sequential.)

As firms that otherwise would have borrowed from banks then turn to the commercial paper market, not only does $r_{P}$ rise, but $\theta_{P}$ increases for either or both of two reasons, both intuitively reflected in equation 14. First, if firms that normally borrow at banks do not have preexisting commercial paper programs, they must incur a cost to establish a relationship with a dealer in this market. ${ }^{39}$ The resulting dealer's profit constitutes a cost that must be paid in some proportion by borrowers and lenders. Second, in addition to the cost of establishing and maintaining a dealer relationship, when firms borrow in the open market someone must monitor their performance and prospects on behalf of lenders. As Ben S. Bernanke has emphasized, in his own work and work with Mark Gertler, a key role traditionally played by banks is to perform just this monitoring function. ${ }^{40}$ When firms that normally borrow at banks move into the open market, the burden placed on market analysts, independent rating agencies, and lending institutions themselves becomes greater.

Depending upon how this additional cost is shared between borrowers and lenders, either $\Delta P^{F}$ shifts outward by less than would otherwise be the case, or $\Delta P^{H}$ shifts inward, or both as illustrated in figure 2 . In addition, with reserves more scarce, banks may increase their eagerness to issue (nonreservable) certificates of deposit, as indicated in equation 9. The new equilibrium in the paper and $C D$ market may have the quantity $\Delta P+\Delta C D$ either greater (as shown in figure 2) or smaller than before the negative monetary policy shock, but the price $r_{P}$ is unambiguously greater. Moreover, because $\theta_{P}$ represents a cost to borrowers or lenders, or both-again, in contrast to $\theta_{L}$, which is an element of the price that lenders receive from borrowers-the increase in $r_{P}$ exceeds the increase in other short-term interest rates to which such costs do not pertain. Hence the credit market consequences of a tightening of monetary policy include not only a decline in the loan-paper mix but also a

39. Nonfinancial corporations do not normally place their own commercial paper.

40. Bernanke (1983) and Bernanke and Gertler (1989). 
widening of the paper-bill spread, even though the inward shift in any or all of $\Delta B^{F}, \Delta B^{B}$ and $\Delta B^{H}$, and the outward shift in $\Delta B^{G}$, increase $r_{B}$ as well. And as long as firms' investment is sensitive to the price and/or nonprice cost of financing, real economic activity declines.

\section{Another Causal Hypothesis: Bank Capital Shocks}

Much of the discussion of the 1990-92 weakness in lending illustrated in figure 1 , and of the connection between the weakness in lending and the sluggishness of the recovery of real economic activity following the March 1991 recession trough, has focused not on monetary policy but on arrangements surrounding banks' capital requirements. ${ }^{41}$ In brief, the argument has three elements: The Basle accord in effect raised $k_{2}$ in equation 8 to 8 percent, while maintaining $k_{4}=0 .{ }^{42}$ Loan losses, especially in their real estate portfolios, reduced $K$ at many banks. And more vigorous supervision by the regulators further reduced many banks' $K$ by classifying as problematic many loans on which borrowers had not yet defaulted.

The effect of an increase in $k_{2}$ and/or a reduction in $K$ is to render the capital requirement binding for some banks at which it was not so already. For yet other banks, following the discussion in the third section, the effect is to narrow the margin by which the requirement is not binding, and hence to increase the shadow cost on capital in a dynamic context. On both counts, banks' willingness to lend is reduced, as indicated in equation 9 , and so $\Delta L^{B}$ again shifts inward as in figure 2 . As firms that cannot obtain bank loans seek funds in the paper market, $\Delta P^{F}+\Delta C D^{B}$ again shifts outward as in figure 2 .

The fact that banks' assets differentially affect their required capital while their liabilities differentially affect their required reserves, however, means that the further consequences of a negative shock to bank capital (or an increase in the capital requirement) are not necessarily as described above for the case of a monetary policy shock. Unlike in the wake of a negative monetary policy shock, here banks have no incentive to issue more certificates of deposit, and so firms' greater issuance of

41. See, for example, Syron (1991).

42. See Baer and McElravey (1993) for a detailed account of the Basle standards and a brief but comprehensive history of previous bank capital requirements in the United States. 
commercial paper is now the only reason why $\Delta P^{F}+\Delta C D^{B}$ in figure 2 would shift outward. Also, as equation 9 indicates, here there is less reason to expect banks to reduce their holdings of securities, and they may even increase their securities holdings in order to avoid shrinking in overall scale when capital is inadequate. Hence the inward shift of $\Delta B^{F}$ $+\Delta B^{B}+\Delta B^{H}$ in figure 2 is now mostly, or perhaps entirely, a matter of firms' and households' behavior. Unlike an open market operation that withdraws reserves, a negative shock to banks' capital positions does not involve any outward shift of $\Delta B^{G}$.

As this comparison makes clear, merely looking at the behavior of interest rates and loan volumes-the standard fare of most discussions of whether greater capital requirements and/or banks' loan losses have created a credit crunch-is not sufficient to distinguish a negative bank capital shock from a negative monetary policy shock. In both cases loan volume falls, all interest rates rise, and the paper rate rises by more than the bill rate. And in both cases these happenings in the financial markets play a directly causal role in retarding real economic activity. Only by bringing into the analysis additional specifics of the banks' balance sheet, like CD issuance and securities holdings, is it possible to distinguish these two kinds of shocks.

\section{A Noncausal Hypothesis: Default Risk Shocks}

While it is certainly plausible that the predictive content of the loanpaper mix and the paper-bill spread reflects a mechanism by which a shock that initially affects the credit markets ultimately affects real output, it is also entirely possible that what underlies the comovement of these variables with real output is not causal at all. Either the mix or the spread may simply fluctuate in anticipation of changes in real activity that occur for independent reasons. ${ }^{43}$ From a purely predictive standpoint-that is, whether the mix or the spread, or both, can serve as leading indicators-the distinction is moot. If the leading indicator is to play a role in the central bank's formulation of monetary policy, however, the distinction is not only relevant but important ${ }^{44}$ Moreover, from the

43. The distinction at issue here is the same as that highlighted by Tobin (1970) in a different context.

44. See, for example, Friedman (1990). 
perspective of gaining an understanding of the nature of interactions between the credit markets and real economic activity, evaluation of competing hypotheses is of the essence.

One of our earlier papers and a paper by Bernanke considered an explanation for the predictive content of the paper-bill spread that implies no causal influence from the credit markets to real activity ${ }^{45}$ In the context of a model like that developed in this paper, this hypothesis can also potentially account for the predictive content of the loan-paper mix (although not of the volume of paper issuance per se). In contrast to the causal hypotheses sketched above, in which the central elements are the nonprice costs of borrowing $\theta_{i}$, here the focus is on the lending risk $\sigma^{2}$.

It is well known (and hardly surprising) that bankruptcies and debt defaults vary with the state of overall economic activity. When lenders anticipate that an economic downturn is about to occur, and hence that defaults by borrowers with cyclically sensitive cash flows have become more likely, the greater perceived risk reduces their willingness to advance funds to private borrowers at any given interest rate. Hence measured interest rates on defaultable credits like bank loans and commercial paper rise relative to rates on default-free credits like Treasury bills. ${ }^{46}$ At the same time, the volume of issuance of defaultable credits declines. If banks are more averse to assuming such risks than are openmarket investors, or if banks are more exposed to such risks because open-market obligations are senior to bank loans in the event of bankruptcy, then loan volume will decline by more than paper volume so that the loan-paper mix also declines.

To the extent that investors' anticipations of future economic fluctuations tend on average to be correct, these induced movements in both the paper-bill spread and the loan-paper mix will predict movements in real output, despite the lack of any causation running from the credit markets to real activity. Further, if investors' anticipations in this regard embody information from disparate sources (like knowledge of individual companies), or information that is otherwise difficult to quantify or to summarize in a compact way, the spread and the mix will have pre-

45. Friedman and Kuttner (1993) and Bernanke (1990).

46. Measured interest rates on defaultable securities would rise relative to default-free rates even if lenders were risk-neutral, because the expected gross return equals the quoted gross interest rate times the probability of payment. The increase will, of course, be greater when lenders are risk-averse. 
dictive content even in the presence of standard aggregate variables that conventionally appear in regressions for real output.

Figure 3 illustrates this mechanism in the context of the model presented in the third section. A positive shock to $\sigma^{2}$ causes the $\Delta L^{B}$ curve to shift inward, increasing $r_{L}$ but reducing $\Delta L$ for a given $\Delta L^{F}$ curve. Similarly, greater $\sigma^{2}$ causes the $\Delta P^{H}+\Delta C D^{H}$ curve to shift inward, increasing $r_{P}$ but reducing $\Delta P$ for a given $\Delta P^{F}+\Delta C D^{B}$ curve. In the bill market, greater $\sigma^{2}$ causes both $\Delta B^{B}$ and $\Delta B^{H}$ to shift outward, while $\Delta B^{F}$ shifts inward as firms liquidate securities holdings as a means of financing. If the outward shift for banks and households is greater than the inward shift for firms, as shown in figure 3 , the result is to reduce $r_{B}$ (for given quantity of bills outstanding and with no response from the central bank). Hence the widening of the paper-bill spread is straightforward, but whether interest rates rise or fall depends on which rate one has in mind. Whether the loan-paper mix increases or declines depends on the relative responses of $\Delta L^{B}$ and $\Delta P^{H}$ to $\sigma^{2}$, as well as on relationships among the various elasticities in equations 6,9 , and 12 . (Once again, this inherently sequential verbal description fails to capture the simultaneity of the underlying model.)

This noncausal hypothesis is similar to the two causal ones described above in that all three imply a widening of the paper-bill spread and, under the right conditions, a decline in the loan-paper mix in advance of a decline in real output. At a finer level of detail, however, the different hypothesized shocks suggest different implications for both prices and quantities. On the price side, a negative monetary policy shock, a negative bank capital shock, and a positive default risk shock all imply increases in $r_{L}$ and $r_{P}$ before a decline in output, but the monetary policy and bank capital shocks imply an increase in $r_{B}$, while the default risk shock implies a decrease in $r_{B}$. On the quantity side, all three shocks imply a decline in $\Delta L$ before a decline in output, but the monetary policy and bank capital shocks imply an increase in $\Delta P$, while the default risk shock implies a decrease in $\Delta P$. At least in principle, these differences should provide a handle by which to distinguish empirically among the various shocks.

\section{Another Noncausal Hypothesis: Cash Flow Shocks}

Finally, in our earlier work we advanced yet another hypothesis to explain the predictive content of the paper-bill spread with respect to 
Figure 3. Effects of a Positive Default Risk Shock

Loan market

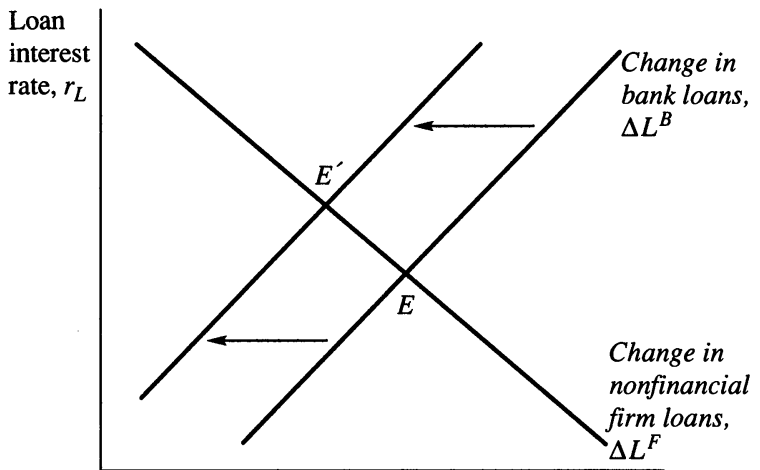

Change in loans, $\Delta_{L}$

Paper market

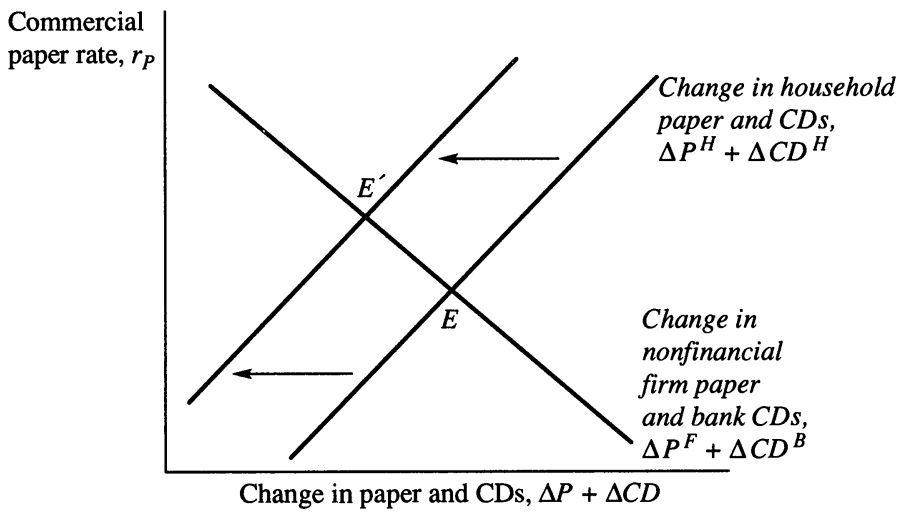

Treasury bill market

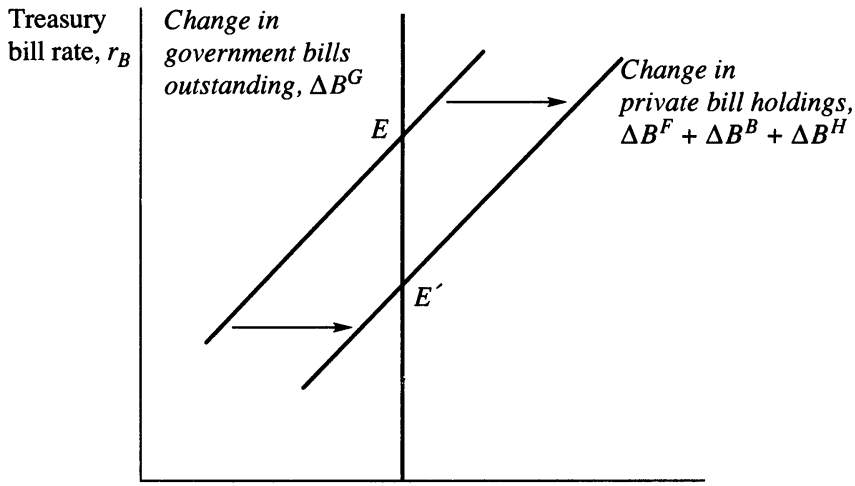

Change in Treasury bills, $\Delta B$ 
real output, and under the right conditions it, too, is consistent with the observed comovement of real output and the loan-paper mix ${ }^{47}$ The central focus of this hypothesis is the cyclical variation in nonfinancial firms' cash flows. As in the case of shocks to default risk, but unlike either monetary policy shocks or bank capital shocks, prediction here does not necessarily imply causality.

As equation 5 makes clear, a crucial determinant of nonfinancial firms' financing is the gap between their investment and their net revenues from operations. Either a positive shock to investment (for example, an increase in unintended inventory accumulation) or a negative shock to revenues-each of which is hardly atypical as economic activity nears a business cycle peak-enlarges firms' financing gap and therefore increases their demand for financing from all sources. In figure 4, a negative shock to net cash flow in this sense (net of investment, that is) causes the $\Delta L^{F}$ and $\left(\Delta P^{F}+C D^{B}\right)$ curves to shift outward (and $\Delta B^{F}$ to shift inward). The result is an increase in quantity in both the loan market and the paper market, and an increase in both interest rates: $\Delta L, \Delta P$, $r_{L}$, and $r_{P}$ are all greater. Given the rise in $r_{L}$ and $r_{P}$, the $\Delta B^{B}$ and $\Delta B^{H}$ curves in the Treasury bill market both shift inward along with $\Delta B^{F}$ Hence $r_{B}$ rises as well.

Once again, either the imperfect substitutability of commercial paper and Treasury bills or the nonprice element of the cost of commercial paper issuance can account for the behavior of the paper-bill spread under conditions of borrower homogeneity. As more firms borrow in the paper market, and in larger amounts, the increasing $\operatorname{cost} \theta_{P}$ drives a bigger wedge between what borrowers pay and what lenders receive. Hence $\Delta P^{H}$ shifts inward (because what is on the vertical axis is just $r_{P}$ ) and $r_{P}$ rises relative to $r_{B}$. From the standpoint of accounting for the behavior of the loan-paper mix, here, as in the case of a default risk shock, what matters is just the relative elasticities exhibited by the relevant aspects of the portfolio behavior of firms, banks, and open-market lenders as specified in equations 6,9 , and 12 , respectively.

Although this analysis of cash flow shocks therefore bears similarities to that of the other shocks considered above, here too there are differences. On the price side, negative cash flow shocks resemble negative monetary policy shocks or negative bank capital shocks, but differ from

47. Friedman and Kuttner (1993). 
Figure 4. Effects of a Negative Cash Flow Shock

\section{Loan market}

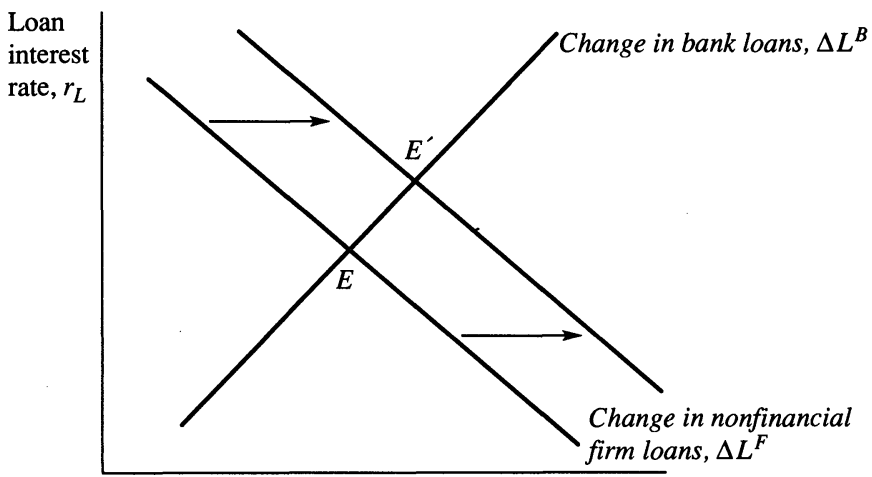

Change in loans, $\Delta_{L}$

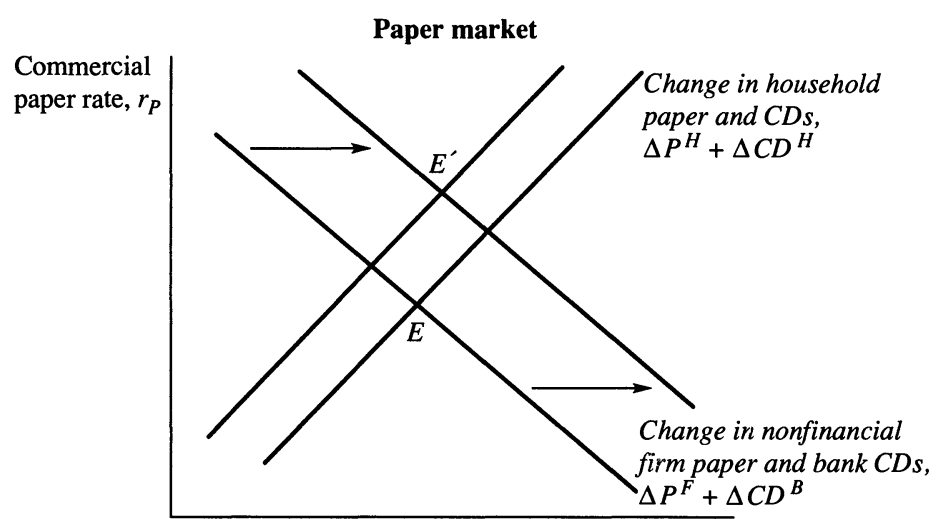

Change in paper and CDs, $\Delta P+\Delta C D$

Treasury bill market

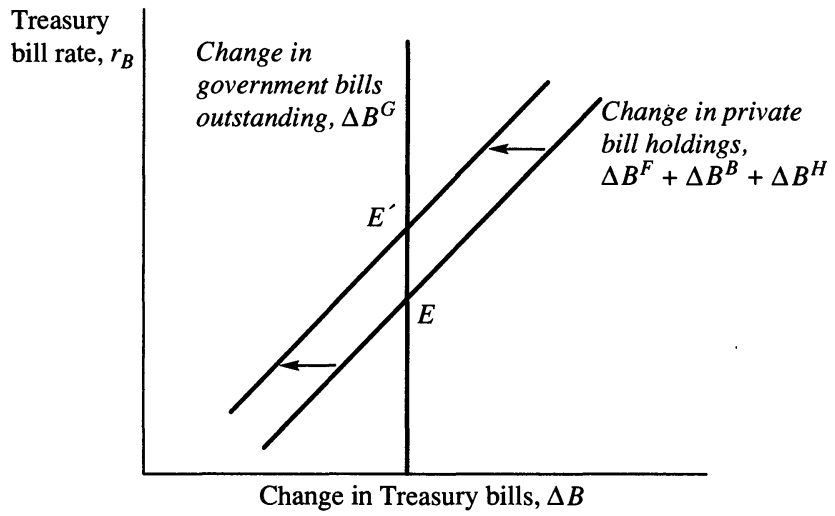


positive default risk shocks, in implying that $r_{B}$ increases along with $r_{L}$ and $r_{P}$ in advance of a downturn in real output. On the quantity side, negative cash flow shocks differ from any of the other three shocks in implying that both $\Delta L$ and $\Delta P$ increase in advance of a downturn. Once again, such differences are the stuff of empirical analysis.

\section{Descriptive Evidence on Responses to Financial Shocks}

The central advantage of a model like that developed here is the facility that it provides for examining just this kind of distinction between the effects of different kinds of shocks. Given the model, it is straightforward to say, qualitatively, what comovements between financial prices and financial quantities, and between financial variables and nonfinancial economic activity, follow from any given kind of shock. The empirical question is then whether the corresponding comovements actually observed bear out these predictions.

\section{Monetary Policy Shocks}

Although the model developed in the third section includes no explicit dynamics, the relationships under discussion there-including especially the role of balance sheet stocks-and the responses to different shocks analyzed in the fourth section surely stretch out over time. Investigating the interactions that ensue following any given shock therefore requires a dynamic representation. Figure 5 presents impulse response functions summarizing the behavior of a series of four-variable vector autoregressions designed to focus on the behavior of financial prices and quantities (as well as aggregate nonfinancial activity) in response to monetary policy shocks.

In each four-variable system examined in figure 5, two of the variables are the level of real output (gross domestic product) and the first difference of the corresponding implicit price deflator, and a third is the federal funds rate, taken as an indicator of monetary policy ${ }^{48}$ The fourth variable in each case is the financial price or quantity variable indicated

48. Bernanke (1990), Bernanke and Blinder (1992), and other researchers have had empirical success using the federal funds rate as a monetary policy indicator. See Sims (1992), however, for arguments against identifying funds rate innovations as monetary policy shocks. 
in the corresponding row of figure 5; each impulse response shown in that row is based on the vector autoregression with that variable as the fourth variable. In each case, the figure shows the estimated impulse response and the associated one-standard-error band around it. For the purpose of calculating these responses, the ordering of the orthogonalization always places output first, the output price index second, the federal funds rate third, and the financial price or quantity last. Hence any effects attributed to monetary policy shocks are due entirely to those movements in the federal funds rate that are not predictable from past output and inflation, and any effects attributed to the financial price or quantity per se are due entirely to that part of its variation not predictable from past output, inflation, or funds rate movements. Each vector autoregression considered is estimated using quarterly data for 1960:11992:4, with four lags on each variable included. ${ }^{49}$

Figure 5 presents three impulse responses for each such system, designed to answer the following three questions. First, do monetary policy shocks affect real output? Second, do monetary policy shocks affect the specific financial price or quantity indicated? And third, does that financial variable affect real output independently, in the sense of doing more than just reflecting whatever effect monetary policy is having?

As the left-most column of panels in figure 5 shows, the answer to the first question is clearly yes. No matter what financial price or quantity the system includes, a positive shock to the federal funds rate always depresses real output. Moreover, these estimated effects are significant not only statistically but also economically. In the case of the first panel shown, for example, a one percentage point increase in the funds rate (again, independent of what past real output and inflation would predict) depresses the level of real output by about 0.75 percent after six quarters. ${ }^{50}$

49. To use data from the entire 1960-92 sample for this purpose is to ignore the many changes in market structures, business practices, and government policies that have taken place during this period. Which if any such changes have amounted to a structural break in the context of the models estimated here is an interesting question, but one that lies well beyond the scope of this paper. See Akhtar and Harris (1987), Bosworth (1989), Friedman (1989), and Mauskopf (1990), for example, for analyses along those lines in the specific context of monetary policy.

50. Not surprisingly, this effect is more muted in samples restricted to the period after Regulation Q interest ceilings ceased to be effective. For example, in the 1975-92 sample used in the seventh section to investigate the most recent experience, a 1 percentage point increase in the federal funds rate depresses real output by 0.33 percent after eight quarters. 

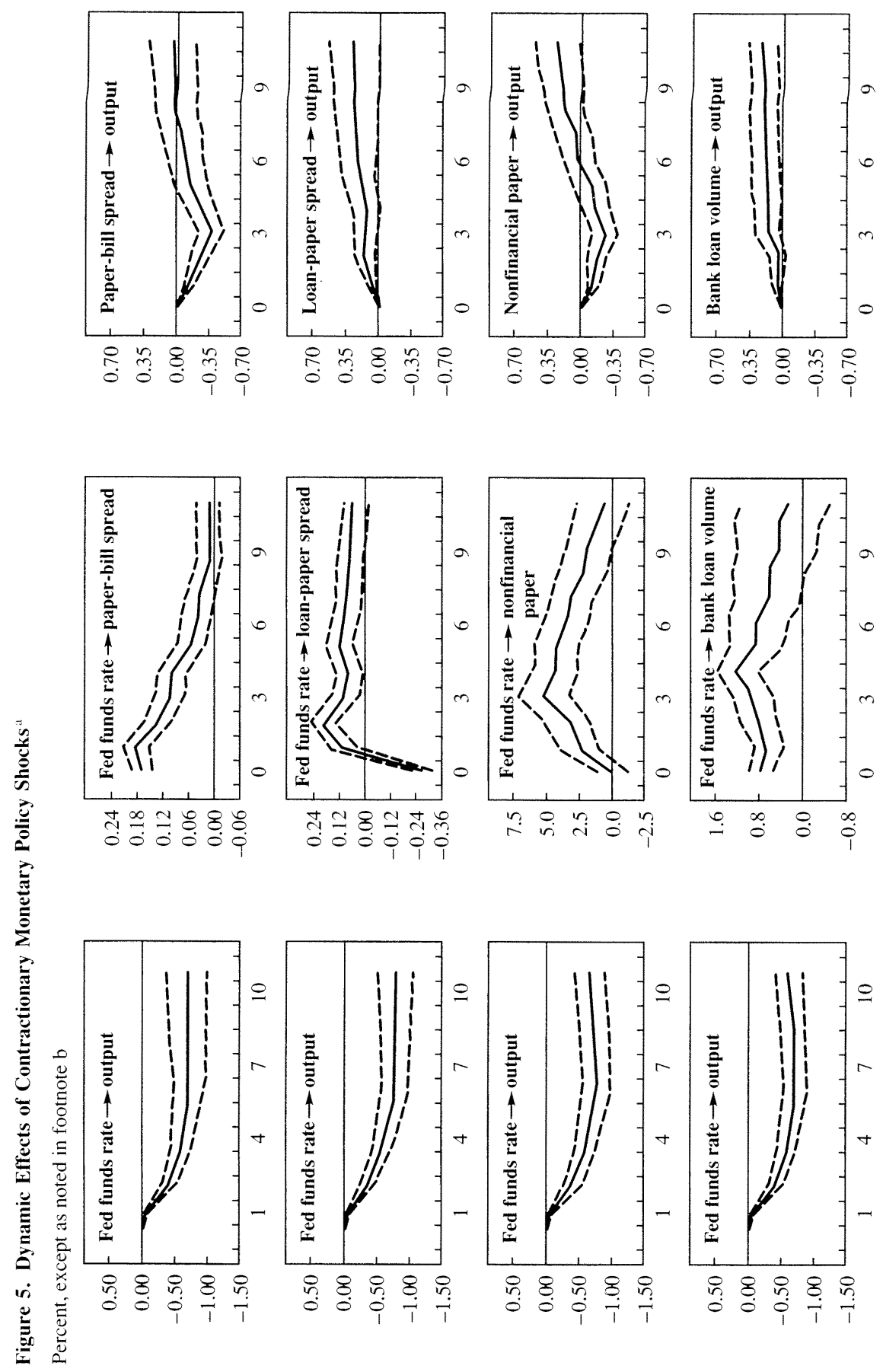

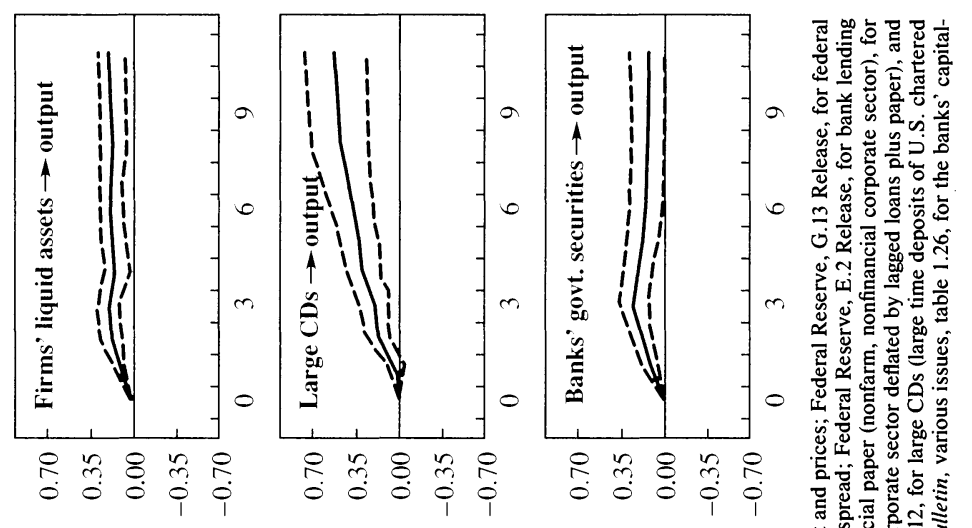

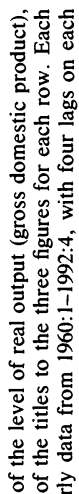

需

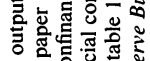

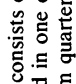

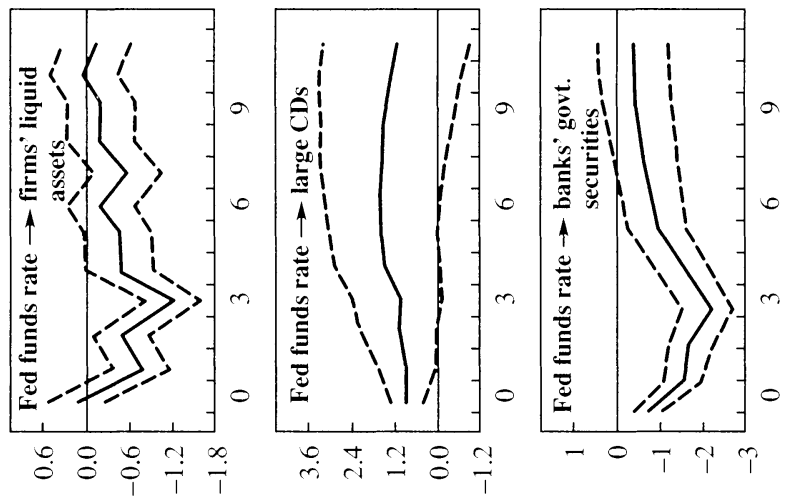

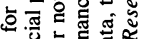

ธิ छّ

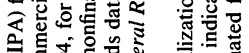

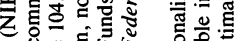

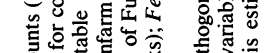

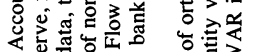

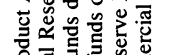

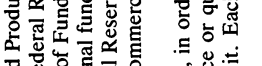

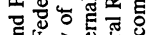

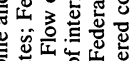

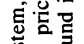

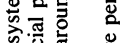

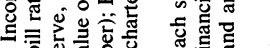

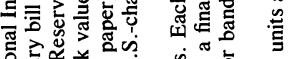

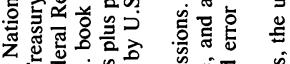

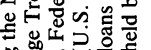
造造䨌

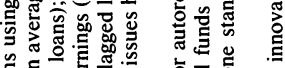
听응 형 छ

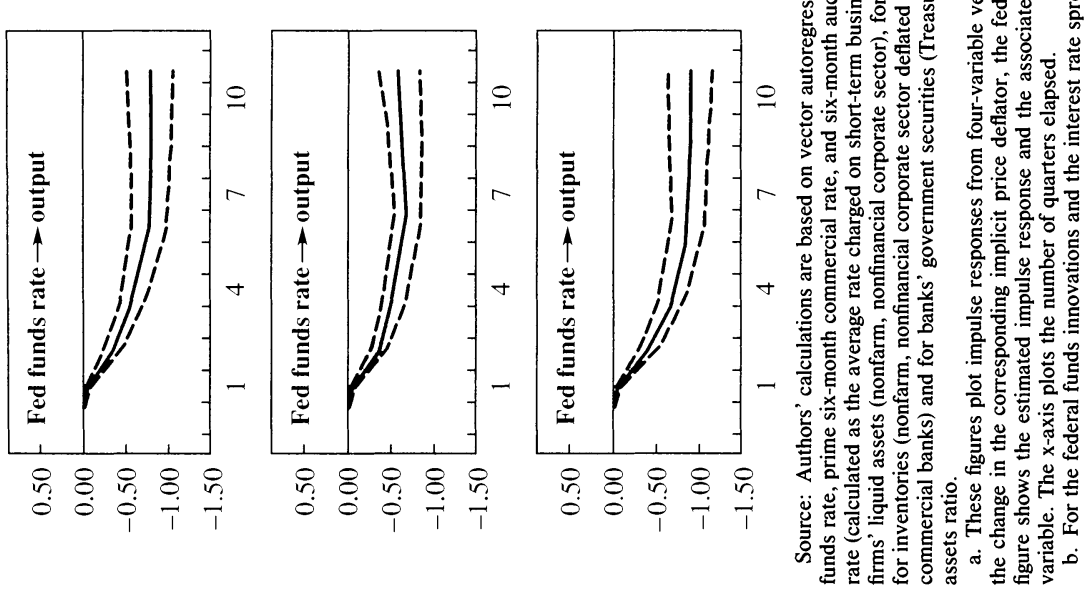


The first system for which impulse responses are shown in figure 5, in the top row, includes the paper-bill spread as the fourth variable. As the middle panel in that row shows, the paper-bill spread rises immediately and sharply in response to a contractionary monetary policy shock, just along the lines of the discussion of monetary policy shocks in the fourth section; hence there is strong ground for interpreting the spread as a kind of monetary policy indicator, as Bernanke; Kashyap, Stein, and Wilcox; and we in our previous work have all suggested. In addition, however, as the right-most panel in that row shows, fully orthogonalized shocks to the paper-bill spread also depress real output in the short run. Hence either the paper-bill spread is capturing aspects of monetary policy shocks not reflected in the federal funds rate, or the spread contains information about effects on real activity due to shocks from other sources. (Either implication is interesting in a monetary policy context.)

In the next system considered, the financial variable included is the spread between the bank loan rate and the commercial paper rate-in principle, the key relative price that motivates the financing behavior of firms, and hence the resulting effects on real output, in the model of Kashyap, Stein, and Wilcox. Although negative monetary policy shocks do widen the loan-paper spread, as the Kashyap-Stein-Wilcox model predicts, they do so only after a sharp initial contrary movement that is presumably due to banks' sluggishness in adjusting their loan rates. ${ }^{51}$ The seemingly counterintuitive finding that fully orthogonalized shocks to the loan-paper spread independently stimulate real output (albeit not significantly) is probably a reflection of this initial contrary movement as well.

The next three systems considered in figure 5 bear on questions of business financing in the sense of equation 6 above. First, as is suggested in the discussion in the fourth section (and also in the analysis of Kashyap, Stein, and Wilcox), a contractionary monetary policy shock causes the volume of commercial paper outstanding to increase. In addition, as is consistent with the discussion of either bank capital shocks or business cash flow shocks in the fourth section, whatever shock apart from monetary policy is causing commercial paper volume to increase also independently depresses output. Second, in contrast to the analysis of

51. This delay could explain part of the timing pattern observed by Romer and Romer (1990). 
Kashyap, Stein, and Wilcox (and the discussion accompanying figure 2 above), negative monetary policy shocks cause bank loan volume to increase. The independent effect on output due to fully orthogonalized shocks to loan volume is expansionary, however, as anticipated. Third, negative monetary policy shocks do cause firms to draw down their liquid assets, as described in the fourth section, and whatever other shocks cause firms to raise their liquid asset holdings (positive cash flow shocks, for example) independently stimulate real output.

The final two systems considered in figure 5 focus on questions of bank portfolio behavior in the sense of equation 9. As the discussion of reserve requirements in the third and fourth sections suggests, negative monetary policy shocks lead banks to increase their outstanding volume of nonreservable certificates of deposit. ${ }^{52}$ Independent shocks to CD volume are expansionary for real output, however, as would be expected. Negative monetary policy shocks also lead banks to reduce their holdings of government securities (roughly mirroring the movements of the opposite direction in their loan portfolios, shown above). Surprisingly, however-at least in the context of the discussion of capital requirements and associated shocks in the fourth section-positive shocks to banks' securities holdings from sources other than monetary policy stimulate real output.

\section{Bank Capital Shocks}

Measuring the adequacy of banks' capital adequacy in a time-series context is problematic for two reasons. First, what matters for banks' portfolio decisions, as in equation 9 , is not only how much capital banks hold but how much they hold compared to required benchmarks that have changed substantially over time. Before 1981, bank regulators in the United States imposed a largely discretionary system of capital requirements based on case-by-case comparisons with similar banks. Between 1981 and 1985, the regulators phased in a uniform minimum requirement of 5.5 percent of assets for "primary capital" consisting of equity plus loan loss reserves. Beginning in 1989, a new system required

52. Not surprisingly, this effect is stronger in post-Regulation $\mathrm{Q}$ samples (see again footnote 50). In the 1975-92 sample, the maximum effect on $C D$ issuance is 1.8 percent and highly significant, in contrast to the marginally significant 1.2 percent at the maximum as shown in figure 5 . 
a minimum ratio to assets of 3-5 percent, depending on portfolio composition and expected future growth, for "tier-1 capital," which excludes loan loss reserves and a portion of preferred equity. ${ }^{53}$ In 1992, the Basle guidelines further mandated minimum requirements of 4 percent for tier1 capital and 8 percent for tier- 2 capital, based not on total assets but "risk-adjusted" assets.

The second difficulty in measuring banks' capital adequacy is that, as the discussion in the third section emphasizes, what matters is not only the amount of capital that banks in the aggregate hold but the distribution of those holdings across individual banks. Apart from mergers and acqusitions, which are typically slow-moving and laborious transactions, there is no market through which a bank with excess capital can transfer that excess to another bank that is deficient. To the authors' best knowledge, there currently exists no publicly available source of time-series data compactly summarizing the adequacy of banks' capital in a way that captures this distributional aspect. ${ }^{54}$

In the absence of a measure that would adequately address these two problems, figure 6 presents impulse response functions summarizing the behavior of a series of vector autoregression systems that include a simple measure of aggregate U.S. bank capital holdings based on the difference between banks' aggregate assets and liabilities, divided by aggregate bank assets. ${ }^{55}$ The strong and consistent effect of monetary policy shocks, not only on output but also on many of the financial variables shown in figure 5, serves as a warning against proceeding to investigate the effects of other kinds of shocks without also including monetary policy shocks in the analysis. Figure 6 therefore shows impulse responses drawn from a series of five-variable vector autoregressions that are directly analogous to those underlying figure 5, except that they also include the logarithm of the aggregate bank capital ratio. The order of or-

53. Again, see Baer and McElravey (1993) for a comprehensive review.

54. In separate research, the authors are currently constructing such a measure by applying the cross-sectional regression approach of Baer and McElravey (1993) to the full set of individual-bank call report data available for each quarter since 1976.

55. Data are drawn from a survey of weekly reporting banks and from quarterly call reports, as reported in the Federal Reserve Bulletin, table 1.25, various issues. The relevant series are available on a consistent basis beginning in 1973:1 and ending (as of the time of writing) in 1992:2. The difference between assets and liabilities is not identical to equity capital as defined in the call reports, but it is conceptually similar and it is also quantitatively similar to the aggregate equity capital from the call reports as given in Federal Reserve Bulletin, special table 4.22, various issues. 
thogonalization in each system is output first, inflation second, monetary policy (the federal funds rate) third, the capital ratio fourth, and whatever specific financial price or quantity the system includes fifth. Each vector autoregression considered is estimated using quarterly data for 1974:1-1992:2, with three lags on each variable included.

Because these systems show little evidence that shocks to bank capital independently affect output, figure 6 shows only the effects of bank capital shocks on specific financial prices and quantities and the fully orthogonalized effects of those prices and quantities on output (corresponding to the impulse responses shown in the middle and right-hand portions of figure 5). When the system's fifth variable is the paper-bill spread, the effect of a negative bank capital shock is to widen that spread, as the discussion in the fourth section predicts, but the effect is not statistically significant. By contrast, the negative effect on the loanpaper spread is directly inconsistent with what the analysis of bank capital shocks in the fourth section implies. Here each spread has significant predictive power with respect to real output, even with the spread placed after the federal funds rate and the bank capital ratio in the orthogonalization.

Negative shocks to bank capital lead to an initial small decline but then, as the discussion in the fourth section predicts, an increase in nonfinancial firms' issuance of commercial paper. What is strikingly at odds with the discussion in the fourth section, however, is that negative bank capital shocks lead to an increase in bank lending. This result presumably reflects the inadequacy of the simple capital-to-asset ratio as discussed above. (Bank loans are a major component of bank assets.) The finding that negative bank capital shocks mostly cause firms to increase their holdings of liquid assets is also inconsistent with the discussion in the fourth section. The positive effect on banks' CD issuance and the negative effect on banks' holdings of government securities are not directly inconsistent with a role for bank capital shocks as described in the fourth section, but they may also be due to the simultaneity problem inherent in using the capital-to-assets ratio in this context.

\section{Default Risk Shocks}

Figures 7 and 8 present results bearing on the default risk hypothesis, as described in the fourth section, by showing impulse responses from a further series of five-variable vector autoregressions that are analogous 
Figure 6. Dynamic Effects of Negative Capital-Assets Shocks

Percent, except as noted in footnote b
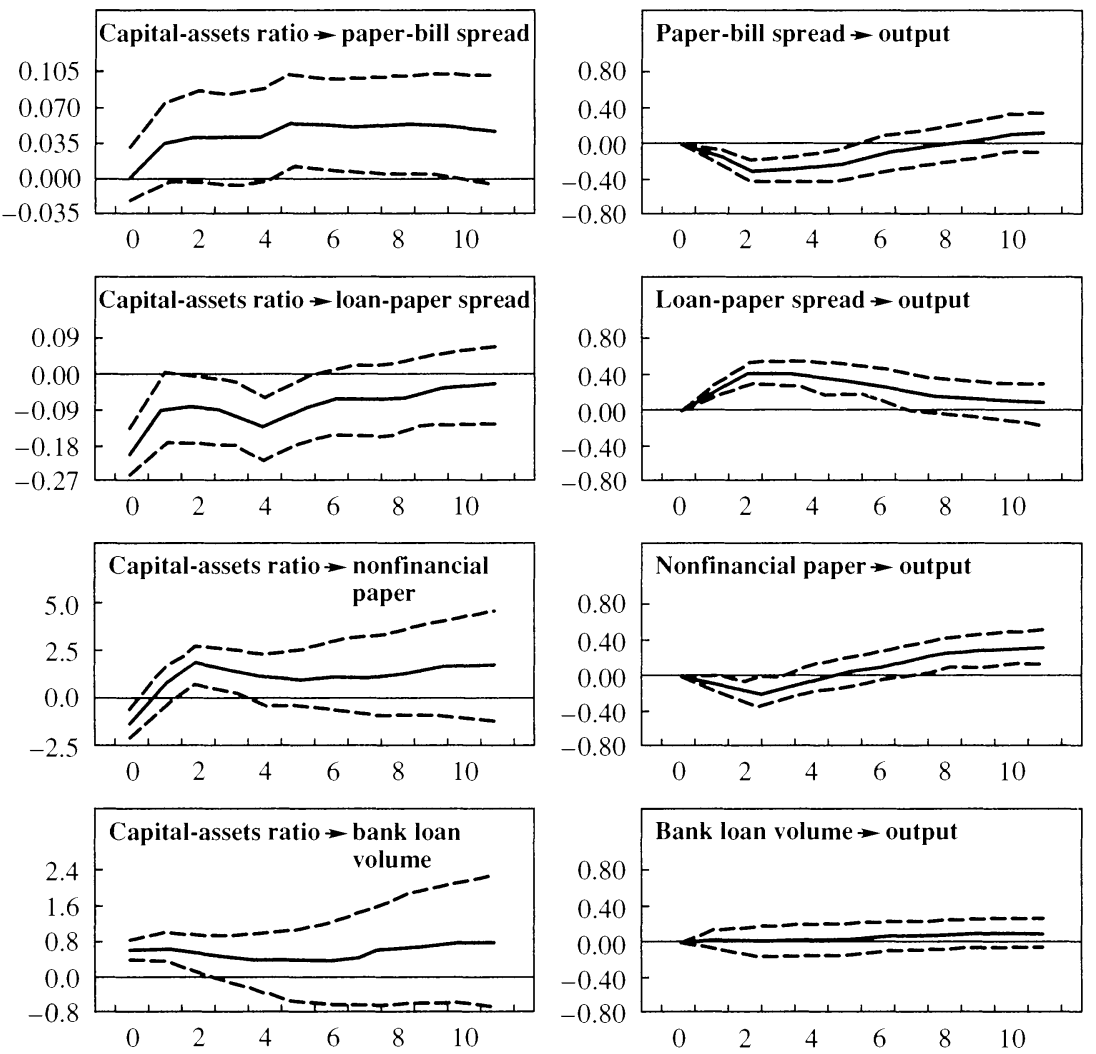

to those underlying figure 6 , except that the variable that is included in the autoregression and ordered fourth in the orthogonalization is not the bank capital ratio but the spread between the respective interest rates on commercial paper rated P2 and P1 (the second-highest and highest ratings, respectively) by Moody's Investors Service. Here the sample used to estimate each autoregression is 1975:1-1992:4. The autoregression includes three lags on each variable.

Figure 7 plots three impulse responses that are similar in all these systems, regardless of which financial price or quantity is the fifth variable, showing as an example the specific results only from the system that includes the paper-bill spread. First, negative monetary policy shocks de- 
Figure 6. (continued)

Percent, except as noted in footnote $b$
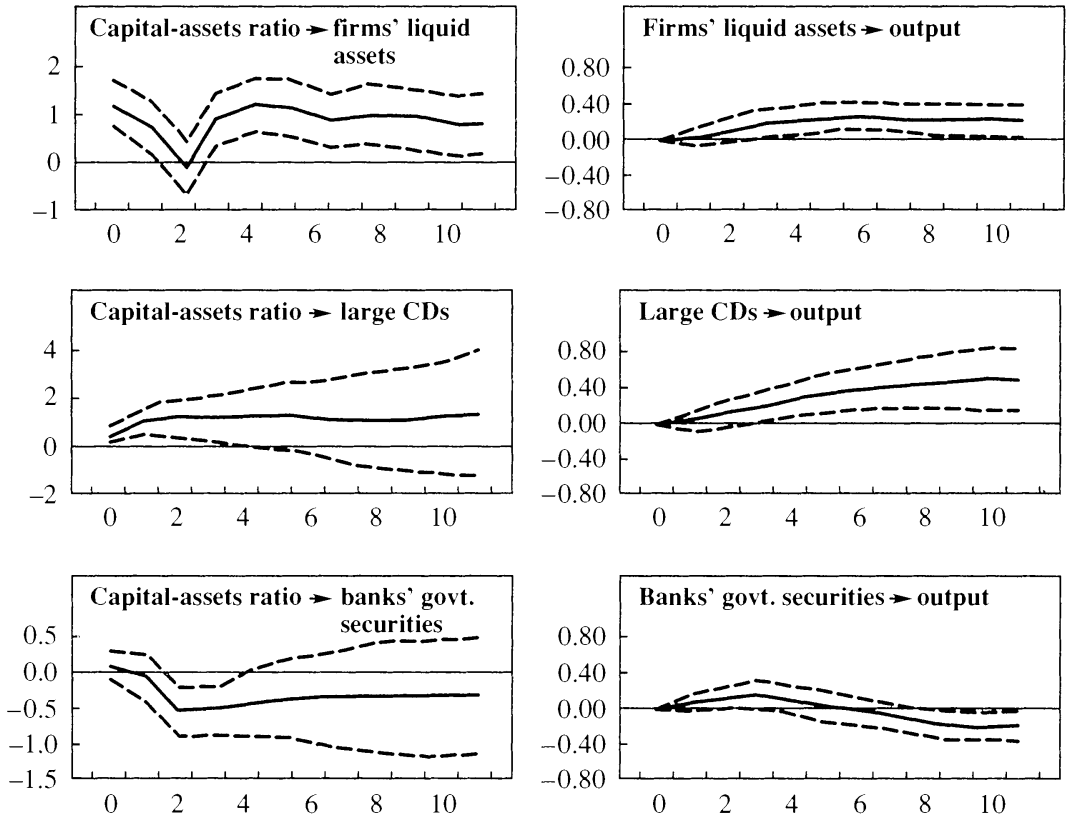

Source: See figure 5 .

a. These figures show impulse responses from five-variable vector autoregressions. Each system consists of the four variables used in figure 5 , and the logarithm of the aggregate bank capital ratio (ordered fourth in the orthogonalization), defined as the difference between banks' aggregate assets and liabilities divided by banks' aggregate assets. Each VAR uses quarterly data from 1974:1-1992:2, with three lags on each variable. The dashed lines depict the one standard error band around the impulse response.

b. For the federal funds innovations and the interest rate-spread innovations, the units are percentage points.

press real output in the presence of the P2-P1 spread, just as was the case in figure 5 based on the four-variable systems. Second, negative monetary policy shocks also cause the P2-P1 risk spread to widen (presumably because a weakening of real economic activity makes defaults more likely). Third, positive default risk shocks-that is, a widening of the P2-P1 spread that is not predictable from real output, inflation, or monetary policy - at first depress output but then, after five or six quarters, are followed by a rise in output (presumably reflecting the nonfinacial economy's usual cyclical properties). Although figure 7 shows the specifics for only one system, these three responses are characteristic of all of the five-variable systems that include the P2-P1 spread as the fourth variable. 
Figure 7. Dynamics of Monetary Policy, Positive Risk Shocks, and Output ${ }^{\mathrm{a}}$

Percent
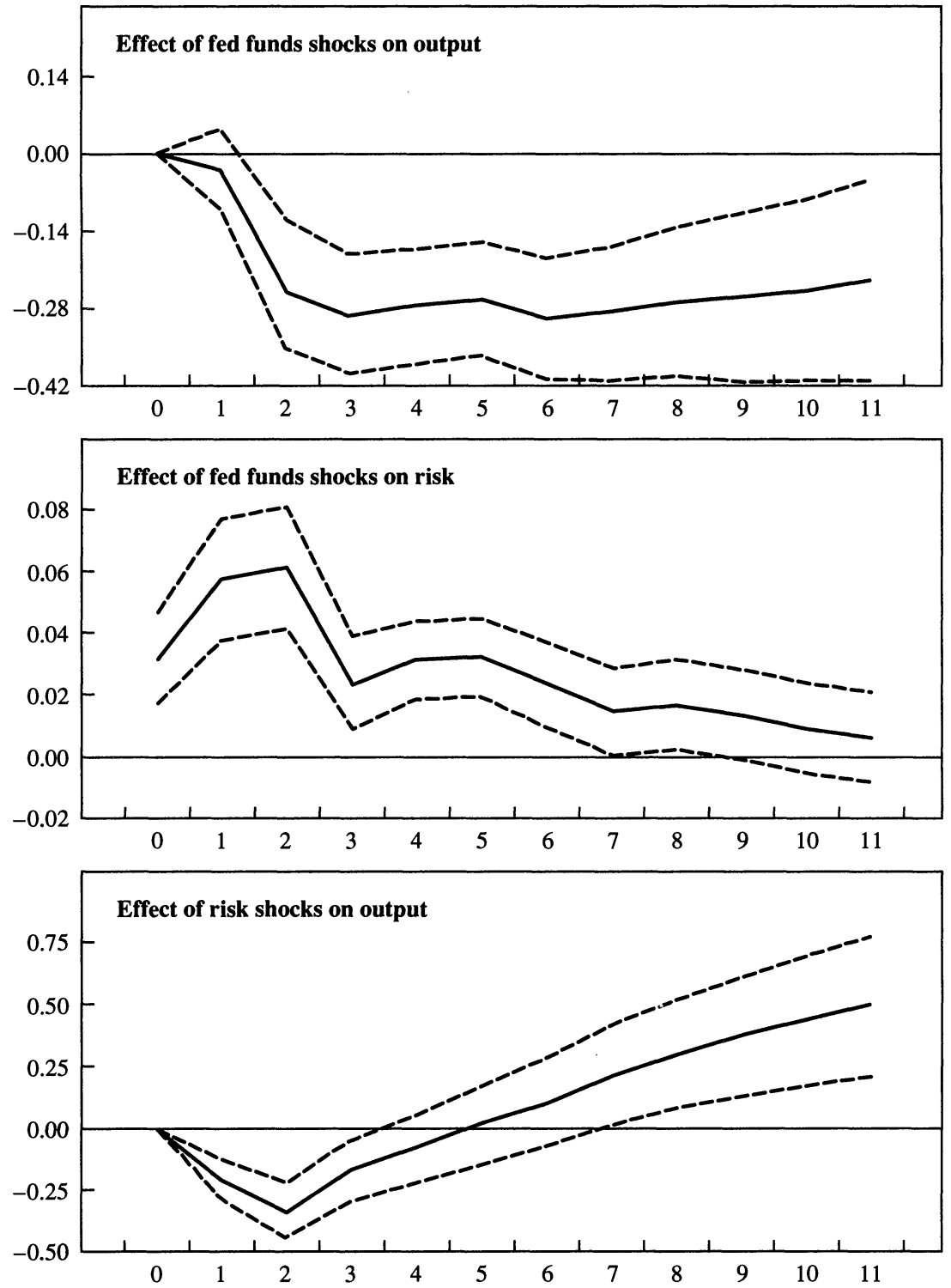

Source: See figure 5 .

a. These figures show the impulse responses from a five-variable vector autoregression. The system consists of the four variables used in the first row of figure 5, and a fifth variable (ordered fourth in orthogonalization), defined as the spread between the interest rates on P2-rated and P1-rated cemmercial paper. The VARs use quarterly data from 1975:1-1992:4, with three lags on each variable. The dashed lines depict the one standard error band around the impulse. 
As figure 8 shows, when the system's fifth variable is the paper-bill spread, the effect of a positive default risk shock is at first slightly to widen the paper-bill spread but then, surprisingly, to narrow it. This response is directly inconsistent with the account of the default risk hypothesis given in the fourth section. It is interesting, however, that the predictive power of the paper-bill spread with respect to real output disappears when, as here, shocks to that spread are orthogonalized with respect to both monetary policy and default risk. Positive default risk shocks briefly widen the loan-paper spread, after an initial delay, but this response by itself neither supports nor refutes an empirically relevant role for default risk shocks as described in the fourth section.

The results in terms of financial quantities are generally more supportive of a role for default risk shocks. After an initial delay, positive default risk shocks reduce the outstanding volume of commercial paper, and they reduce the volume of bank loans right away. They also cause firms to build up their holdings of liquid assets. Positive default risk shocks also cause banks to cut back on their issuance of CDs and to favor government securities in their asset portfolios.

\section{Cash Flow Shocks}

As is clear from equations 5 and 6 , what firms need to finance is the gap between their investment and their net revenues. Either a positive shock to investment (in unintended inventories, for example) or a negative shock to net revenues creates a greater need for financing. Figures 9-11 provide evidence on the cash flow shocks hypothesis of the fourth section by presenting results that are analogous to those shown in figures 7 and 8 , except that here the variable that is included in the vector autoregression and ordered fourth in the orthogonalization is either inventory accumulation or corporate earnings. Here the sample used is 1960:1-1992:4, and the autoregressions include four lags on each variable.

When the measure of cash flow shocks is inventory accumulation, the results of these investigations are mostly supportive of an empirical role for cash flow shocks as described in the fourth section. As the upper panels of figure 9 show, using the system with the paper-bill spread to illustrate a result that appears in all of these systems, negative monetary policy shocks (again represented by the federal funds rate) at first in- 
Figure 8. Dynamics of Positive Risk Shocks, Financial Variables, and Output ${ }^{\mathrm{a}}$

Percent, except as noted in footnote $b$
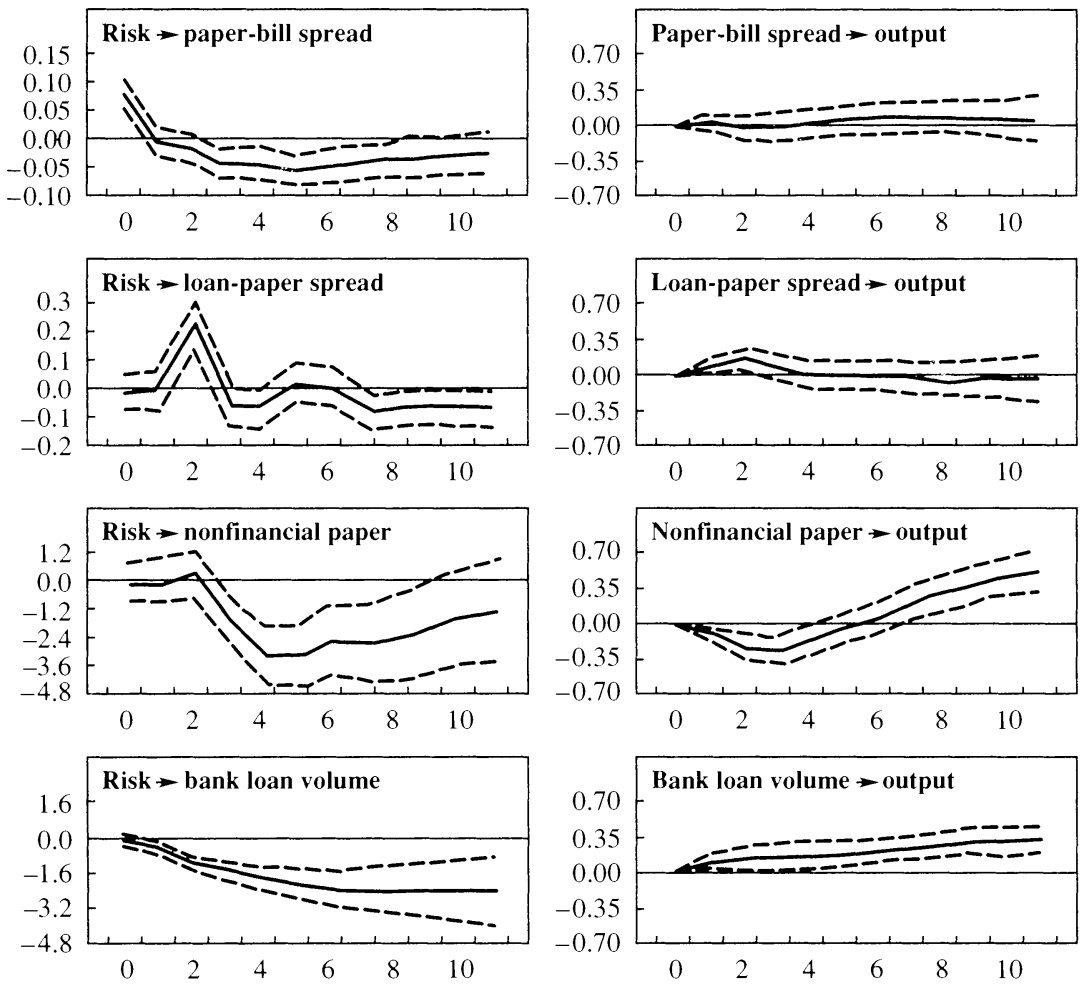

crease but then depress firms' inventory holdings, while positive inventory shocks (orthogonalized with respect to output, inflation, and the federal funds rate) depress subsequent real output. As figure 10 shows, positive inventory shocks initially widen the paper-bill spread and increase the volume of commercial paper, and lead firms to reduce their liquid asset holdings, all as predicted in the fourth section. Interestingly, bank loan volume at first does not respond when there is a positive inventory shock, and then declines (perhaps because investment itself subsequently declines). It is also interesting that most of these financial price and quantity variables retain their predictive power with respect to output, even when they are placed after both the federal funds rate and inventory movements in the orthogonalization. Banks' CD volume 
Figure 8. (continued)

Percent, except as noted in footnote $b$
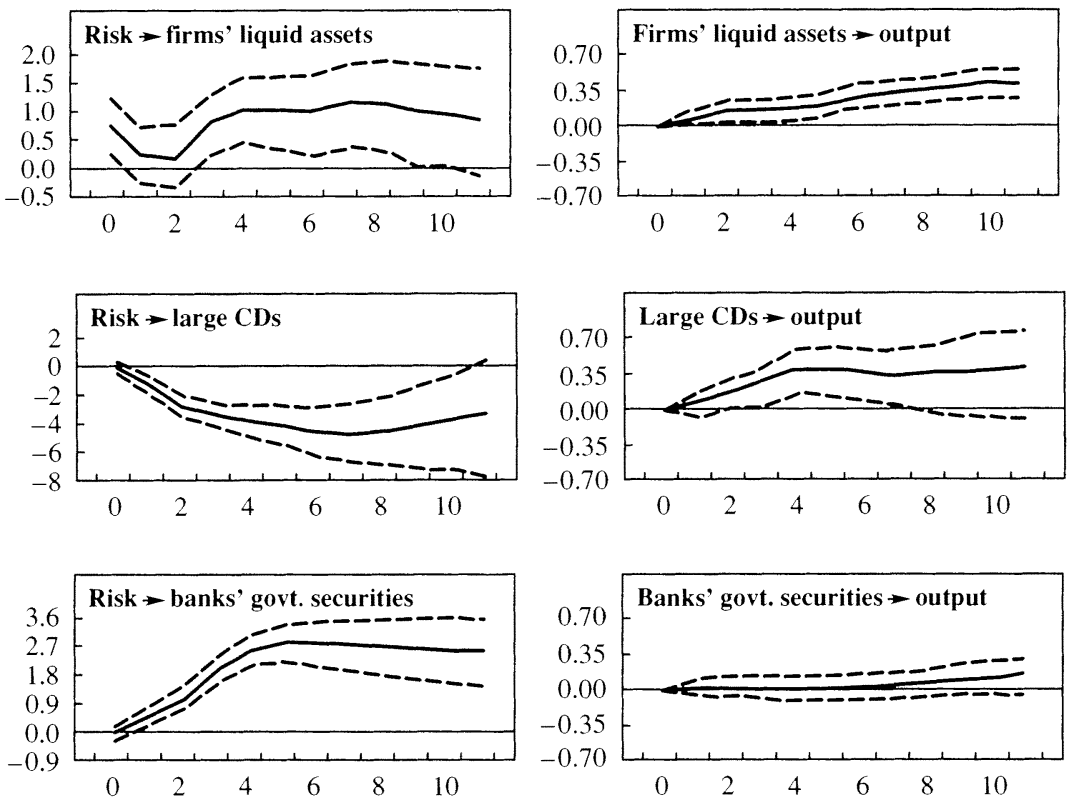

Source: See figure 5 .

a. These figures show the impulse responses from five-variable vector autoregressions. Each system consists of the four variables used in figure 5 , and a fifth variable (ordered fourth in orthogonalization), defined as the spread between the interest rates on P2-rated and P1-rated commercial paper. The VARs use quarterly data from 1975:11992:4, with three lags on each variable. The dashed lines depict the one standard error band around the impulse response.

b. For the federal funds innovations and the interest rate-spread innovations, the units are percentage points.

does not respond significantly to inventory shocks, but banks' holdings of government securities decline.

As the lower panels of figure 9 illustrate, again using as an example the system including the paper-bill spread, negative monetary policy shocks depress firms' earnings, while independent earnings shocks depress subsequent output but not significantly. As figure 11 shows, both the paper-bill spread and the loan-paper spread at first widen (as predicted) and then narrow when a negative earnings shock occurs, and commercial paper volume increases (also as predicted) for three quarters. Surprisingly, negative earnings shocks cause bank loan volume to decrease. As expected, in the face of negative earnings shocks, firms reduce their holdings of liquid assets. Banks' reduced CD issuance is con- 
Figure 9. Negative Monetary Policy Shocks, Negative Cash Flow Shocks, and Output ${ }^{\mathrm{a}}$

Percent, except as noted in footnote $b$
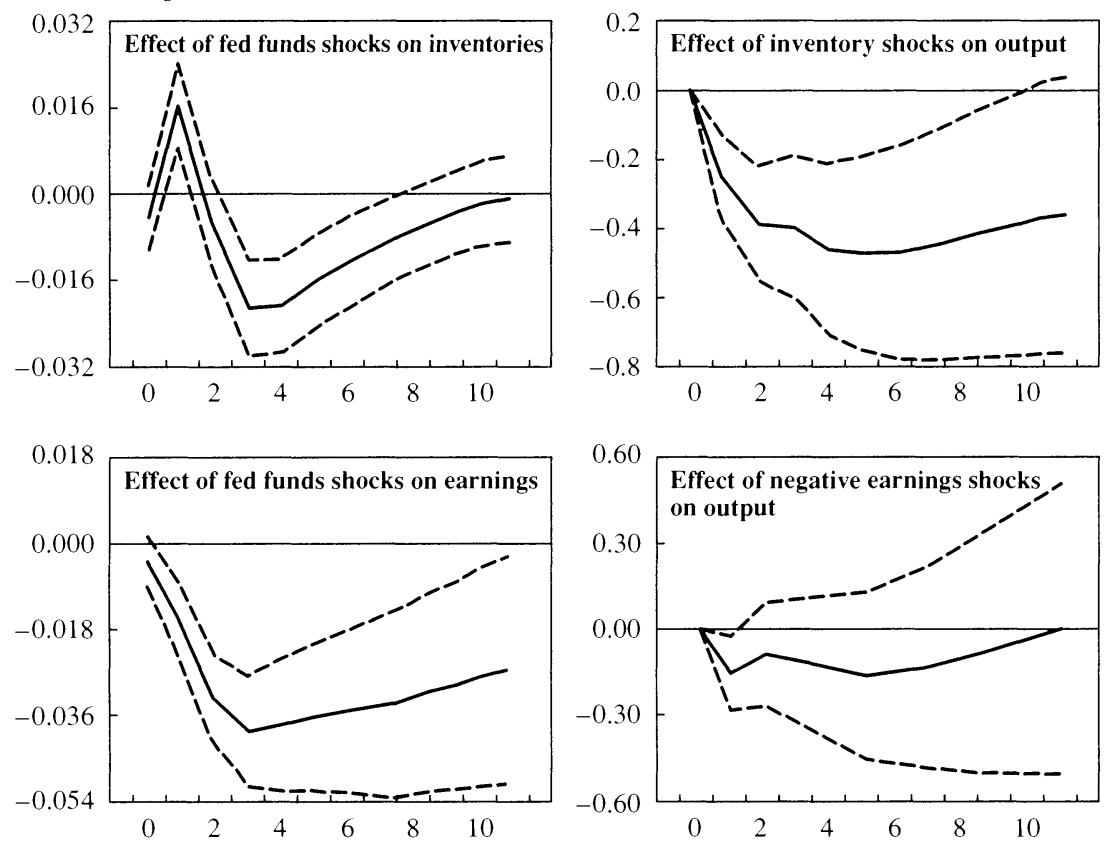

Source: See figure 5 .

a. These figures show the impulse responses from a five-variable vector autoregression. The system consists of the four variables used in the first row of figure 5, and a fifth variable (ordered fourth in orthogonalization), defined as either inventory accumulation or corporate earnings. The VARs use quarterly data from 1960:1-1992:4, with four lags on each variable. The dashed lines depict the one standard error band around the impulse response.

b. For earnings and inventories the units are a percentage of the lagged total of loans and paper.

sistent with the reduced need to fund in lending, and there is also an initial (mostly not significant) decrease in banks' government securities holdings.

\section{Overview}

Several broad conclusions emerge from this inspection of descriptive results on financial market behavior and real output changes in response to specific kinds of shocks. First, the evidence is broadly supportive of 
an empirical role for monetary policy shocks not only in affecting real output (that much is well known already) but also in accounting for movements of financial variables like the paper-bill spread and the volume of commercial paper that systematically vary in anticipation of real output fluctuations. Other aspects of these descriptive results are also consistent with what the model developed in the second section implies about how the financial markets respond to monetary shocks. Even so, these results do not support the view that the role of the paper-bill spread as a monetary policy indicator accounts for the entirety of its predictive content with respect to real output.

Second, these exercises provide little evidence to support a role for shocks to bank capital positions in accounting for the comovements of financial prices and quantities, and of nonfinancial economic activity, that are under study here. As the discussion above indicates, however, this negative finding may simply be due to the absence of a satisfactory time series that not only measures aggregate bank capital in comparison to changing capital requirements but also reflects the distribution of banks' capital within the aggregate.

Third, the evidence is broadly supportive of an empirical role for default risk shocks in explaining observed comovements between financial prices and quantities and nonfinancial activity.

Fourth, the evidence is also broadly consistent with an empirical role for cash flow shocks in explaining these comovements, especially when the measure of such shocks is firms' inventory accumulation, but also when the measure used is firms' earnings.

Finally, as is the case for the much simpler exercises reported in the second section, which are informative but have no interpretation of specific shocks in the context of a behavioral model, the results presented here warn against relying heavily on bank-centered variables (most obviously, loan rates and loan volumes) or narrowly bank-centered explanations to capture relationships between the financial markets and nonfinancial economic activity. In part this may be due to the well-known inability to measure loan interest rates accurately. But the evidence assembed here, viewed as a whole, also strongly suggests that other shortterm credit markets like the commercial paper market play a role in these financial-nonfinancial relationships that is worth bringing explicitly into the analysis. 
Figure 10. Positive Inventory Shocks, Financial Variables, and Output ${ }^{\mathrm{a}}$

Percent, except as noted in footnote $b$
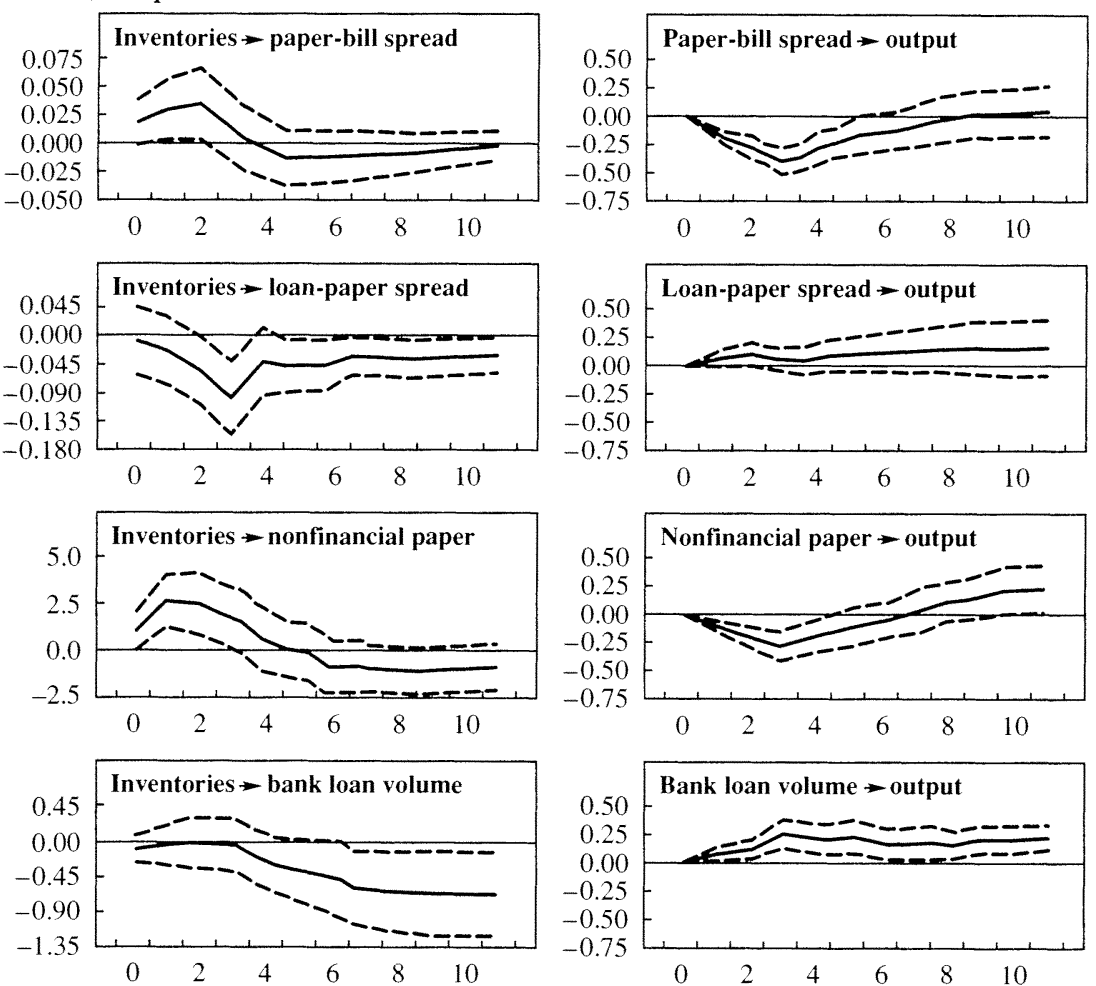

\section{Structural Estimates of Key Relationships}

Estimating an all-inclusive empirical counterpart to the model developed in the third section, with all relevant simultaneities taken into account, is a task that clearly lies beyond the scope of this paper. Even so, it is useful at least to examine on a one-by-one basis structural estimates of several of the relationships in equations 6,9 , and 12 that are particularly central to the analysis of the different kinds of shocks considered in the fourth and fifth sections. The question at issue is whether there is empirical support for assuming that these shocks cause specific behavioral relationships to shift in the way illustrated in figures 2,3 , and 4 . 
Figure 10. (continued)

Percent, except as noted in footnote $b$
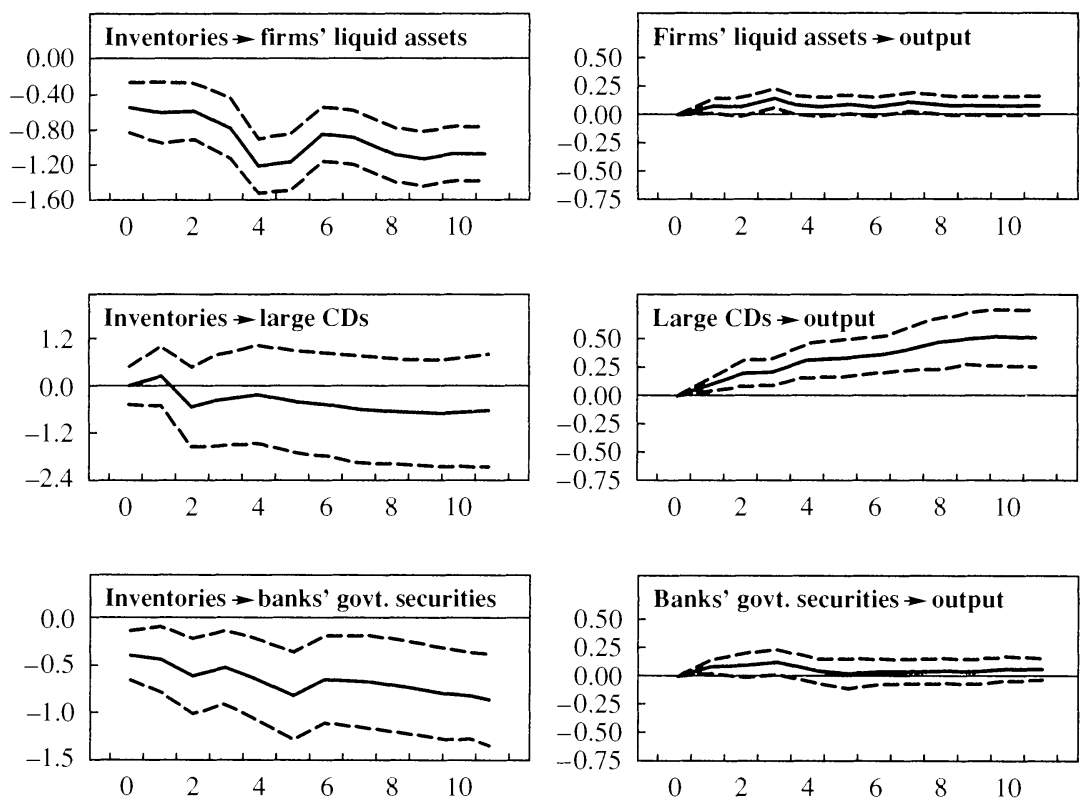

Source: See figure 5 .

a. These figures show the impulse responses from five-variable vector autoregressions. Each system consists of the four variables used in figure 5 , and a fifth variable (ordered fourth in orthogonalization), inventory accumulation. The VARs use quarterly data from 1960:1-1992:4, with four lags on each variable. The dashed lines depict the one standard error band around the impulse response.

b. For the federal funds innovations and the interest rate-spread innovations, the units are percentage points, and for inventories the units are a percentage of the lagged total of loans and paper.

Table 5 presents estimates of four portfolio relationships that play pivotal roles in the model's story of how different shocks affect the financial markets and, through the resulting financial price and quantity effects, nonfinancial economic activity. Each equation is individually estimated twice, once by ordinary least squares and once by two-stage least squares, with quantities $\Delta P$ and $\Delta L$ and prices $r_{P}, r_{L}$, and $r_{B}$ taken to be endogenous. ${ }^{56}$ The set of instruments used for the two-stage esti-

56. Because each equation is individually estimated, the estimates are not as efficient as they would be if the four equations were estimated jointly as a single system. In addition, because only four equations are estimated, instead of the ten included altogether in equations 6,9 , and 12 , these estimates do not exploit the relevant cross-equation restrictions. 
Figure 11. Negative Earnings Shocks, Financial Variables, and Output ${ }^{\mathrm{a}}$

Percent, except as noted in footnote $b$
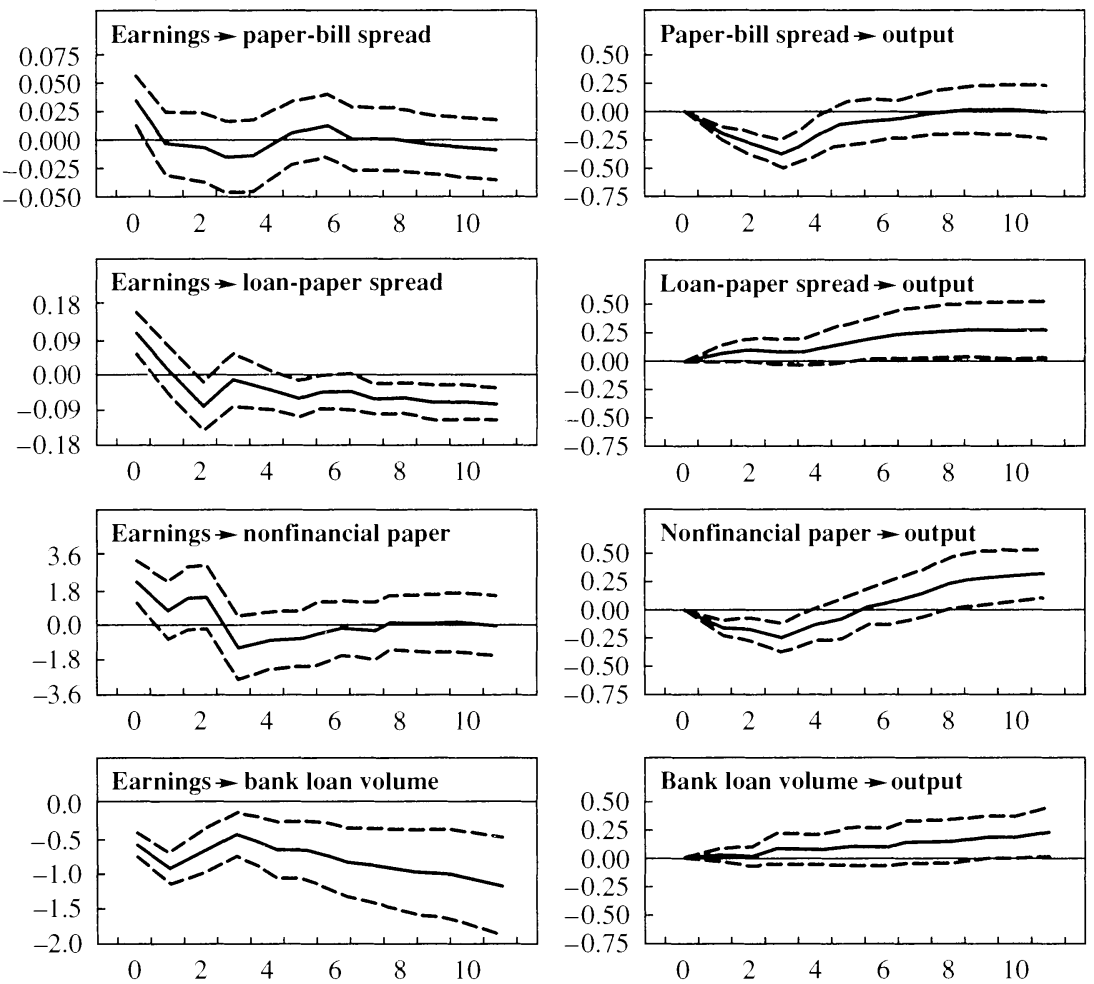

mation includes all exogenous variables that appear in any of the four equations, together with all endogenous variables (or transformations of endogenous variables) that appear as lagged variables. Estimates are based on quarterly data for 1975:1-1992:4. In addition to the variables indicated in the table, each equation also includes a constant, a time trend, and two dummy variables to allow for the imposition of credit controls in 1980:2 and the tax code change at 1986:4-1987:1. The numbers shown in parentheses below the estimated coefficients are the corresponding $t$-statistics corrected for heteroskedasticity and for fourthorder moving-average serial correlation. 
Figure 11. (continued)

Percent, except as noted in footnote $b$
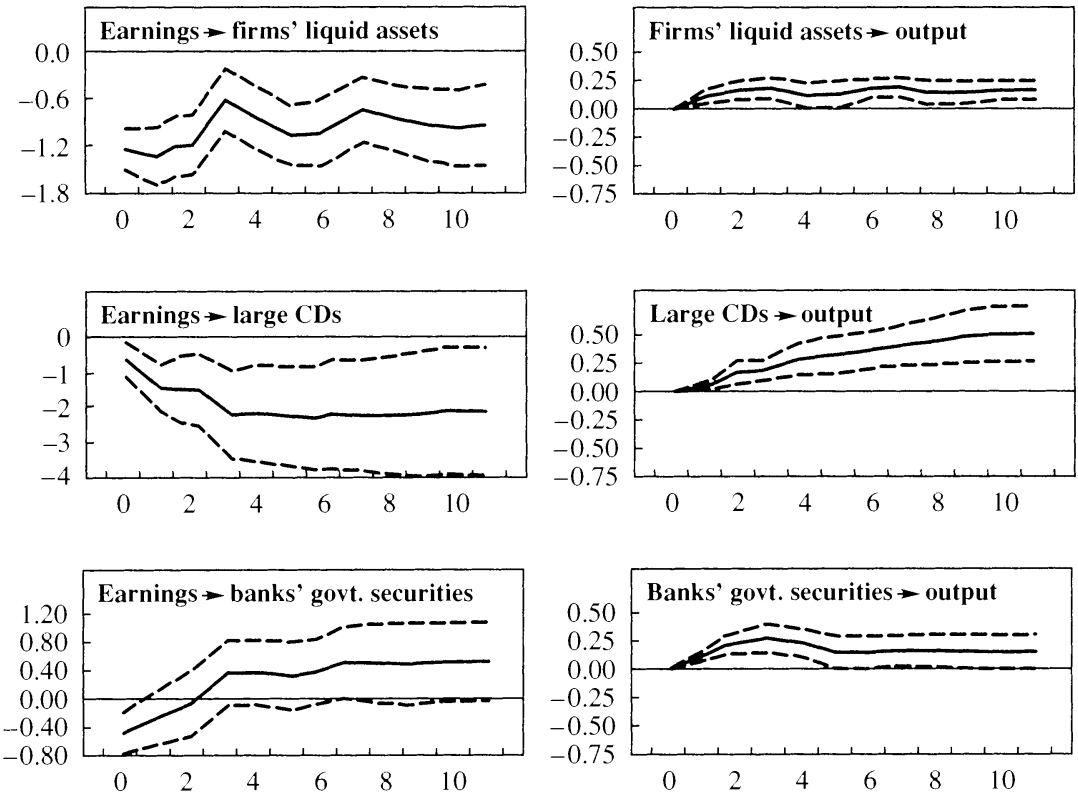

Source: See figure 5 .

a. These figures show the impulse responses from five-variable vector autoregressions. Each system consists of the four variables used in figure 5, and a fifth variable (ordered fourth in orthogonalization), corporate earnings. The VARs use quarterly data from 1960:1-1992:4, with four lags on each variable. The dashed lines depict the one standard error band around the impulse response.

b. For the federal funds innovations and the interest rate-spread innovations, the units are percentage points, and for earnings the units are a percentage of the lagged total of loans and paper.

\section{Firms' Financing}

The first two regressions in table 5 show results for the change in nonfinancial firms' outstanding bank loans, $\Delta L^{F}$, normalized by dividing by the lagged outstanding stock of loans plus commercial paper. The estimated coefficients are, with only one exception, in line with the presumptions indicated in the third section and reflected in the discussion in the fourth section. In terms of price effects, a wider loan-paper spread reduces firms' bank borrowing. Including the commercial paper rate independently of the spread shows that while the respective coefficients 


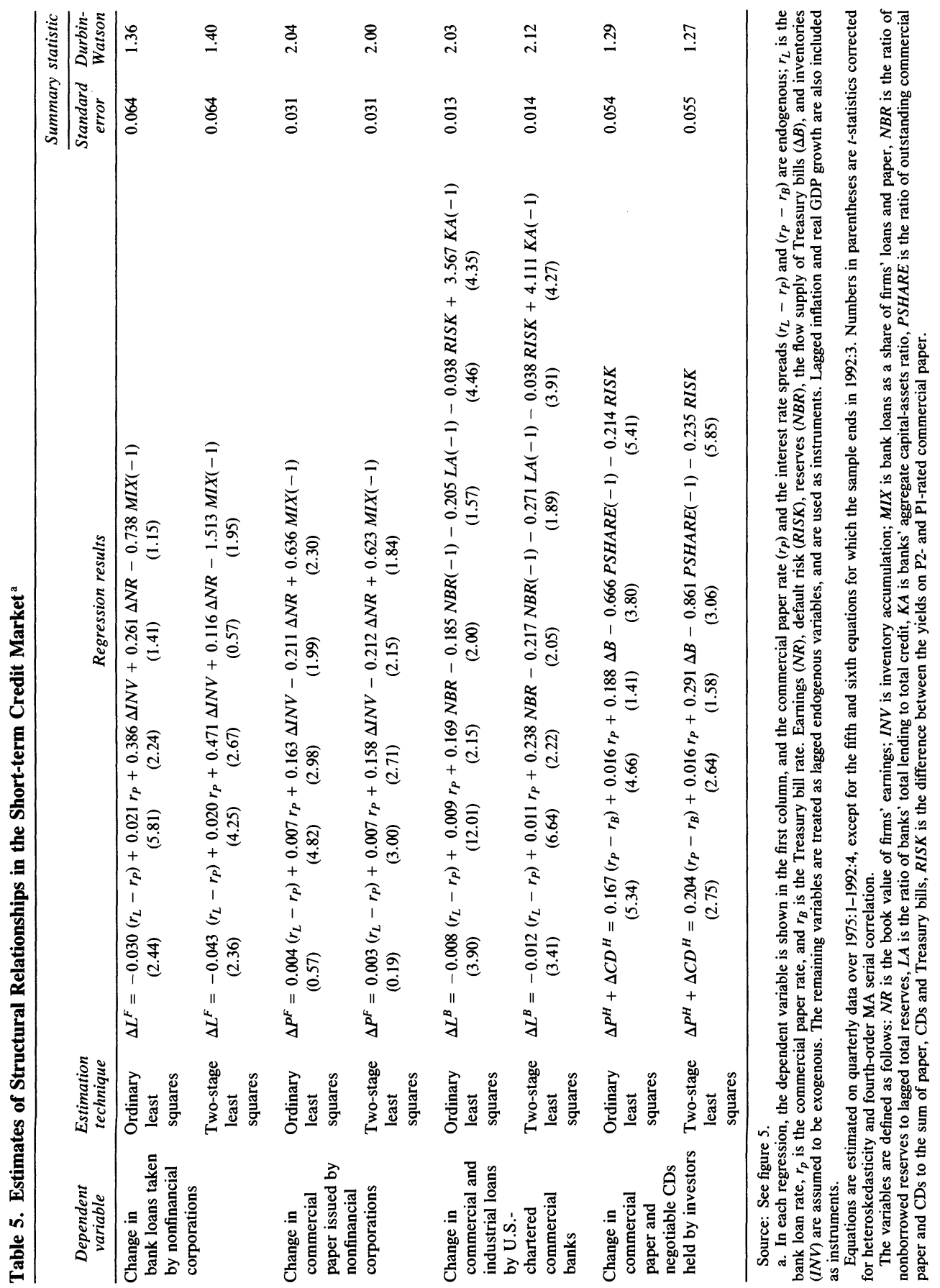


on the loan rate and the paper rate are of opposite sign, they are not equal in magnitude. In terms of quantity flow effects (normalized analogously to the dependent variable), greater inventory accumulation increases firms' bank borrowing as in figure 4 , at the rate of nearly fifty cents per dollar in the two-stage least squares estimate. ${ }^{57}$ In terms of quantity stock effects, a greater share of bank loans in firms' existing short-term liabilities reduces their incremental bank borrowing, although this estimated effect is only marginally significant even in the two-stage estimate. The one exception to the presumptions of the third and fourth sections is that greater earnings do not reduce firms' bank borrowing. (The point estimate for this coefficient is even positive, but it is not statistically significant.) The contrast between inventories and earnings in this regard parallels the differences in the analysis of impulse responses reported in the fifth section.

The next two regressions show analogous results for the change in nonfinancial firms' outstanding commercial paper, $\Delta \boldsymbol{P}^{\boldsymbol{F}}$, again normalized by dividing by the lagged outstanding stock of short-term liabilities. In contrast to the results shown above for bank borrowing, issuance of commercial paper displays no discernible response to the loan-paper spread, and the estimated effect of the paper rate has the "wrong" sign. Even in the two-stage procedure, the estimation has presumably failed to identify supply versus demand in this respect. ${ }^{58}$ Greater inventory accumulation does increase firms' paper issuance, by sixteen cents on the dollar. Unlike the case of bank loans, greater earnings reduce firms' paper issuance, by twenty-one cents on the dollar. The lagged balance sheet stock effect also has the expected sign, and the coefficient is both statistically and economically significant.

\section{Bank Lending}

The fifth and sixth regressions in table 5 show results for the change in banks' outstanding business loans. ${ }^{59}$ Comparison to the first two re-

57. Allowing for the joint determination of firms' inventory accumulation and bank borrowing by treating inventories as endogenous for purposes of the two-stage estimation further raises the estimated coefficient to 0.665 .

58. An alternative explanation is that when interest rates rise, firms' financing requirements increase for reasons not otherwise captured by the equation's independent variables.

59. Because this equation includes the lagged bank capital ratio, the sample extends only through 1992:3 (again, see footnote 55). 
gressions shows that, in terms of price effects, even the two-stage procedure has again failed to distinguish demand and supply behavior. In other respects, however, the results are in line with the presumptions of the third and fourth sections. Expansionary monetary policy, here represented by a greater level of nonborrowed reserves relative to total reserves,${ }^{60}$ leads banks to increase their lending as in figure 2 . Specifically, a 0.01 increase in the nonborrowed reserve ratio (about equivalent to a half-billion-dollar open market operation at 1993 levels) causes banks to increase their loans by 0.24 percent relative to outstanding liabilities (or about $\$ 7$ billion at 1993 levels) on an annualized basis, although this effect appears to take the form of a change effect. An increase in the default risk associated with business obligations, represented by the P2P1 spread, reduces banks' lending as in figure 3. An increase in banks' capital adequacy, again represented by the simple aggregate capital-toassets ratio used in the fifth section but here lagged to avoid at least some of the obvious simultaneity, increases banks' lending. ${ }^{61}$ The lagged balance sheet composition also has the expected effect.

\section{Households' Lending}

The last two regressions in table 5 show results for the change in open-market investors' holdings of commercial paper plus certificates of deposit. The demand for commercial paper and CDs depends positively on the paper-bill spread, as expected, and the magnitude of this effect is greater in the two-stage estimate. Inclusion of the paper rate separately again shows that the respective coefficients on the paper rate and the bill rate are of opposite sign but not equal magnitude. Greater perceived default risk, again represented by the P2-P1 spread, reduces investors' de-

60. The ratio of nonborrowed reserves to total reserves-or, equivalently, one minus the borrowed reserve ratio-is a standard indicator of monetary policy that is usually assumed to be closely related to the federal funds rate. Using the funds rate directly to represent monetary policy shocks, as in the impulse response analysis in the fifth section, seemed to be a poor idea here in light of the presence in the equation of the loan rate and the paper rate.

61. This result is especially noteworthy in that the simple correlation between the aggregate capital ratio and bank lending is negative, and the impulse response for bank lending shown in figure 6 also has the unexpected sign. 
mand for paper and CDs as in figure $3 .^{62}$ The balance sheet stock variable also exhibits the expected effect.

\section{Overview}

Overall, the four sets of results shown in table 5 provide further support for thinking about the effects of different kinds of shocks along the lines described in the fourth section. Not very surprisingly, these estimated relationships do not always pin down price effects-that is, the slopes of the curves drawn in figures $2-4$. The equations describing firms' financing decisions, for example, suggest that bank borrowing responds strongly to the relative cost of loans and commercial paper, while paper issuance does not. On the other side of the market, investors' demand for commercial paper bears the expected relationship to relative financial prices, but banks' lending does not. By contrast, these equations do indicate that the kinds of shocks hypothesized in the fourth section to shift the curves in figures 2-4 actualiy do so, and that such shifts are both statistically significant and of a magnitude to be economically relevant. Further, here the relative magnitudes are also informative. For example, the respective responses of firms' commercial paper issuance and bank borrowing to changing cash flows are not just mirror images of one another, in that inventory accumulation dominates bank borrowing while earnings fluctuations play a greater role in paper issuance.

\section{Analyzing the 1988-92 Credit Slowdown}

What then caused the dramatic slowdown in lending that took place in the U.S. credit markets during 1989-92? And to what extent did the factors underlying the credit slowdown play a role in bringing on the 1990-91 business recession, or the unusually sluggish business recovery that has followed?

62. One way to gauge intuitively the magnitude of the effect of greater default risk is to renormalize the equation so that the paper-bill spread is the dependent variable and investors' net purchases of commercial paper is an (endogenous) independent variable. Estimating the equation in this inverted form indicates that a given widening of the P2-P1 spread widens the paper-bill spread by an approximately equal magnitude. 
Figure 12 illustrates the unusual character of the recent slowdown in short-term business credit extensions by plotting the quarterly net increase in the two categories of lending that are the main focus of the model in the third section and the empirical investigations in the fifth and sixth sections: commercial and industrial loans at banks, and commercial paper issued by nonfinancial businesses (scaled in each case by dividing by the sum of loans and paper outstanding at the end of the previous quarter). Especially for commercial and industrial bank loans, the experience from late 1989 onward was quite extraordinary. In the fifteen years before 1990, bank loan contraction was limited to a few isolated quarters, such as the credit control episode in 1980 and the time of the tax law change at year-end $1986 .{ }^{63}$ By contrast, the outstanding volume of bank loans shrank steadily throughout 1991-92. Net issuance of commercial paper was also negative for a sustained period from late 1990 to early 1992, although this phenomenon does not represent such a sharp contrast with previous experience.

Figure 13 plots the independent innovations, from 1986-92, for the four variables used above to represent the different shocks analyzed in the fourth section: monetary policy (the federal funds rate); bank capital (the capital-to-assets ratio); default risk (the P2-P1 spread); and business cash flows (inventory accumulation). Each series of innovations is extracted from a distinct vector autoregression system analogous to those described in the fifth section. The federal funds rate innovations are from a system including output growth, inflation, the federal funds rate, and bank loans (normalized by the lagged stock of loans plus paper), orthogonalized in that order. The capital ratio innovations are from the system including output growth, inflation, the federal funds rate, the capital ratio, and bank loans, orthogonalized in that order. The P2-P1 spread innovations and the inventory innovations are from systems analogous to that used for the bank capital innovations, but with either the spread or inventory accumulation used as the fourth variable. The sample used to estimate the underlying autoregressions is 1975:1-1992:4 (1975:1-1992:2 in the case of the system including the capital ratio). The dotted lines plotted for each series indicate one standard deviation bands.

63. Commercial and industrial bank loans also contracted during the 1974-75 recession. 
Figure 12. Commercial and Industrial Lending and Commercial Paper Issuance, 1978:1-1992:3
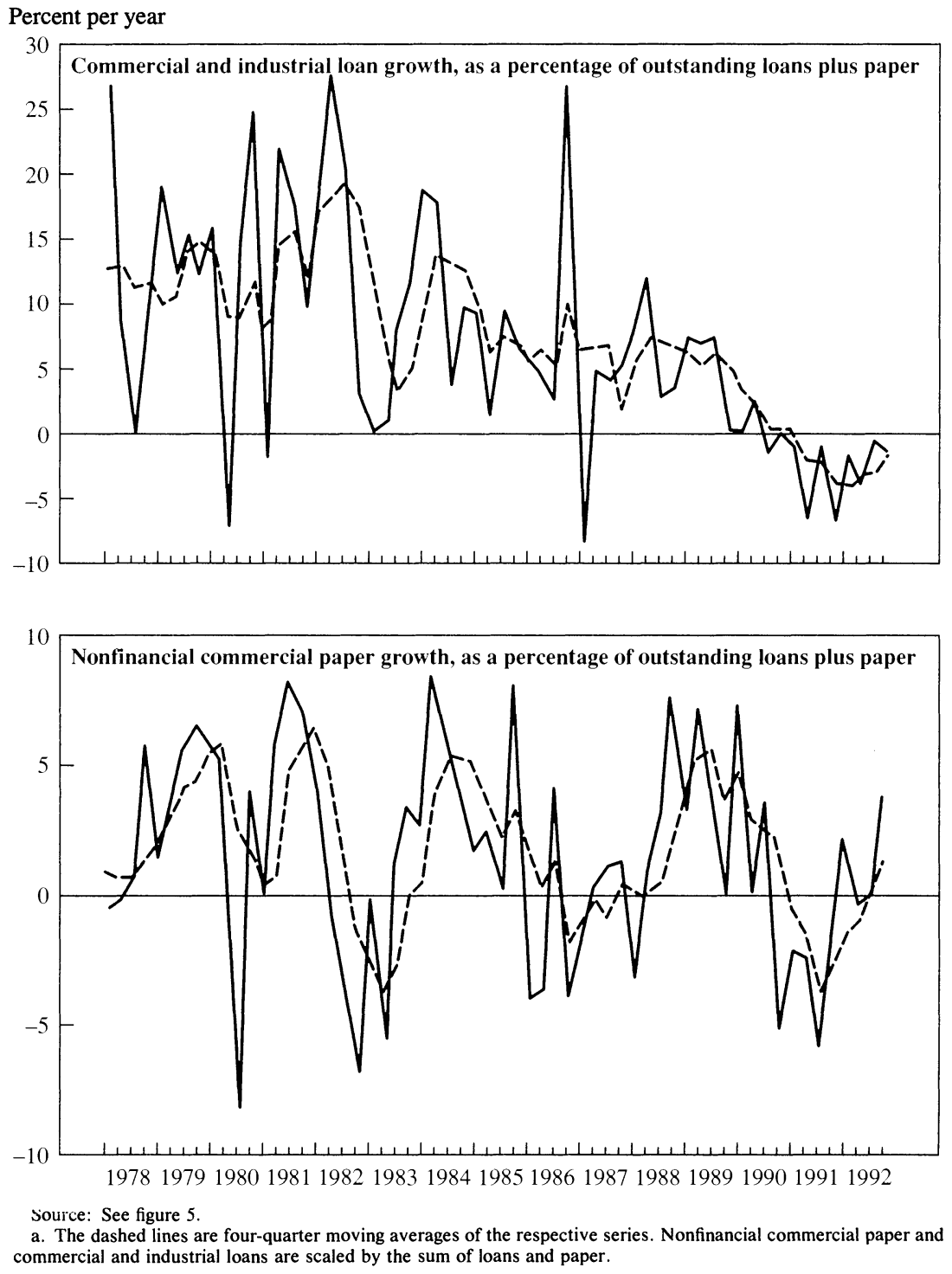
Figure 13. Estimates of Recent Shocks, 1986-92 ${ }^{\mathrm{a}}$

Percent
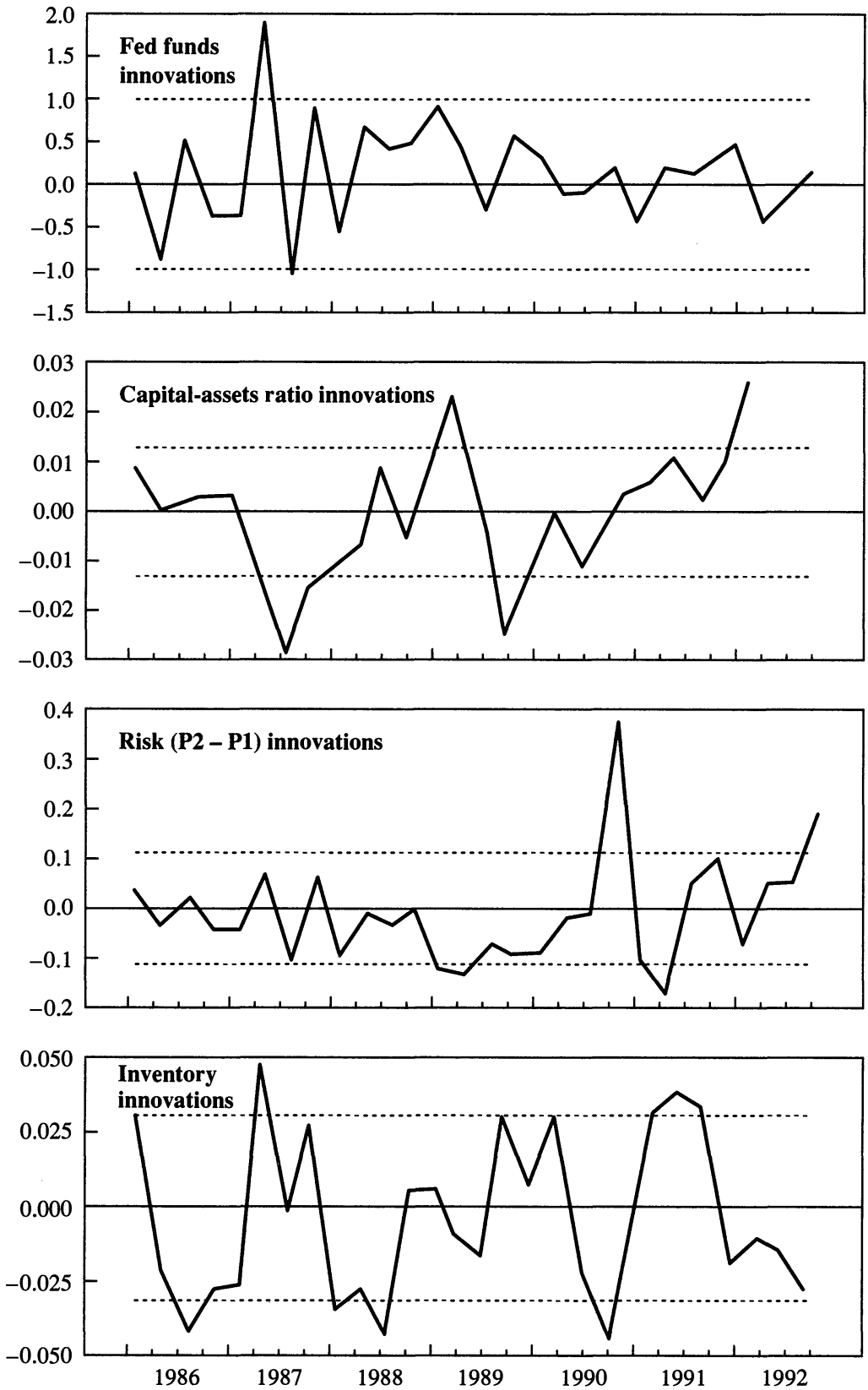

Source: Authors' vector autoregressions.

a. The federal funds rate innovations are based on a four-variable VAR containing output growth, inflation, the federal funds rate, and bank loan growth (scaled by the lagged stock of loans plus paper), orthogonalized in that order. The remaining three sets of innovations are from five-variable VARs expanded to include the additional variable being analyzed, ordered between the federal funds rate and loan growth in the orthogonalization. The dashed lines in each panel represent one-standard-error bands. 
Given the response patterns predicted in the fourth section and (to a greater or lesser extent, depending on the specific variable in question) documented empirically in the fifth and sixth sections, several of the innovation series shown in figure 13 constitute potentially contributing factors behind the slowdown in bank lending. Monetary policy shocks were mostly positive (that is, contractionary) during this period, albeit also mostly small except in early 1987 . Bank capital shocks were sharply negative in 1987 and again in late 1989, but sharply positive in between (and also at the end of 1992). Default risk shocks were very sharply positive in late 1990. Inventory shocks varied substantially, but never much exceeded one standard deviation.

Figure 14 plots the cumulative effect on outstanding bank loans attributable to each of these four series of innovations. ${ }^{64}$ Because each innovation from figure 13 and therefore each cumulative effect shown here is based on a separate autoregression system, it is not legitimate to "add up" these effects as if they were consistently estimated components of a unified explanation of the lending slowdown. Nonetheless, the results are at least intuitively informative. Especially for 1991-92, the period of sharpest decline in outstanding loans (again, see figure 13), these results point to bank capital shocks, default risk shocks, and cash flow shocks as all having played a noticeable role. By contrast, the effect of monetary policy shocks was to increase bank lending throughout this period.

Figure 15 plots the cumulative effect on output growth attributable to the same four series of innovations. Here monetary policy shocks do play a major role in accounting for the generally slow growth of real output beginning in 1989. Default risk shocks are also especially important during the recession that, according to the official NBER chronology, began in July 1990 and ended in March 1991. It is interesting that bank capital shocks, which did play a role in the 1990-92 credit slowdown as shown in figure 14, had no discernible independent effect on real output throughout this period. ${ }^{65}$ Nor did inventory accumulation.

Repeating this set of exercises with the focus on commercial paper in

64. The computation takes account of the entire past history of each innovation (since 1975:1), not just the series beginning in 1986:1.

65. See again, however, the discussion in the fifth section of the inadequacy of the simple capital-to-assets ratio for purposes of this paper. The more satisfactory time series that the authors are constructing from the call report data, using the method of Baer and McElravey (1993), may yield different results. 
Figure 14. Shocks' Estimated Cumulative Effect on Commercial and Industrial Lending, 1986-92
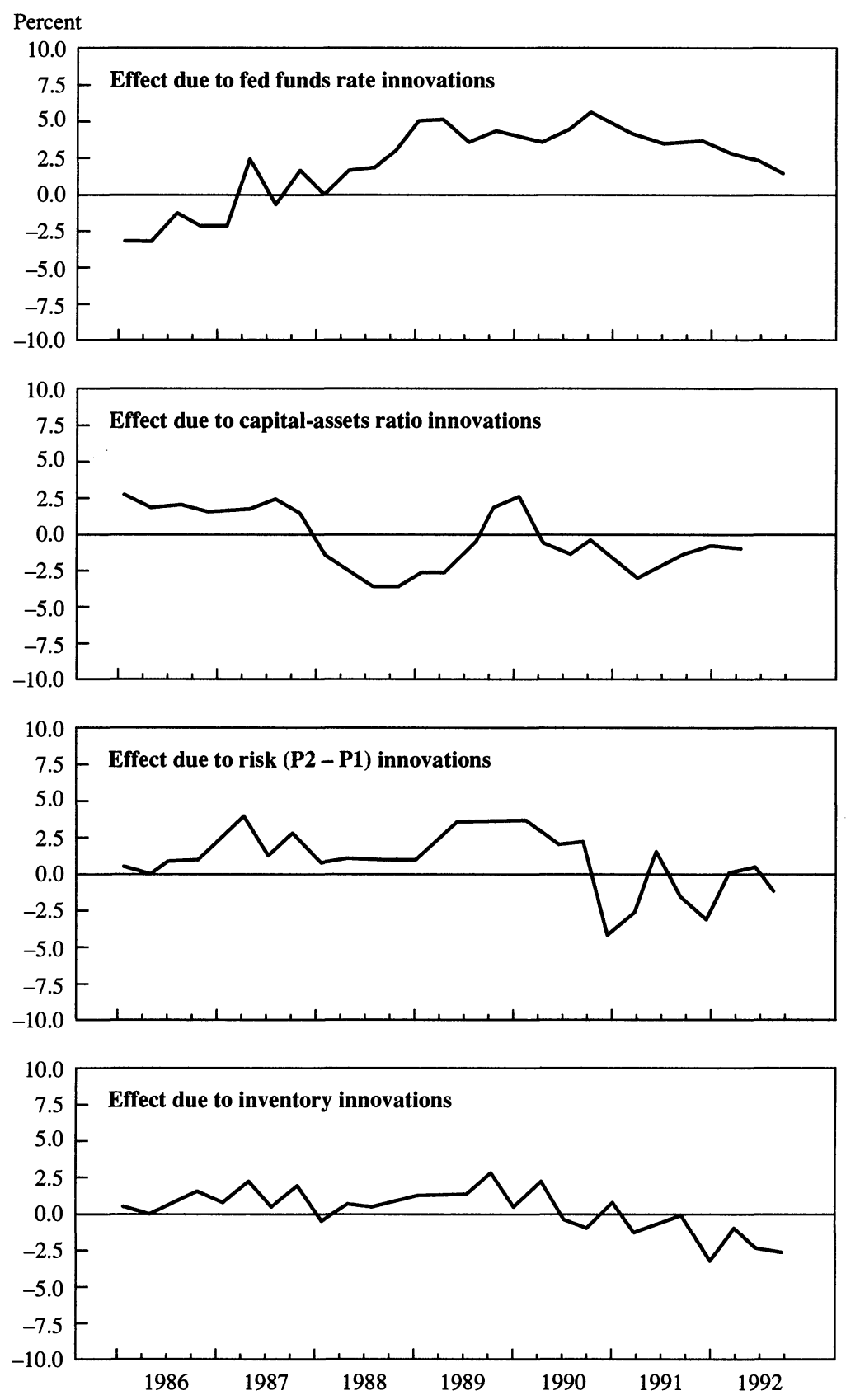

Source: See figure 13.

a. Plots the cumulative effect on commercial and industrial loan growth attributable to each of the innovations described in figure 13 . 
Figure 15. Shocks' Estimated Cumulative Effect on Real GDP Growth ${ }^{\mathrm{a}}$
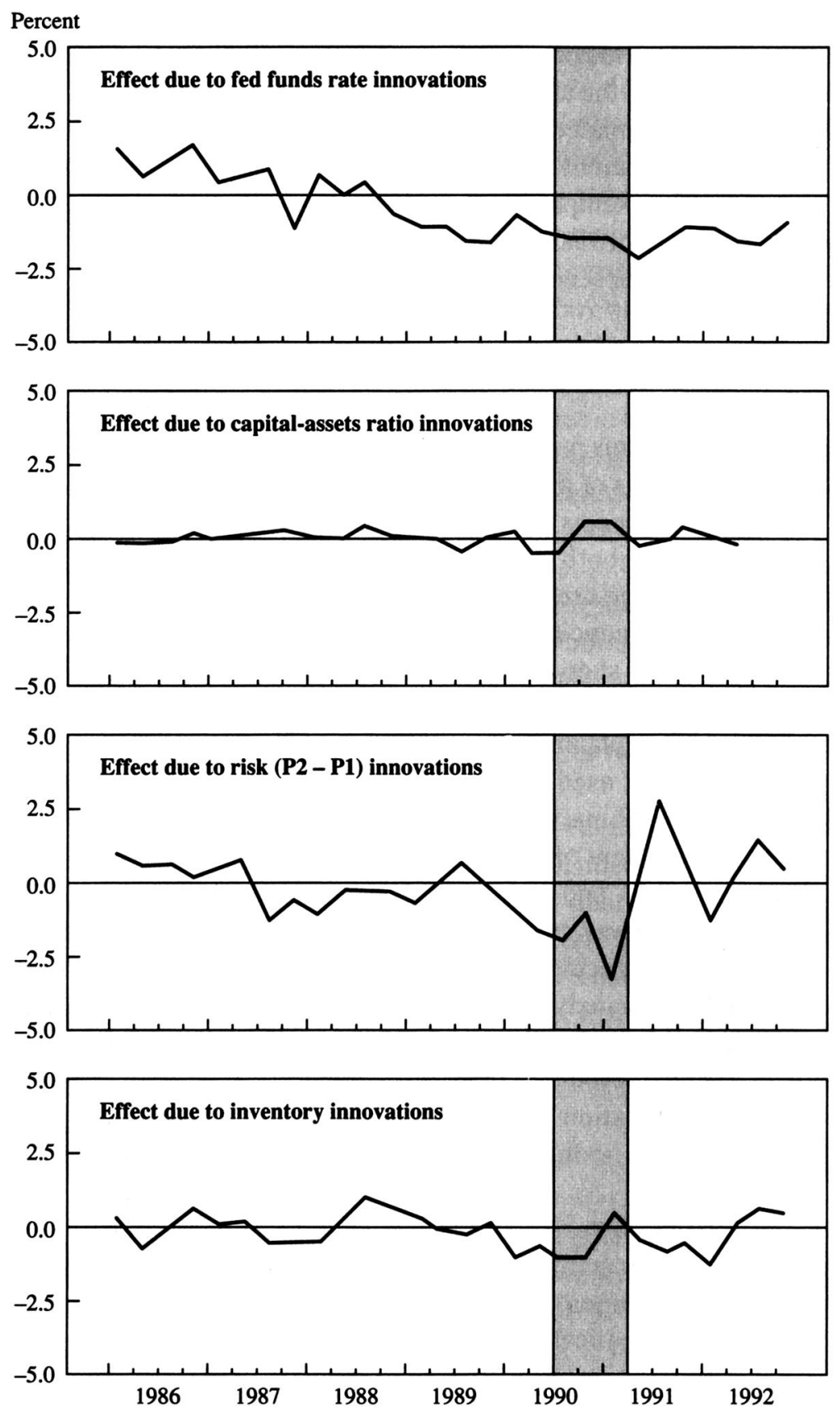

Source: See figure 13.

a. Plots the cumulative effect on real GDP growth attributable to each of the innovations described in figure 13. Shaded region depicts the most recent recession according to the official NBER chronology. 
place of bank loans yields broadly similar results. ${ }^{66}$ The most interesting difference is that when the autoregression system's final variable is commercial paper, the estimated effect on real output attributable to default risk shocks is even greater than shown in figure 15. In the trough quarter of the recession, for example, the contribution of default risk to the annualized growth rate of real output is -4.5 percent, rather than -3.3 percent as shown in the second panel of figure 15 .

\section{Summary of Empirical Conclusions}

The overall goal of this paper is to move the focus of the rapidly growing credit view analysis of financial-nonfinancial interactions, and especially the empirical aspects of that analysis, toward a perspective that explicitly incorporates both financial prices and financial quantities. The model of the short-term credit markets provided here shows how both financial prices and financial quantities can bear on nonfinancial economic activity. It also shows that at least the qualitative aspects of observed relationships among financial prices, financial quantities, and real activity can be explained in a fairly straightforward way, once the conceptual framework used for the analysis is broad enough to encompass the relevant credit market pnenomena.

Because a key element of this model (nonprice costs of borrowing) is not readily observable, and also because the task would lie beyond the scope of this paper in any case, the empirical analysis here stops short of estimating a fully specified version of the model that stands behind the paper's qualitative analysis. Even so, the several levels of empirical investigation carried out in the paper-single-equation estimation, examination of impulse responses from estimated vector autoregressions, and simultaneous-equation estimation of specific structural relationships-lead to specific findings that, for the most part, reinforce one another.

First, financial price variables and financial quantity variables both have predictive power with respect to real economic activity. Moreover, the predictive content of financial prices and financial quantities, respectively, is not identical. These two dimensions of what is happen-

66. These results, in a form comparable to figures $13-15$, are not shown here but are available from the authors on request. 
ing in the credit markets contain at least partly independent information about subsequent fluctuations of real output. Among financial prices, much of that information is contained in relative interest rate relationships like the paper-bill spread or the P2-P1 quality spread.

Second, monetary policy plays an important role in affecting both the credit markets and nonfinancial economic activity. Monetary policy shocks systematically shift behavioral relationships that are central to financial effects on nonfinancial activity. They also account for part of the predictive power of financial price and quantity variables with respect to real output. Variables like the paper-bill spread also have predictive content with respect to real output that is beyond what can readily be ascribed to their role as indicators of monetary policy, however. In the most recent experience in the United States, tight monetary policy appears to have been important in accounting for the slow growth of real output, but not the slowdown in credit per se.

Third, shocks to banks' capital positions also appear to have significant effects on financial variables (including in the recent credit slowdown), albeit not discernibly beyond the financial markets. An important limitation here, however, stems from the conceptual shortcomings of the time series used in this paper as a measure of capital adequacy.

Fourth, changing perceptions of the risk of default on business liabilities also systematically shift the behavior of lenders in the credit market, and these shifts in turn affect key financial quantity variables like the volumes of financing done in various short-term markets. The evidence also suggests that these shifts in turn importantly affect both financial price relationships and nonfinancial activity. In the most recent experience, an increase in perceived default risk appears to have been an important factor underlying the credit slowdown as well as the business recession.

Fifth, effects arising from business firms' nonfinancial activitiestheir inventory accumulation and their operating earnings-shift their financing behavior, and these shifts also affect both prices and quantities in the short-term credit markets. Firms' inventories and earnings not only respond to monetary policy, and hence act as a vehicle for conveying the effect of monetary policy shocks to the demand side of the short-term credit markets, but also have effects on these markets independently of monetary policy. 
Finally, a consistent result running throughout this paper's empirical analysis is that the observed movements of either price or quantity variables defined specifically with respect to the banking system (interest rate spreads involving the bank loan rate, for example, or in some cases the volume of bank lending) bear a weaker correspondence to prior expectations than do the movements of analogous variables defined with respect to the credit markets more broadly (for example, spreads involving the commercial paper rate, or the volume of commercial paper issuance). This finding is certainly not inconsistent with a credit view perspective, but it does caution against centering any credit view analysis narrowly on the role of the banking system. 


\section{Comments and Discussion}

Ben S. Bernanke: Benjamin Friedman and Kenneth Kuttner have done a nice job of bringing together a number of ideas and pieces of evidence from the recent literature on the role of short-term credit markets in macroeconomics. The identification of structural relationships in this area is notoriously difficult, and this paper does not provide the definitive solution to the identification problem. Nevertheless, I find the authors' interpretations of the evidence to be coherent and generally quite plausible. In my comments I will first briefly discuss the paper's theoretical model, with an eye toward placing it in the context of the existing literature. I will then list and discuss what I consider to be the main empirical findings.

Friedman and Kuttner begin their paper with a useful taxonomy of classical, neoclassical, and credit-based models. ${ }^{1}$ To locate their own model within their taxonomy, I introduce a concept known as the Brainard number. ${ }^{2}$ The Brainard number of a theory or model is the number of imperfectly substitutable financial assets that are assumed to exist. For example, in classical Arrow-Debreu-type models, all financial assets are implicitly perfect substitutes (given the state-contingent pattern of payouts); thus the Brainard number is one. The conventional IS-LM model (an example of what Friedman and Kuttner call a neoclassical model) has two imperfectly substitutable assets-money and bonds-and thus has a Brainard number of two.

1. I have one small quibble. The authors seem to identify credit models of monetary policy with the bank lending channel of monetary policy discussed by other analystsincluding Alan Blinder and me in our 1988 work. But the credit view admits nonstandard channels of monetary policy other than that operating through bank lending, such as the effects of changes in interest rates on borrower cash flows and collateral values. See, for example, Gertler and Gilchrist (1993b).

2. With apologies to James Tobin. 
An important feature of virtually all macroeconomic models based on the "credit view" is that their Brainard number exceeds two. For example, in our 1988 paper, Alan Blinder and I modified the standard IS-LM setup to allow for three imperfectly substitutable assets: money, bonds (either government or corporate), and bank loans. ${ }^{3}$ This modification permitted us to analyze the macroeconomic effects of phenomena such as credit controls or bank capital shortages and to examine the role of bank lending in monetary policy transmission, none of which is feasible in the two-asset IS-LM model.

What Friedman and Kuttner have done is to raise the Brainard number to five. (The five assets in their model are money or bank deposits, Treasury bills, bank loans, bank-issued certificates of deposit, and commercial paper.) The disadvantages of adding more assets are that the analysis becomes more cluttered (much of the theory portion of the paper consists of writing down the various asset demand and supply equations and the balance sheet constraints), and the theoretical predictions are sometimes less sharp. However, there are two important advantages to adding more assets. First, the expanded model allows the authors to analyze the behavior of some interesting variables, such as the commercial paper-Treasury bill interest spread and the loan-commercial paper "mix," about which simpler models have nothing to say.

The second important advantage of considering a larger number of assets (and the associated asset prices) is that the identification of the underlying shocks is facilitated. This point has been stressed in this literature before, most notably by Anil K. Kashyap, Jeremy C. Stein, and David W. Wilcox, who used information about commercial paper issuance to distinguish shocks to bank loan supply from shocks to bank loan demand. ${ }^{4}$ In a similar vein, Cara S. Lown and I used information about bank $C D$ issuance and the CD-Treasury bill rate spread to distinguish monetary shocks to bank loan supply from shocks to loan supply originating from bank capital. ${ }^{5}$ The significant contribution of Friedman and Kuttner's paper is to provide a framework for bringing all this information together-both prices and quantities-thus tackling the identification problem more systematically. This unified approach represents definite progress.

The principal way in which Friedman and Kuttner exploit their identi-

3. Bernanke and Blinder (1988).

4. Kashyap, Stein, and Wilcox (1993).

5. Bernanke and Lown (1991). 
fication restrictions empirically is through VAR analysis. Although their interpretations are plausible and represent an improvement over earlier work, I urge some caution in the use of VARs in this way. (I say this as a frequent user of these methods myself.) One problem is that the interpretation of shocks to endogenous variables is potentially ambiguous; what is a "cash flow shock," anyway? Another is that the economic structure is not likely to be stable over long periods (a particularly relevant issue in the analysis of financial markets). For these reasons I applaud Friedman and Kuttner's attempts to supplement the VARs with analysis of a particular episode (the 1990-91 recession) and by structural estimation (although these estimates are still rather preliminary).

To conclude the discussion of Friedman and Kuttner's theoretical framework we might ask, is this the ultimate credit-based model? Or should we try to push the Brainard number even higher? My sense is that the main direction for improvement at this point is not in adding more assets but in improving the treatment of stock variables and stock-flow interactions. Although the authors recognize the importance of stock variables such as outstanding quantities of debt and other balance sheet items, the formal model is expressed almost entirely in terms of flows. Incorporating stock variables into the analysis will at some point be necessary to study economic dynamics from the perspective of the credit view.

On the empirical side, I will focus my comments on three principal findings of the paper. First, the commercial paper-Treasury bill rate spread is a remarkably good predictor of future economic activity. Second, the information in Kashyap, Stein, and Wilcox's "mix" variable is contained almost entirely in the rate of commercial paper issuance, rather than in bank lending. Third, shocks to corporate cash flows appear to be an important determinant of prices and quantities in shortterm credit markets.

The predictive power of the commercial paper-Treasury bill spread is indeed remarkable, and Friedman and Kuttner deserve credit for their earlier work that brought it to our attention. In my 1990 paper I compared this variable's ability to forecast nine measures of real activity with a number of other interest rates and rate spreads and found it to be an easy winner (although its forecasting power deteriorates somewhat after 1980). ${ }^{6}$ The CP-Treasury spread seems even to contain information that is not in the index of leading indicators.

6. Bernanke (1990). 
Why is this spread so predictive? In my paper I argued that the CPTreasury spread is informative partly because it reflects the stance of monetary policy; the idea is that tight money constrains bank lending and forces firms into the commercial paper market. This hypothesis has the virtue of being consistent with the failure of the spread to predict the 1990-91 recession (which was perhaps the only recession of the last thirty years not immediately preceded by a monetary tightening). Friedman and Kuttner provide support for the monetary policy hypothesis and add another explanation, that shocks to corporate cash flow arising from sources other than monetary policy both lead the cycle and move the spread. There is clearly something to this explanation (more on this point below), although again I would like to know the ultimate source of the shocks to cash flow. On a final potential explanation-that the spread is predictive because it reflects the market's assessment of default risk-a bit of disagreement remains between the authors and me. Although Friedman and Kuttner give the default risk explanation some credence, I believe that cyclical variation in default risk contributes little to the predictive power of the spread. Supporting evidence for my view is that default rates for the highest-rated paper are almost zero, and that the spread is nearly uncorrelated with other natural measures of default risk, such as the spread between Baa and Aaa corporate bond rates. ${ }^{7}$

Let me now consider the finding that the information in Kashyap, Stein, and Wilcox's "mix" variable is contained entirely in commercial paper issuance. While this finding is correct as a statement about forecasting, it is important not to confuse predictive power with structural significance. In particular, it would be premature to conclude from this result that bank lending does not play a role in monetary transmission or in cyclical dynamics more generally. The fact that bank lending appears to be a lagging variable (due perhaps to factors such as contractual commitments) does not undercut Kashyap, Stein, and Wilcox's point that commercial paper issuers appear able to satisfy their increased demand for short-term credit at the onset of a recession, while bank-dependent borrowers cannot. Disaggregation of bank lending by class of borrower strengthens this point. Much recent research documents that the share of bank loans going to the strongest borrowers (for example, belowprime borrowers or those with preexisting lines of credit) rises following

7. See my 1990 paper for more discussion. 
a tightening of monetary policy. ${ }^{8}$ Thus borrowers who are truly bankdependent are squeezed in short-term credit markets by even more than the Kashyap, Stein, and Wilcox "mix" variable suggests.

Friedman and Kuttner do not appear to argue that bank lending is macroeconomically irrelevant, only that we should look at short-term credit markets more broadly. With this conclusion I completely agree.

The last finding of the paper that I want to stress is that shocks to corporate cash flow play an important role in determining prices and quantities in short-term credit markets. Despite the reservations that I have expressed about treating these shocks as fundamental, it seems clear that the strong correlations between cash flows and variables such as commercial paper issuance are an important feature of the data, with which future analyses will have to deal. Documenting these correlations is a significant contribution. However, I would like to correct an impression that some readers might take away, that cash flow shocks represent some sort of alternative hypothesis to the credit view. Quite to the contrary, the links between cash flows and creditworthiness are an important part of the "financial accelerator" mechanism that is at the heart of the credit-based approach to business cycles. ${ }^{9}$ In contrast, models with a Brainard number of two or less have no means to discuss the links among cash flows, credit extension, and real activity, except in a completely ad hoc way.

Let me conclude by repeating that what macroeconomics needs is more models with a Brainard number greater than two.

Mark Gertler: The best way to understand this paper is to place it in the context of the literature. Three developments are particularly relevant.

The first is the work by Benjamin M. Friedman and Kenneth N. Kuttner and James H. Stock and Mark W. Watson that uncovered the strong predictive power of the six-month commercial paper-Treasury bill spread. Indeed, the spread qualified as a "Darwinian regressor," having passed the test of the survival of the fittest. Whether it still deserves this label or instead has become a victim of the "Law of the Forecasting Jungle" is an issue I will take up later.

8. Bernanke, Gertler, and Gilchrist (1993) survey the evidence for this "flight-to-quality" effect.

9. See Bernanke, Gertler, and Gilchrist (1993). 
The second stage is the work by Ben S. Bernanke and by Christina D. Romer and David H. Romer that linked movements in the spread to monetary policy. Using different methods to identify shifts in monetary policy, these authors found that tightening of monetary policy tended to raise the spread. Bernanke further proposed that this phenomenon might be explained by firms substituting from bank loans to commercial paper in the wake of tight monetary policy. To the extent the paper market is not fully liquid, a surge in paper issues might temporarily widen the spread.

The third stage is the work by Anil K. Kashyap, Jeremy C. Stein, and David W. Wilcox that pursued the substitution hypothesis by directly examining the behavior of credit quantities. Kashyap, Stein, and Wilcox found that following tight money, commercial paper issues in fact rise sharply relative to commercial and industrial (C\&I) loans, evidence that is certainly consistent with the substitution hypothesis. They also found that the movement of commercial paper relative to bank loans has predictive power for output. In Friedman and Kuttner's terminology, the evidence suggests that the quantity side of the money market has predictive power mirroring that of the price side.

The objective of Friedman and Kuttner's paper is to synthesize this literature and pin down the underlying economics. In the process, the authors try to draw out the implications for the transmission of monetary policy and, more generally, for how the performance of credit markets might influence aggregate activity.

To organize the authors' arguments and my own comments, it is useful to refer to the schematic diagram of the money market in the table below. There are commercial banks that hold reserves, securities, and loans. They fund these assets with deposits, large certificates of deposit (large CDs), and equity. There are also nonbank intermediaries-let me call them money market mutual funds-that issue deposits to fund the private instruments of the money market. These instruments include commercial paper, large CDs, and bankers' acceptances. Despite appearances, I am not trying to set the record for the Brainard number; later, I explain why I include bankers acceptances.

\begin{tabular}{l|l}
\multicolumn{2}{c}{ Commercial banks } \\
Assets & Liabilities \\
\hline Reserves & Deposits \\
Loans & Large CDs \\
Securities & Equity
\end{tabular}

Money market mutual funds

\begin{tabular}{l|l}
\multicolumn{1}{c|}{ Assets } & Liabilities \\
\hline $\begin{array}{l}\text { Commercial Paper } \\
\text { Large CDs } \\
\text { Bankers Acceptances }\end{array}$ & Deposits \\
\end{tabular}


The authors next consider four hypotheses to explain the joint behavior of prices and quantities in the money market and aggregate real activity. The first is the tight money-loan substitution hypothesis that I alluded to earlier. Tightening of monetary policy contracts bank deposits, possibly forcing banks to shed loans. Borrowers at the margin substitute to the commercial paper market; and conversely, deposits move from banks to the money market. A critical assumption throughout is that banks cannot perfectly decouple loans from deposits by issuing large CDs; otherwise, a contraction in deposits need not force a contraction in bank loans.

Under the second hypothesis, the contractionary disturbance is a decline in bank capital. For either regulatory or precautionary reasons, banks desire a fixed fraction of capital to loans. A contraction in capital thus induces substitution of credit flows from banks to money markets, much the same as the tight money experiment described above. If the resulting decline in credit to bank-dependent borrowers has a noticeable impact on aggregate spending, then the "capital shock" may produce movements in output and in the prices and quantities of the money market that match the data.

The third alternative is the "cash flows" hypothesis. The drop in revenues that precedes a downturn creates an increased demand for shortterm funds to finance unintended inventory accumulation and other fixed obligations. This leads to a surge in short-term instruments such as commercial paper, causing the spread to widen prior to a recession. The last alternative is that movements in the paper-bill spread simply reflect shifts in default risk.

None of the alternatives escapes unscathed in this analysis, although they fall short by widely varying degrees. The simple default risk story appears the least satisfactory. The swings in the spread seem way too large to be explained by simple default risk, especially given that only the highest quality firms borrow in the paper market. There is supporting but mixed evidence for the other alternatives. For example, the substitution hypothesis has the strong implication that paper and bank loans should enter with equal and opposite signs in a forecasting equation for output, but the authors soundly reject this restriction. The cash flows hypothesis explains the rise in paper prior to downturns, but does not explain why bank loans remain relatively flat.

I would like to offer a fifth alternative that I think fits the facts reasonably well. Let me call this alternative the "quality mix" hypothesis. It begins with the idea that-as in the cash flows hypothesis-there is a 
countercyclical demand for short-term credit. It adds to this notion the simple idea that not all borrowers have equal access to the credit market. The high-grade borrowers in the commercial paper market obtain funds easily. Short-term funds flow less smoothly to information-intensive borrowers that must rely on banks. As a consequence, commercial paper issues rise relative to bank loans at the onset of recessions. This phenomenon reflects a shift in the quality mix of credit. It need not be explained by borrowers substituting between loans and paper.

The behavior of commercial paper, C\&I loans, corporate earnings, and inventories around periods of tight money, as identified by Romer dates, offers some descriptive evidence in favor of the quality mix hypothesis. A striking regularity is that commercial paper surges after Romer dates, as Kashyap, Stein, and Wilcox found. However, the rise in paper appears to (almost perfectly) mirror a decline in corporate earnings. These facts suggest that the large high-grade firms in the paper market borrow extensively to offset revenue shortfalls. C\&I loans do not similarly surge. Bank-dependent firms thus do not appear to borrow to smooth out earnings declines, at least relative to the firms in the paper market. Differential terms of credit (reflecting the differential quality of borrowers) could explain this phenomenon. ' The relative movements in paper, loans, and earnings are consistent with the authors' findings that paper is negatively correlated with earnings, while C\&I loans are positively correlated.

The quality mix hypothesis suggests that underlying relative movements in commercial paper and bank loans is a relative reallocation of credit from small firms that normally obtain credit from banks to large firms that are able to issue paper. Around Romer dates, it turns out that short-term credit for large firms behaves very much like the commercial paper, rising sharply for a number of quarters after tight money. Shortterm credit to small firms, on the other hand, bears a closer resemblance to C\&I loans. It never rises sharply, and actually declines precipitously in several episodes.

1. Another possibility is that, over recessions, demand falls unevenly across small and large firms. However, Gertler and Gilchrist (1993a) show that small firm short-term debt contracts relative to large firm short-term debt, even after controlling for relative differences in the movement of sales. Differences in demand, therefore, do not explain these results. See also Morgan (1992), who uses information from the Survey of Small Business Lending to identify a credit supply effect. 
On average, the mix of short-term credit between small and large firms behaves very similarly after Romer dates to the bank loan-commercial paper mix. ${ }^{2}$ Finally, a "quality mix" effect arises within in the category of C\&I loans, in that short-term bank loans to large firms rise sharply after tight money, relative to short-term loans to small firms. Indeed, short-term bank loans to large firms behave very similarly to commercial paper. All these results, combined, suggest that the quality mix hypothesis may account for a substantial part of the relative movements in the various short-term credit aggregates that occur both after tight money and prior to recessions.

What about the commercial paper-Treasury bill spread? Also, why did the spread fail to anticipate the last recession in the way it seemed to have anticipated previous recessions? I now turn to these issues.

Most theories of the spread, including the authors', focus on nonfinancial commercial paper. However, nonfinancial paper accounts for a relatively small share of private money market instruments. Despite the relative growth in nonfinancial paper issues, this instrument still accounts for less than 20 percent of the market. Large CD issues account for the lion's share, more than half the market.

The next point to note is that all three instruments-paper, large CDs, and bankers acceptances-appear to be close substitutes. The rates on the three instruments are virtually identical, and move in lockstep over time. Thus, while the paper-bill spread may have predictive power for output, the same is true for the CD-bill and bankers acceptance-bill spreads. It seems somewhat strange, therefore, to restrict attention to the nonfinancial paper market to try to understand the dynamics of the spread.

Now let me explain why I bothered to include bankers acceptances in the table above. These instruments are liabilities that are fully guaranteed by banks. The underlying risk, therefore, involves the risk of the issuing bank. The same of course is true for large CDs, which banks issue directly. What is perhaps less well understood is that commercial paper issues also typically involve bank risk. Except for a few very highquality borrowers, most paper issuers offer, as collateral, back-up lines of credit or guarantees from commercial banks. Any story of the spread therefore ought to feature the behavior (and the condition) of commercial banks.

2. See Gertler and Gilchrist (1993b) and Oliner and Rudebusch (1993). 
There is, in fact, a close connection between large CD issues by commercial banks and movements in the spread. Large CD issues tend to surge around periods of tight money, and the spread tends to widen when the growth rate of large CDs rises. Tight money forces banks into the $\mathrm{CD}$ market to fund their asset positions, as shown in the table above. In addition, banks also float CDs (at least partially) to accommodate the rise in the demand for short-term credit that stems from the decline in cash flows induced by tight money. For related reasons (discussed earlier), nonfinancial paper rises, although $\mathrm{CD}$ issues dominate the movement in the broad money market aggregates.

Note that the surge in money market instruments comes at a time when banks are pressured both by tight money and a downturn in economic activity. This might explain the rise in the spread on private money market instruments, especially given that the payoffs on these instruments are ultimately contingent on bank performance.

This story also explains why the spread failed to signal the previous recession. First, tightening of monetary policy did not closely precede the recession, in contrast to the previous downturns. Monetary policy was tight during 1988 . And both large $C D$ issues and the spread rose during this time. However, monetary policy began to ease well prior to the downturn. A second key factor involved problems in banking. The combination of high loan losses and the implementation of new capital standards under the Basle Accord induced banks to cut back asset positions. One manifestation was a huge drop-off in CD issues. This drop-off began in 1989 and continued through the recession. Thus, in contrast to previous recessions, the supply of private money market instruments was contracting rather than rising as the downturn settled in. For this reason, the spread did not rise. In this vein, the failure of the spread to signal the recent downturn simply suggests that there was something different about the last recession, and not that the spread has become an irrelevant concept.

I would like to conclude with some comments on the general problem of identification in time-series models. Much of the empirical work involves tracing out the response of various financial prices and quantities to a set of orthogonalized innovations in variables such as interest rates, cash flow, and default risk. Because these variables are not truly exogenous, it is often difficult to know how to interpret these results. What, for example, drives a cash flow shock? Knowing the answer, I think, is key to interpreting the results. 
A related issue is that, as is well known, the dynamic response to shocks depends in general on identifying restrictions on the interaction between the contemporaneous innovations. The uniform assumption that the authors make is that monetary policy always contemporaneously affects the financial variable of interest, but that the behavior of the financial variable does not instantly affect the course of monetary policy.

Under the authors' identifying restrictions about the impact of monetary policy on the behavior of C\&I loans, tightening of monetary policy produces a rise in $C \& I$ loans. This rise is due mainly to an instantaneous jump at the time of the tight money shock. The cash flows hypothesis could explain a rise in loans, as revenues eventually decline and inventories eventually creep up. But this should take time to play out, and should not resemble an instantaneous, once-and-for-all jump in loans. Indeed, the authors' results indicate that inventories do not rise until at least a quarter after the shock.

Another possible explanation for the sharp instantaneous jump in loans is simultaneity. The Fed may be tightening in response to a boom in bank credit, or else a boom in some other variable that is correlated with rising bank credit. In this instance, the positive blip in C\&I loans associated with a positive funds rate shock simply reflects reverse causation. I recomputed the response of bank loans to tight money, under the assumption that monetary policy reacts contemporaneously to movements in bank loans-and not vice versa-and found that C\&I loans do not rise. Thus, the outcome is highly sensitive to the a priori restrictions. All this suggests that it is important to carefully justify the identifying assumptions.

\section{General Discussion}

Several panel members followed up on Ben Bernanke's comment about how many assets need to be included in a macroeconomic model used to analyze monetary policy. Greg Mankiw suggested that a Brainard-Tobin number of two is just fine for understanding the basic issues of monetary and fiscal policy. Benjamin Friedman and Mark Gertler both disagreed, arguing that the required number of assets depends on the question being analyzed; more than two assets must be included to understand the effects of events like the recent credit crunch on the real 
economy. Friedman argued further that models with just two assets are rejected empirically, and can not account for the predictive power of financial market variables like the paper-bill spread. Friedman and James Tobin both pointed out that a Brainard-Tobin number greater than two is not always sufficient to yield a model with a credit channel. For example, a model with three assets-money, bonds, and capital-may be sufficient to analyze crowding out, but would be unable to assess the role of credit. Friedman suggested that including "inside" assets and liabilities is crucial for understanding the interaction of financial and real activity; this effectively rules out representative agent models. Tobin suggested inclusion of long-term assets, including mortgages and long-term Treasury securities, noting that their rates had behaved somewhat differently than rates on assets of shorter maturity during the recent episode. Tobin also suggested it would be desirable to include the stock of assets-in addition to the flows-because much of the action likely is coming from short-term dynamics of stock adjustment. Ralph Bryant added that it would be important, for at least some issues, to include financial aspects of the foreign sector in the model, as well.

James Medoff suggested that the impact of financial events on the labor market in recent years could be understood in terms of the portfolio approach in this paper. In particular, labor's claim on the firm could be viewed as a liability. Medoff noted that the ratio of permanent to total job losses has been extremely high recently, and that workers aged thirty-five to fifty-four have been especially hard hit. At the same time, the ratio of corporate net interest to cash flow has been very high. Because firms adjust to high debt ratios by reducing their real liabilities as well as financial ones, it is not surprising that they have attempted to reduce the claims of labor. Middle-aged employees are hardest hit because they represent the largest net liability in present value terms, given their age-earnings profiles.

There were several comments about the difficulty of identification in this type of research, as well as general comments about the empirical analysis. Chris Sims illustrated the difficulty of identification, using as an example the robust finding that interest rate innovations are followed by increases in inflation. If interest innovations are regarded as monetary policy shocks, this suggests that policy is itself responding to the sources of inflation. When variables are added that might be regarded as having predictive value for inflation-such as commodity prices, ex- 
change rates, or other auction market prices-it appears that monetary policy tightens in response to inflationary news and is followed by recession. This raises the possibility that recessions conventionally attributed to monetary policy may largely be attributed to nonmonetary shocks. If this view is correct, monetary contractions should not be credited with causal significance. Similarly other financial market indicators-such as the mix of commercial paper and loans-that appear to play an important role might just be proxying for the true shocks.

Several panel members suggested other reasons for questioning the reliability of the paper-bill spread as a macroeconomic indicator. Martin Baily suggested that just two episodes-1974-75 and 1979-82-were responsible for its apparent importance, and that this variable should not have been expected to remain a useful predictor. Mankiw was also suspicious of the paper-bill spread. He noted that the variable was identified as a predictor only after researchers extensively reviewed macroeconomic variables. Mankiw added that the NBER index of recession that relied heavily on the paper-bill spread variable failed to predict the first recession after the index's debut in the late 1980s. Kenneth Kuttner defended the paper-bill spread by pointing out that a number of other financial indicators, including monetary aggregates and interest rates, also failed to predict the latest recession.

Robert Shiller noted that the commercial loan rate is, in effect, a longer-term rate than the rate on commercial paper, because firms expect their relationships with banks to extend past the lifetime of a loan. Therefore, incorporating lags of the loan-paper spread into the models might improve their fit. He also suggested that the impulse response functions be recalculated with monthly data, as a robustness check. Dan Sichel cautioned that the asymmetry between positive and negative monetary shocks may require researchers to differentiate between expansionary and contractionary periods; three ways to do this would be to run separate regressions over expansion and contraction periods, to include dummy variables for Romer dates, and to use techniques to differentiate between the impulse response functions for positive and negative innovations.

Robert Gordon noted the awkwardness of estimating a model designed to illuminate the credit crunch using data spanning the last twenty years when so many features of the recent recession are quite distinctive. Gordon noted a number of recent puzzles: the breakdown of the 
predictive power of interest rates and interest rate spreads; instability in M1 and M2 velocity; the failure of everything to do with bank loans; and the massive shift out of the banking system into bond and equity mutual funds. In addition, the usual "laundry list" of possible explanations have not yet been sorted out. These include high ratios of debt to income, the S\&L debacle, and tighter bank regulation. Gordon suggested that an analysis of the recent out-of-sample properties of Friedman and Kuttner's model could be especially helpful.

Finally, Tobin told an anecdote that showed both the importance of the issues raised by Friedman and Kuttner and how differently some people in the banking industry view the recent behavior of credit markets. He related a comment of the CEO of Citibank speaking at the recent economic summit in Little Rock. In Tobin's paraphrase, "If you want $\$ 80$ billion to $\$ 100$ billion of stimulus without any effect on the deficit, just tell the regulators to ease up on the banks, and we'll take care of it." 


\section{References}

Akhtar, M. A., and Harris, Ethan S. 1986. "Monetary Policy Influence on the Economy-An Empirical Analysis." Federal Reserve Bank of New York Quarterly Review 11(4): 19-34.

Anderson, W. H. Locke. 1964. Corporate Finance and Fixed Investment: An Econometric Study. Boston: Harvard University Graduate School of Business.

Baer, Herbert L., and John N. McElravey. 1993. "Capital Shocks and Bank Growth-1973 to 1991." Economic Perspectives 17(4): 2-21.

Bernanke, Ben S. 1983. "Nonmonetary Effects of the Financial Crisis in the Propagation of the Great Depression." American Economic Review 73(3): 257-76.

1990. "On the Predictive Power of Interest Rates and Interest Rate Spreads." New England Economic Review (Nov./Dec.): 51-68.

$\longrightarrow$, and Alan S. Blinder. 1988. "Credit, Money, and Aggregate Demand." American Economic Review 78(2): 435-39.

- and Alan S. Blinder. 1992. "The Federal Funds Rate and the Channels of Monetary Transmission." American Economic Review 82(4): 901-21.

- and Mark Gertler. 1989. "Agency Costs, Net Worth, and Business Fluctuations." American Economic Review 79 (1): 14-31.

—, Mark Gertler, and Simon Gilchrist. 1993. "The Financial Accelerator and the Flight to Quality." Unpublished paper. Princeton University.

- and Cara S. Lown. 1991. "The Credit Crunch." BPEA,2:1991, 205-39.

Bosworth, Barry. 1989. "Institutional Change and the Efficacy of Monetary Policy." BPEA, 1:1989, 77-110.

Brainard, William C. 1964. "Financial Intermediaries and a Theory of Monetary Control." Yale Economic Essays 4 (2): 431-82.

Duesenberry, James S. 1958. Business Cycles and Economic Growth. New York: McGraw-Hill.

Eckstein, Otto, and Allen Sinai. 1986. "The Mechanisms of the Business Cycle in the Postwar Era." In The American Business Cycle: Continuity and Change, edited by Robert J. Gordon. Chicago: University of Chicago Press.

Fazzari, Steven M., R. Glenn Hubbard, and Bruce C. Petersen. 1988. "Financing Constraints and Corporate Investment." BPEA, 1:1988, 141-95.

Friedman, Benjamin M. 1989. "Changing Effects of Monetary Policy on Real Economic Activity. In Monetary Policy Issues in the 1990s. Kansas City: Federal Reserve Bank of Kansas City.

- 1990. "Targets and Instruments of Monetary Policy." In Handbook of Monetary Economics, vol. 2, edited by Benjamin M. Friedman and Frank H. Hahn. Amsterdam: North-Holland Publishing.

— Rates." American Economic Review 82(3): 472-92. 
and Kenneth N. Kuttner. 1993. "Why Does the Paper-Bill Spread Predict Real Economic Activity?" In Business Cycles, Indicators, and Forecasting, edited by James H. Stock and Mark W. Watson. Chicago: University of Chicago Press.

Gertler, Mark, and Simon Gilchrist. 1993a. "Monetary Policy, Business Cycles, and the Behavior of Small Manufacturing Firms." Finance and Economics Discussion Series 93-4. Washington: Division of Research and Statistics, Division of Monetary Affairs, Federal Reserve Board (February).

$\longrightarrow \rightarrow$, and Simon Gilchrist. 1993b. "The Role of Credit Market Imperfections in the Monetary Transmission Mechanism: Arguments and Evidence." Scandanavian Journal of Economics 95(1):43-64.

Greenwald, Bruce C., and Joseph E. Stiglitz. 1988. "Examining Alternative Macroeconomic Theories." BPEA, 1:1988, 207-60.

Hodgman, Donald R. 1961. "The Deposit Relationship and Commercial Bank Investment Behavior." Review of Economics and Statistics 43(3): 257-68.

Jensen, Michael C., and William H. Meckling. 1976. "Theory of the Firm: Mana gerial Behavior, Agency Costs, and Ownership Structure." Journal of Financial Economics 3(4): 305-60.

Kashyap, Anil K., Jeremy C., Stein, and David W. Wilcox. 1993. "Monetary Policy and Credit Conditions: Evidence from the Composition of External Finance." American Economic Review 83(3): 78-98.

Kuttner, Kenneth N. 1992. "Monetary Policy and External Finance: Interpreting the Behavior of Financial Flows and Interest Rate Spreads." Working Paper 92-17. Federal Reserve Bank of Chicago (September).

Mauskopf, Eileen. 1990. "The Transmission Channels of Monetary Policy: How Have They Changed?" Federal Reserve Bulletin 76(12): 985-1008.

Meigs, Alexander James. 1962. Free Reserves and the Money Supply. Chicago: University of Chicago Press.

Modigliani, Franco, Robert Rasche, and J. Philip Cooper. 1970. "Central Bank Policy, the Money Supply, and the Short-Term Rate of Interest." Journal of Money, Credit and Banking 2(2): 166-218.

Morgan, Donald. 1992. "The Lending View of Monetary Policy and Bank Loan Commitments." Unpublished paper. Federal Reserve Bank of Kansas City.

Myers, Stewart C., and Nicholas S. Majluf. 1984. "Corporate Financing and Investment Decisions When Firms Have Information That Investors Do Not Have." Journal of Financial Economics 13(2): 187-221.

Oliner, Stephen D., and Glenn D. Rudebusch. 1993. "Is There a Bank Credit Channel for Monetary Policy?" Unpublished paper. Washington: Federal Reserve Board (March).

Owens, Raymond E., and Stacey L. Schreft. 1992. "Identifying Credit Crunches." Working Paper 92-1. Richmond: Federal Reserve Bank of Richmond.

Romer, Christina D., and David H. Romer. 1990. "New Evidence on the Monetary Transmission Mechanism." BPEA, 1:1990, 149-98. 
Sims, Christopher A. 1980. "Comparison of Interwar and Postwar Business Cycles: Monetarism Reconsidered.” American Economic Review 70(2): 25057.

1992. "Interpreting the Macroeconomic Time Series Facts: The Effects of Monetary Policy." European Economic Review 36(5): 975-1000.

Stiglitz, Joseph E., and Andrew Weiss. 1981. "Credit Rationing in Markets with Imperfect Information." American Economic Review 71(3): 393-410.

Syron, Richard F. 1991. "Are We Experiencing a Credit Crunch?" New England Economic Review (July/Aug.): 3-10.

Theil, Henri. 1971. Principles of Econometrics. New York: John Wiley \& Sons.

$\rightarrow$ Tobin, James. 1961. "Money, Capital and Other Stores of Value." American Economic Review, Papers and Proceedings 51(2): 26-37.

- 1969. "A General Equilibrium Approach to Monetary Theory." Journal of Money, Credit and Banking 1(1): 15-29.

- 1970. "Money and Income: Post Hoc Ergo Propter Hoc." Quarterly Journal of Economics 84(2): 301-17.

Whited, Toni M. 1991. "Investment and Financial Asset Accumulation." Journal of Financial Intermediation 1: 307-37.

Wojnilower, Albert M. 1980. "The Central Role of Credit Crunches in Recent Financial History." BPEA, 2:1980, 277-326.

1992. "Discussion." In Real Estate and the Credit Crunch, edited by Lynn E. Browne and Eric S. Rosengreen. Boston: Federal Reserve Bank of Boston. 